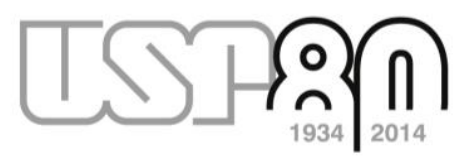

$$
\text { UNIVERSIDADE DE SÃo PAULO }
$$

Faculdade de Odontologia de Ribeirão Preto

\title{
ZBIGNIEW FEDOROWICZ
}

A Comparative Effectiveness Research (CER) Synthesis of Two Cochrane Systematic Reviews on the Effects of Interventions in

\section{Treating Halitosis}

\section{Ribeirão Preto}





\section{ZBIGNIEW FEDOROWICZ}

\section{A Comparative Effectiveness Research (CER) Synthesis of Two Cochrane Systematic Reviews on the Effects of Interventions in}

TREATING HaLITOSIS

Tese apresentada à Faculdade de Odontologia de Ribeirão Preto da Universidade de São Paulo, para a obtenção do título de Doutor no Programa de Reabilitação Oral, fundamentada no artigo 8o, do Capítulo II do Regimento de Pós-Graduação da Universidade de São Paulo.

Área de concentração: Reabilitação Oral

Orientador: Prof. Dr. Vinícius Pedrazzi

Ribeirão Preto 


\section{AUTORIZO A REPRODUÇÃO E DIVULGAÇÃO DO TEOR TOTAL OU PARCIAL DESTE TRABALHO POR QUALQUER MEIO CONVENCIONAL OU ELETRÔNICO, PARA FINS DE ESTUDO E PESQUISA, DESDE QUE CITADA A FONTE.}

Ficha catalográfica elaborada pela Biblioteca Central do Campus USP Ribeirão Preto

Fedorowicz, Zbigniew

A Comparative Effectiveness Research (CER) Synthesis of Two Cochrane Systematic Reviews on the Effects of Interventions in Treating Halitosis. Ribeirão Preto, 2015.

201 p.: il.; $30 \mathrm{~cm}+2$ CD-ROM

Tese de Doutorado, apresentada à Faculdade de Odontologia de Ribeirão Preto/USP. Área de Concentração: Reabilitação Oral.

Orientador: Pedrazzi, Vinícius.

1. Revisão sistemática. 2. Halitose. 3. Higienização de língua. 4. Tratamento. 5. Pesquisa comparativa de efetividade. 


\section{FOLHA DE APROVAÇÃO}

Zbigniew Fedorowicz. A Comparative Effectiveness Research (CER) Synthesis of Two Cochrane Systematic Reviews on the Effects of Interventions in Treating Halitosis

Tese apresentada à Faculdade de Odontologia de Ribeirão Preto, da Universidade de São Paulo, para obtenção do título de Doutor em Odontologia.

Área de Concentração: Reabilitação Oral

Aprovado em:

\section{Banca Examinadora:}

1) Prof. Dr.:

Instituição:

Assinatura:

/ Presidente da Banca

2) Prof.(a). Dr.(a):

Instituição:

Julgamento:

Assinatura:

3) Prof.(a). Dr.(a):

Instituição:

Julgamento:

Assinatura:

4) Prof.(a). Dr.(a):

Instituição:

Julgamento:

Assinatura: 

Dedicatória 



\title{
DEDICO ESTE TRABALHO
}

\begin{abstract}
A DEUS,
Pela presença constante, pelas oportunidades, e por sempre ter me proporcionado na vida a força de vontade necessária para superar os obstáculos que surgem durante o caminho. É meu Norte, minha proteção!
\end{abstract}

\begin{abstract}
À minha amada esposa Ruri,
Minha companheira, minha amiga, meu amor. Obrigado pela compreensão, paciência e em particular pelo meu comportamento um pouco anti-social durante longos períodos de ausência gastos no computador. Também pelo seu incentivo, eu dedico este trabalho a você com todo o meu amor, e por viver ao meu lado, dividindo comigo os momentos felizes e as horas difíceis. Sem você esse trabalho não teria se realizado.
\end{abstract}





\section{Agradecimentos Especiais}





\section{AGRADECIMENTOS ESPECIAIS}

\section{Ao Prof. Dr. Vinícius Pedrazzi,}

Gostaria de agradecer ao meu orientador, o Professor Vinícius Pedrazzi, que me guiou com atenção e paciência durante os altos e baixos deste projeto. Ele tem sido um pilar de força durante os longos e árduos dias, um verdadeiro farol que me iluminou o caminho, quando havia escuridão e desespero, mostrando-se um verdadeiro amigo e colega de confiança. Sua precaução incrível e seu conhecimento provaram serem os principais catalisadores para o sucesso deste projeto e por isso sou eternamente grato a ele.

\section{À minha Família,}

Agradeço à minha filha e ao meu filho por suas palavras de encorajamento, não obstante os seus comentários realmente surpreendentes sobre os desafios que eu me dispus a enfrentar neste momento na minha carreira profissional e pessoal. Talvez haja, afinal, um elemento de competição saudável, que ajudou encorajando-me, no sentido de obter o doutorado antes que minha filha conseguisse obter o dela.

\section{À Colaboração Cochrane}

Reservo-me a maior dívida de gratidão para com os meus colegas da Colaboração Cochrane, que sutilmente arquitetaram meu apego pessoal, ao longo dos últimos anos, para uma organização que é a incontestável líder mundial no fornecimento de informações precisas e atualizadas sobre os efeitos de intervenções na saúde. 

Agradecimentos 

AGRADECIMENTTOS

À Faculdade de Odontologia de Ribeirão Preto, da Universidade de São Paulo, a qual me recebeu de braços abertos para o Workshop Saúde Baseada em Evidências em 2007, nas pessoas das Profas. Dras. Marisa Semprini (Diretora) e Sada Assed (Vice-Diretora), e agora para meu doutorado, nas pessoas da Diretora Profa. Dra. Léa Assed Bezerra da Silva e do Vice-Diretor Prof. Arthur Belem Novaes Júnior,

À Universidade de São Paulo, referência nacional e mundial nas áreas do saber, por ter me recebido para uma etapa importantíssima na minha carreira, a quem agradeço nas pessoas da Sra. Pró-Reitora de Pós-Graduação, Profa. Dra. Bernadette Dora Gombossy de Melo Franco, e do Sr. Secretário Geral, Prof. Dr. Ignacio Maria Poveda Velasco,

Aos Professores e Servidores Técnicos e Administrativos do Departamento de Materiais Dentários e Prótese da Faculdade de Odontologia de Ribeirão Preto, a quem agradeço nas pessoas da chefe do Departamento Profa $^{A}$. Dra . Cláudia Helena lovato da Silva e da Vice chefe Prof ${ }^{A}$. Dr ${ }^{A}$. Valéria Oliveira Pagnano de Souza,

Ao Presidente da Comissão de Pós-Graduação da FORP/USP, Prof. Dr. Manoel Damião de Sousa Neto, por toda colaboração, incentivo e apoio na orientação do processo, tornando-o viável, 
À Coordenadora do Programa de Pós-Graduação na área de Reabilitação Oral, Prof ${ }^{a}$. Dra . Rossana Pereira de Almeida Antunes, por todo apoio oferecido para a realização deste sonho,

Ao Prof. Dr. Raphael Freitas de Souza, pela convivência harmoniosa como amigo e também pesquisador e divulgador da Cochrane Collaboration,

Ao Doutor Jerônimo Manço de Oliveira Neto, pelo auxílio na realização deste trabalho, pela convivência harmoniosa como amigo e também pesquisador e divulgador da Cochrane Collaboration,

Aos funcionários da Faculdade de Odontologia de Ribeirão Preto, da Universidade de São Paulo, em especial à Isabel Cristina Galino Sola, Mary Possani Carmessano, Fernanda Talita de Freitas, Regiane de Cássia Tirado Damasceno, Ana Paula Xavier, por todo suporte a mim oferecido durante o processo e pelo carinho constante e bons momentos compartilhados,

Enfim, a todos que, direta ou indiretamente, colaboraram com a realização deste trabalho, deste sonho.

$$
\text { OMike Obrigado! }
$$


Resumo 

FEDOROWICZ, Z. A comparative effectiveness research (CER) synthesis of two Cochrane systematic reviews on the effects of interventions in treating halitosis. 2015. 201f. Tese (Doutorado em Reabilitação Oral). Faculdade de Odontologia de Ribeirão Preto, Universidade de São Paulo, Ribeirão Preto, 2015.

\section{RESUMO}

Este trabalho foi desenvolvido objetivando uma síntese da pesquisa de efetividade comparada (CER) de duas revisões sistemáticas da Cochrane sobre os efeitos das intervenções no tratamento da halitose, e para avaliar o rigor na sua conduta e qualidade metodológica usando uma ferramenta validada que foi desenvolvida especificamente para a avaliação de várias revisões sistemáticas (AMSTAR). Métodos: bases de dados eletrônicas foram pesquisadas a partir de sua criação até 2005 e atualizadas até fevereiro de 2009. Essas pesquisas recuperaram 990 citações e, após avaliação da pertinência, 20 estudos remanesceram como potencialmente elegíveis. A aplicação independente e em duplicata dos critérios de inclusão excluiu 13 destes, permanecendo 7 para revisão adicional. Listas de referências foram manualmente buscadas para assegurar que nenhum ensaio foi perdido. Resultados: Um total de sete ensaios foram identificados. Dois forneceram algumas evidências fracas e pouco confiáveis para o uso de higienizador de língua como um meio de controlar a halitose. A redução dos níveis de compostos sulfurados voláteis (CSV) em um estudo teve pouca duração e o outro mostrou uma pequena quantidade de trauma da língua induzido após 1 semana de higienização da língua com escova de cerdas macias. Cinco ensaios forneceram dados para a aplicação de enxaguantes bucais: bochechos com (Clorexidina 0,05\% + 0,05\% de Cloreto de cetilpiridínio $+0,14 \%$ de Lactato de zinco) reduziram significativamente a variação média (desvio-padrão (SD)) dos escores organolépticos dos dados iniciais em comparação com uso de placebo $(-1,13(1,1) \mathrm{P}<0,005$ versus $-0,2(0,7))$ e também causaram uma redução mais significativa na variação média (DP), em nível de pico de compostos sulfurados voláteis (CSV) (-120 (92) partes por bilhão (ppb) versus 8 (145) ppb de placebo). Bochechos com Cloreto de Cetilpiridínio + Clorexidina + Lactato de zinco mancharam mais significativamente a língua ( $P$ $<0,001)$ e dentes $(P<0,002)$ comparados ao placebo. A avaliação do caráter

metodológico das revisões sistemáticas com base nos 11 itens da ferramenta Amstar, confirmou a sua alta qualidade. Conclusões: Esta síntese de investigação 
comparativa demonstrou a eficácia do efeito de curta duração da higienização da língua na redução dos níveis de CSV e que o potencial para efeitos adversos com o seu uso em longo prazo deve ser balanceado, frente à duração limitada dos seus benefícios na redução do CSV. Ela também destacou a diversidade na eficácia de alguns dos mais populares anti-sépticos bucais de venda livre no tratamento contra halitose. Antissépticos bucais antibacterianos, tais como clorexidina ou cloreto de cetilpiridínio podem reduzir os níveis de bactérias no dorso da língua, mas a eficácia de anti-sépticos bucais contendo dióxido de cloro e zinco na neutralização dos compostos odoríferos de enxofre não deve ser subestimada. Parece lícito, portanto, haver um lugar na estratégia de controle da halitose com a utilização de formulações que incluam e combinem alguns destes componentes. Seguindo um dos princípios fundamentais das revisões sistemáticas Cochrane, este trabalho foi atualizado em abril de 2014 e apenas um dos estudos escolhidos atingiu os critérios para inclusão, porém não acrescentou novas informações que modificassem as conclusões desta tese. Estudos clínicos randomizados controlados bem elaborados e em obediência ao CONSORT são necessários, e futuras investigações devem explorar tanto os resultados que são relevantes e também baseados na preferência do paciente tendo como objetivo fornecer provas para as pessoas tomarem decisões informadas sobre quais desses tratamentos são eficazes.

Unitermos: 1. Revisão sistemática. 2. Halitose. 3. Higienização de língua. 4. Tratamento. 5. Pesquisa comparativa de efetividade. 
A6stract 

FEDOROWICZ, Z. A comparative effectiveness research (CER) synthesis of two Cochrane systematic reviews on the effects of interventions in treating halitosis. 2015. 201f. Tese (Doutorado em Reabilitação Oral). Faculdade de Odontologia de Ribeirão Preto, Universidade de São Paulo, Ribeirão Preto, 2015.

\begin{abstract}
The aim of this research was to perform a Comparative Effectiveness Research (CER) synthesis of two Cochrane systematic reviews on the effects of interventions in treating halitosis and to evaluate the rigour in their conduct and methodological quality using a validated tool that has been developed specifically for the assessment of multiple systematic reviews (AMSTAR). Methods: Electronic databases were searched from their inception to 2005 and further updated to February 2009. These searches retrieved 990 citations, which after assessment for relevance left 20 potentially eligible studies. Independent and duplicate application of the inclusion criteria excluded all but 7 of these reports from further review. The reference lists were handsearched to ensure that no trials had been missed. Results: A total of seven trials were identified. Two provided some weak and unreliable evidence for the use of tongue scraping as a means of controlling halitosis. Reduction of volatile sulphur compounds (VSC) levels in one trial was short lived and the other showed a small amount of tongue trauma induced by 1 week of tongue scraping. Five trials provided data for the mouthrinses: $0.05 \%$ chlorhexidine $+0.05 \%$ cetylpyridinium chloride $+0.14 \%$ zinc lactate mouthrinse significantly reduced the mean change (standard deviation (SD)) of organoleptic scores from baseline compared to placebo $(-1.13(1.1) \mathrm{P}<0.005$ versus $-0.2(0.7))$ and also caused a more significant reduction in the mean change (SD) in peak level of VSC (-120 (92) parts per billion (ppb) versus 8 (145) ppb in placebo). Chlorhexidine cetylpyridinium chloride zinc lactate mouthrinse showed significantly more tongue $(P<0.001)$ and tooth $(P<0.002)$ staining compared to placebo. Assessment of the methodological quality of the systematic reviews based on the 11-item AMSTAR tool confirmed their high quality. Conclusions: This comparative effectiveness research synthesis has illustrated the short-lived effect of tongue scraping on reducing VSC levels and that the potential for adverse effects with their long-term use should be off set against the possibly limited duration of their benefits in VSC reduction. It also highlighted the diversity in effectiveness of some of the more popular over the counter mouthrinses in treating
\end{abstract}


halitosis. Antibacterial mouthrinses such as chlorhexidine or cetylpyridinium chloride can reduce bacterial levels on the tongue but the effectiveness of chlorine dioxide and zinc containing mouthrinses in neutralisation of odoriferous sulphur compounds should not be underestimated. There would therefore appear to be a place in the management strategy of halitosis for formulations, which include and combine some of these constituents. Following one of the fundamental principles of the Cochrane Systematic Reviews, this work was updated in April 2014 and only one of the chosen studies met the inclusion criteria, but added no new information that would alter the conclusions of this thesis. Further well-constructed randomized controlled trials, which comply with CONSORT, are necessary and future research should explore outcomes that are both relevant and patient-preferred and should aim to provide evidence for people to make informed decisions whether these treatments are effective.

Keywords: 1. Systematic review; 2. Halitosis; 3. Tongue cleaning; 4.Treatment; Tongue scraping; 5.Comparative effectiveness research. 


\section{List of A66reviations}





\section{LIST OF ABBREVIATIONS}

CER - Comparative Effectiveness Research

AMSTAR - Assessment of Multiple Systematic Reviews

VSC - Volatile Sulphur Compounds

SD - Standard Deviation

PPB - Parts Per Billion

CONSORT - Consolidated Standards of Reporting Trials

DARE - Database of Reviews of Effects

CRD - Centre for Reviews and Dissemination

CDSR - Cochrane Database of Systematic Reviews

WHO - World Health Organization

EBMWG - Evidence-Based Medicine Working Group

EBM - Evidence-Based Medicine

RCTs - Randomized Controlled Trials

EBD - Evidence-Based Dentistry

CEBM - Centre for Evidence-Based Medicine at Oxford

GRADE - Grading of Recommendations Assessment, Development and Evaluation

RCT - Randomized Controlled Trial

MRC - Medical Research Council

CCT - Controlled Clinical Trials

CENTRAL - Cochrane Central Register of Controlled Trials

ICTRP - International Clinical Trials Registry Platform

QUOROM - Quality Of Reporting Of Meta-analyses

PRISMA - Preferred Reporting Items for Systematic Reviews and Meta-analyses

CRD - Centre for Reviews and Dissemination

OHG - Oral Health Group

OTC - Over The Counter

Cl - Confidence Interval

MeSH - Medical Subject Headings

MEDLINE - Medical Literature Analysis and Retrieval System Online

LILACS - Latin American and Caribbean Health Sciences Literature

EMBASE - Excerpta Medica database

CHSSS - Cochrane Highly Sensitive Search Strategy

CINAHL - Current Index to Nursing and Allied Health Literature

RevMan - Review Manager

GMC - Geraldo Maia Campos

VSCI - Volatile Sulfur Compounds Indexes

CPC - Cetylpyridinium Chloride

OLS - Organoleptic Scores

CHX - Chlorhexidine 

List of Tables 



\section{LIST OF TABLES}

Table 1. Summary of inclusion criteria for identification of relevant studies............. 105

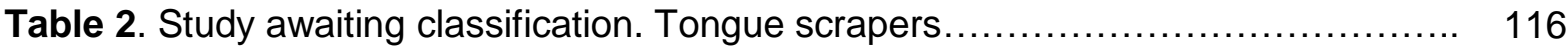

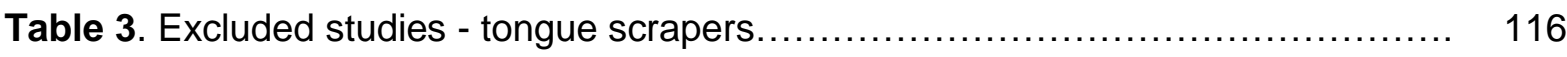

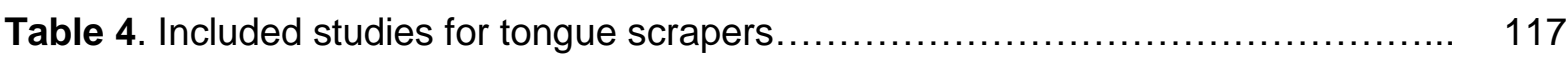

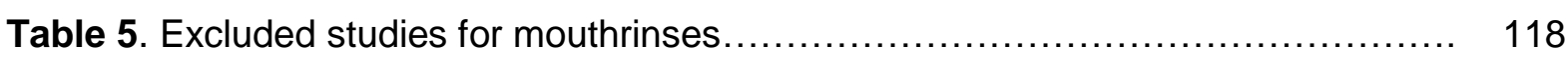

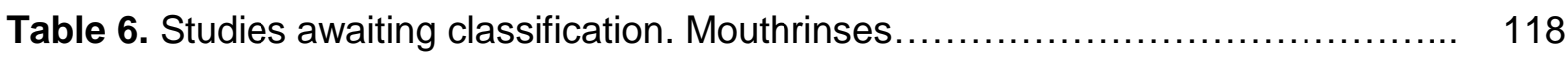

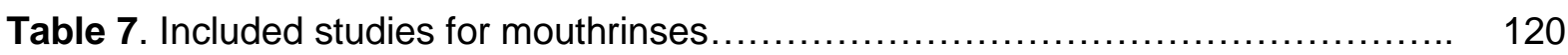

Table 8. Pedrazzi 2004 - Risk of Bias Judgments................................ 136

Table 9. Seemann 2001 - Risk of Bias Judgments............................... 137

Table 10. VSC ppb: Baseline/Mean value/percentages (SD) (Seemann 2001)......... 141

Table 11. Baseline and Final VSC Index: Scale 1-4. (Pedrazzi 2004) ................. 142

Table 12. (Borden 2002) Change in organoleptic \& halimeter ratings.................. 145

Table 13. (Kozlovsky 1996) Organoleptic ratings \& peak VSC levels: week 0-6........ 146

Table 14. (Rassameemasmaung 2007) VSC levels at baseline \& day $15 \ldots \ldots \ldots \ldots \ldots . \ldots \ldots$

Table 15. (Winkel 2003) Organoleptic and VSC scores: baseline \& week 2........... 148 



\section{List of Figures}





\section{LIST OF FIGURES}

Figure 1. Hierarchy of Evidence: Levels I-V Reproduced from: Oxford Centre for Evidence-based Medicine (May 2001) [Note: this has been recently updated (March 2009) to include sub-classifications to each of the levels and now includes additional columns to cover prognosis, diagnosis and economic decision analyses....

Figure 2. Summary of the search results across the four databases

Figure 3. Risk of Bias summary (Tongue scraping). Methodological quality summary: review authors' judgements about each methodological quality item for each included study.

Figure 4. Risk of Bias graph (Tongue scraping). Methodological quality graph: review authors' judgments about each methodological quality item presented as percentages across all included studies.

Figure 5. Risk of Bias summary (Mouthrinses). Methodological quality summary: review authors' judgements about each methodological quality item for each included study

Figure 6. Risk of Bias graph (Mouthrinses). Methodological quality graph: review authors' judgments about each methodological quality item presented as percentages across all included studies. 

Summary 



\section{SUMMARY}

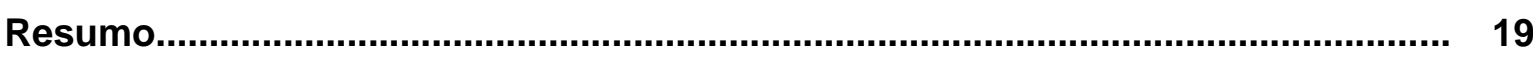

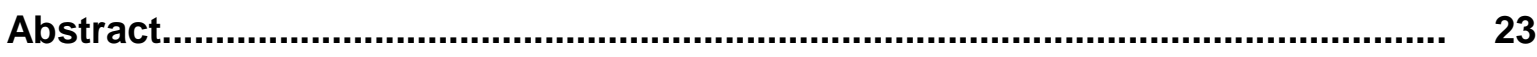

List of Abbreviations........................................................................ 27

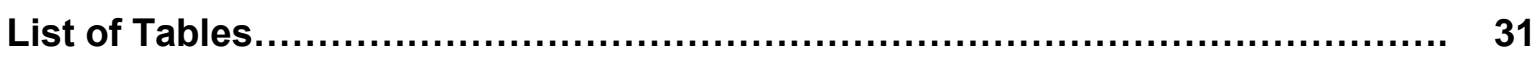

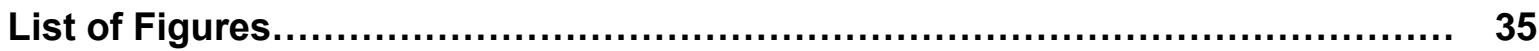

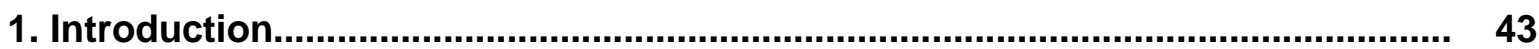

2. Literature Review............................................................................... 49

2.1. Effectiveness of healthcare interventions...................................... 51

2.2. Effectiveness and expert opinion................................................ 53

2.3. Effectiveness and evidence: a paradigm shift................................... 58

2.4. The essence of the evidence-based concept.................................... 61

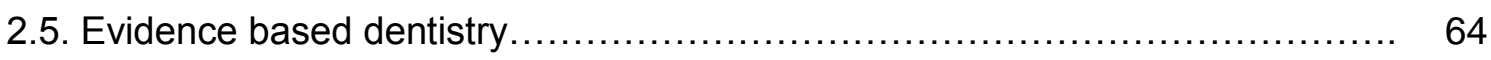

2.6. From traditional hierarchies to the 'Hierarchy of Evidence........................ 66

2.7. Hierarchy of evidence and Dental Public Health................................. 69

2.8. A 'gold standard': the randomized controlled trial.................................. 69

2.9. Randomized controlled trials in Public and Dental Public Health................. 76

2.10. Literature and narrative reviews of effectiveness of healthcare.................. 77

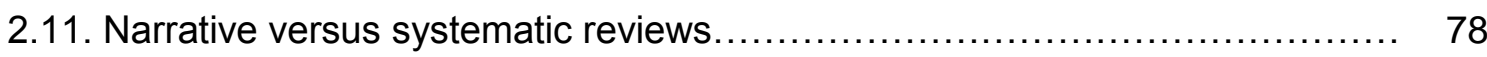

2.12. Research synthesis: a systematic review, the 'platinum standard'.............. 80

2.13. Systematic reviews and systematic bias...................................... 81

2.14. Benefits of systematic reviews.................................................. 85

2.15. Clinician perceived disadvantages of systematic reviews....................... 85

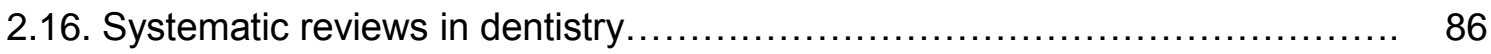

2.17. The background to the research question..................................... 87

2.18. Sources of background information: clinical references and internet

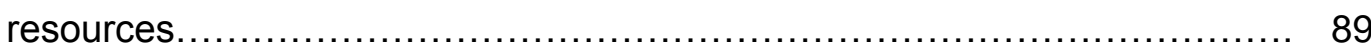

2.19. Aetiology, clinical symptoms, definitions and diagnostic tests.................. 89

2.20. Electronic scoping search...................................................... 94

2.21. Personal collection of relevant bibliographical references....................... 95

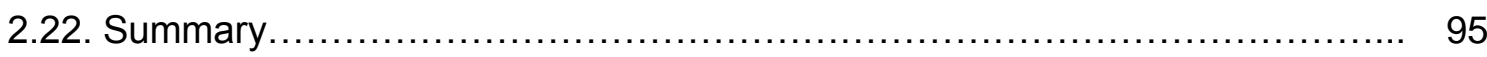

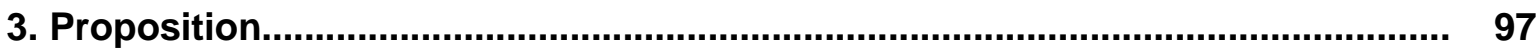

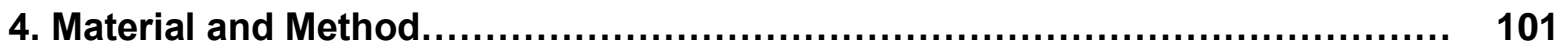

4.1. Criteria for considering studies for this review.................................. 103

4.2. Search Strategy for identification of studies................................... 106

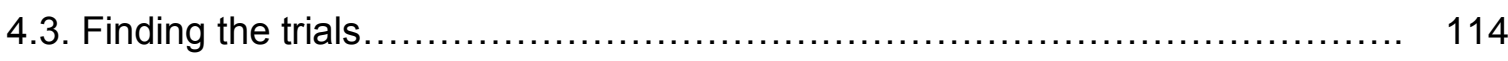


4.4. Assessment of risk of bias .............................................. 121

4.5. Data collection ......................................................... 121

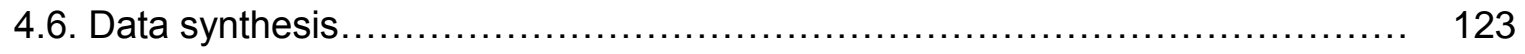

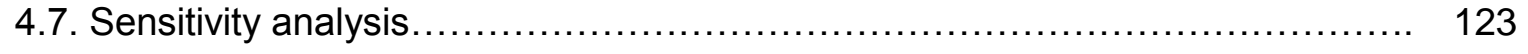

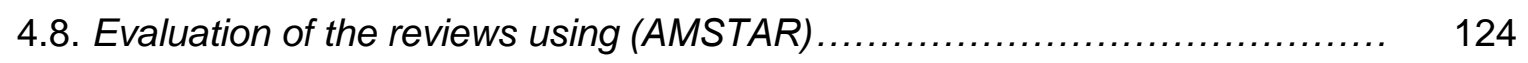

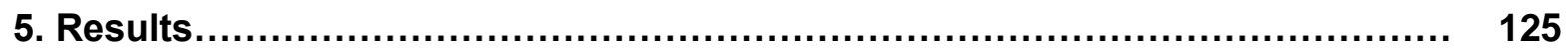

5.1. Summary of trial details................................................. 127

5.2. Assessment of risk of bias in the included studies............................. 134

5.3. Effects of interventions Addendum ........................................ 141

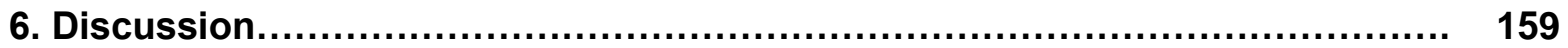

6.1. Summary of main results (the effects: benefits and harms) $\ldots \ldots \ldots \ldots \ldots \ldots \ldots \ldots 1$

6.2. Overall completeness and applicability of evidence......................... 163

6.3. Quality of the evidence................................................. 165

6.4. Potential biases in the review process ................................... 165

6.5. Agreements and disagreements with other studies or reviews............... 166

6.6. Implications for research.................................................... 166

6.7. Discussion after the Addendum......................................... 168

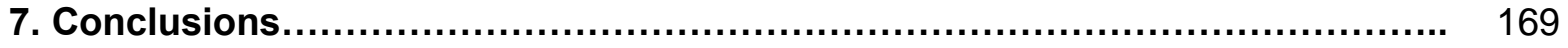

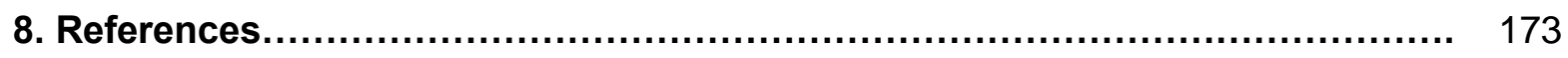

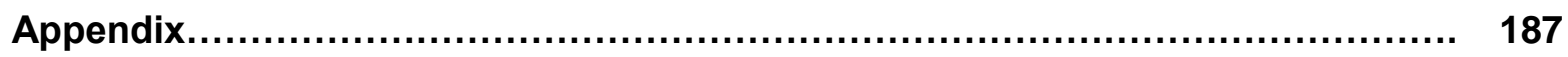




\section{Introduction}





\section{INTRODUCTION}

My interest in this research topic was prompted by several factors; a steadily increasing interest in the evidence-based concept and its translation into clinical practice as well as the increased involvement of patients in not only the decision making process but in formulating outcomes which are relevant to them.

Albeit a late adopter I was particularly influenced by a concept which was in essence alien to me as I had received my undergraduate training in an era when a clinician's experience skills and knowledge were the principal factors controlling healthcare decision making. The translation of research obtained through the application of rigorous methodology into current best evidence of the effectiveness of healthcare interventions is to my mind the sine qua non of best evidence into best care. It was not long before I acquired an all-consuming passion for the evidencebased concept in healthcare and subsequently became one of its avid proponents.

A large volume of empirical research had already been conducted around the globe on the topic of halitosis and I was particularly impressed by the sheer quantity of high quality of studies that had been conducted in Brazil. It was to be the fortuitous contact with several of these investigators based in Ribeirão Preto and Piracicaba that ultimately led to the expansion of an earlier review of tongue scraping to include an investigation of the effects of mouthrinses in the management of halitosis, both of which served as precursors for this thesis.

\section{Rationale for a systematic review}

Systematic reviews provide a logical synthesis of the research base by answering specific and narrow focused clinical questions which are formulated 
explicitly according to four discrete variables; population, intervention, comparison and the potential outcome (Cook, Mulrow and Haynes 1997). Through a clearly defined process, they are able to provide a well-balanced and impartial summary of the existing research evidence, which can ultimately inform healthcare decision makers (Oxman and Guyatt, 1993). In addition, they represent one of the best opportunities for dental clinicians to understand and accurately apply the current best evidence, which has been assembled from a methodologically robust and comprehensive search for solutions to dental problems.

The use of mouth rinses is well accepted and, albeit the perception of the expected benefits may well exceed the reality of their effectiveness, the availability of large scale empirical research which appears to support their effectiveness may well be shaped by the agendas and commercial interests of the manufacturers of some of these products. Whilst there may be not dissimilar perceptions about the effects of tongue scraping its apparent lack of widespread acceptance may be explained by issues of social etiquette rather than any perceived lack of effectiveness. Recommendations for the use of either may be influenced or driven by the media as much as by the dental clinician and with the not infrequent involvement of vested commercial interests. These endorsements also tend to have a cyclical pattern and may be geared to the release of some new product, or merely a change to the existing range of mouthrinses or modification to a tongue scraping device.

\section{Prior systematic reviews}

A key component of not only systematic reviews but of all research is that "efforts should be made to ensure that a good quality review in the field of interest does not already exist' (Khan et al. 2001, p.4) and a scoping search should be used 
to map out the literature before commencing a review. A scoping search of The Cochrane Library to include the two major databases of systematic reviews, DARE (Database of Reviews of Effects) which is available at the Centre for Reviews and Dissemination (CRD) and the Cochrane Database of Systematic Reviews (CDSR), was conducted before developing the protocol for both of these systematic reviews.

Reviewing relevant research reports about the effectiveness of treatments for halitosis is likely to highlight the matches and gaps in the evidence-base, may lead to filling in of some of the voids and ultimately underpin the highest level of evidence to enable patient-preferred decision making. The examination of prior reviews also has the potential to generate new relevant questions for future clinical research. However, the characteristics of high quality reviews reside not only in their methodological rigor and their relevance to providers and receivers of care but, as would be expected for all forms of research, in the completeness and quality of their reporting. This project seeks to match all of these criteria. 

2. Literature Review 



\section{LITERATURE REVIEW}

\section{FOUNDATION TO THE EVIDENCE-BASE FOR THE RESEARCH PROJECT}

\subsection{Effectiveness of healthcare interventions}

Effectiveness has been defined by the Centre for Reviews and Dissemination (CRD) as "the extent to which an intervention (therapy, prevention or diagnosis) produces a beneficial outcome under ordinary day to day circumstances" (KHAN et al. 2001, p. 4).

Thus, effectiveness seeks to address several questions:

- Does the intervention work (clinical effectiveness)?

- In whose opinion is this intervention considered to be effective (expert or evidence based)?

- What is the strength of the evidence for this effectiveness (hierarchy of evidence)?

At the core of this research project was an assessment of the effectiveness of several interventions for the treatment and management of halitosis, and whilst the principal aim might appear to focus on providing reliable evidence and thus biased somewhat in favor of only identifying positive benefits, the possibility of harms and adverse events should not be discounted and therefore these were also considered.

Effectiveness is a key component of the evidence-based approach but this 'new paradigm' does not hold the exclusive copyright to the concept of 'effectiveness' in healthcare interventions. Appeals for clinicians around the world to utilise effective healthcare interventions have, over the years, been met with intense waves of enthusiasm interspersed by the comparative calm of indifference. One such wave 
came in the late 1970s as Kerr White and Archie Cochrane, the two giants of clinical epidemiology and agents provocateurs of the medical establishment, traversed the world, clashing with each other and at the same time attracting a degree of global notoriety (Maynard and Chalmers, 1997). The transglobal efforts of these latter day champions have left a lasting legacy in the battle for ensuring robust evidentiary support for effectiveness in healthcare interventions. The most visible result being the establishment of the Cochrane Collaboration, which prepares, maintains and promotes the accessibility of systematic reviews of the effects of healthcare interventions (www.cochrane.org).

At the Alma-Ata Conference in 1979, the World Health Organization (WHO 1981) added to the momentum through the timely release of a statement which was an international clarion call for healthcare decision making to be guided by the best evidence of effectiveness in healthcare interventions. At this conference the Director General of the WHO, Halfdan Mahler, succeeded in coalescing the often disparate views of the representatives of 134 governments and crafted a statement which may now be considered prophetic for its time. In this statement the delegates unanimously agreed that:

"the time has come for all levels of the health system to review critically their methods, techniques equipment and drugs, with the aim of only using those technologies that have really proved their worth and can be afforded' (World Health Forum, WHO 1981).

Prophetic this statement was in so far as it would be at least a decade before Guyatt (1991) would coin the phrase 'evidence-based medicine' and almost 15 years before its advocates would proclaim their 'new paradigm'. This new paradigm required healthcare decisions to be based on the best available evidence obtained 
through the explicit synthesis of the outcomes from methodologically sound studies (EVIDENCE-BASED MEDICINE WORKING GROUP, 1992).

The terms effectiveness and effects are not entirely synonymous and albeit they may often be used interchangeably this will depend on context. Effectiveness is biased in favour of the degree of positive benefits of an intervention that range from nil, whereas the 'effects' of an intervention would in general encapsulate both harms and benefits.

\subsection{Effectiveness and expert opinion}

A sound knowledge of the effectiveness of healthcare interventions is not only a requirement but an ethical imperative for all clinicians and should form part of the dental undergraduate programme.

The development of dental undergraduate curricula is a multifaceted process which incorporates faculty consensus and the collective agreement of a recognized expert dental authority. Regrettably, in dentistry the evolution from an expert to an evidence-based approach has been less visible than some of the more volatile changes seen in medicine. This slow progress may be due to certain inbuilt resistors within the 'culture' of traditional dental training which classically approaches innovations and the adoption of new ideas with caution, and requires both professional and organizational culture shifts to implement change.

Dental undergraduate curricula are required to conform to the statutory requirements of licensing or educational regulatory bodies all of which are subject to government oversight. In the UK the General Dental Council, which receives its mandate from Central Government, is the primary regulatory body. In its Guidance Document The First Five Years, the General Dental Council defines the key principles in dental undergraduate programmes which ensure that "academic 
institutions provide modern systems of education and training" (GDC 2002). Significantly it also requires that dental undergraduate clinicians are taught how to apply evidence-based treatment. Similarly in the USA, the American Dental Association Commission on Accreditation oversees dental education and requires dental schools to ensure that undergraduate curricula include the development of skills needed to interpret scientific information using a process of critical appraisal (BRUNETTE, 1996).

The early part of dental undergraduate training focuses on the development of competency, skills and knowledge which are chiefly expert or opinion based and which have been euphemistically dubbed 'eminence-based' (Fedorowicz and Keenan, 2003). This traditional reliance of undergraduate curricula on celebrated experts and their scholarly opinions, and not infrequently their self-authored course text books, has in the past provoked criticism for what has been, perhaps unfairly, described as an outmoded and non-evidence based approach to undergraduate education (Goldstein and Preston, 2002). Nevertheless future clinical practice should be based on a level of expert knowledge and the teaching of time tested and scientifically sound techniques both of which will permit the graduate to safely enter general practice. Consequently, the earlier years of dental undergraduate training are very much dependent on the extent of knowledge and breadth of clinical experience of the 'expert' and his/her ability to successfully transmit that knowledge and experience to the student.

After graduation the dental clinician is possibly less influenced by observations based on some of his undergraduate experiences, and may be more accepting of anecdotal evidence, practical 'tips' from a colleague, of information gained at continuing education courses, through reading of journals and even 
through technical advice offered by trade representatives, a combination of which may be used to mould future decision making.

Clearly the process of acquisition of knowledge and clinical competencies by a dental undergraduate is complex and is achieved through the integration of expert based experience and opinion, personal experiences, and varying levels of exposure to evidence-based methods (Goldstein and Preston, 2002). The exact proportion of each of these components may to some extent depend on the level of acknowledgement or indeed scepticism not infrequently exhibited by senior faculty members towards the currently fashionable concept of evidence-based dentistry. It would not be unreasonable to expect that some of these 'expert' clinicians may be less than enthusiastic or even resilient to altering their well entrenched teaching and clinical practices. These, after all, are based on cumulative years of experience and the perception by the 'expert' that he/she has always provided the best and most appropriate dental care. However, the plural of anecdote is decidedly not evidence and the days are long gone when a clinician might "justify a healthcare decision based on one of the following; it seems to me... in my experience... I was taught" (GOODMAN, 2003).

The discrepancies which can occur with a reliance on expert knowledge were highlighted by Antman (1992) who examined the evidence accumulated, over a thirty year period (1960-1990), on the effectiveness of antiarrhythmic medications, to reduce the risk of heart attack. Health care interventions which were supported by 'current best evidence' were then compared with the interventions that the experts were recommending. Their study revealed major disagreement between the accumulating evidence and the experts' recommendations and also showed that where studies had shown treatments to be effective, the experts' recommendations 
lagged several years behind the evidence. In summary they noted that some experts "have not yet mentioned effective therapies, while others continue to recommend those that are ineffective or possibly harmful" (Antman, 1992, p. 246). In his book, Deadly Medicine, Thomas Moore (1995) exposed the culpability of some of the manufacturers of antiarrhythmic drugs and the extraordinary lengths that they went to in order that they might 'influence' expert opinion. Ultimately, the widespread use of some of these antiarrhythmic drugs may have led to the deaths of tens of thousands of Americans.

It is all too easy to be dismissive of individual expert or consensus opinion but each has a role to play in enhancing or formulating recommendations where there is very little high level evidence or if there are concerns about the methodological quality of the studies supporting that evidence. These concerns are especially pertinent to clinical dentistry where many interventions are unsupported by high-quality studies and may only be supported by anecdotal evidence and thus the role of the expert becomes more pertinent. However, additional concerns about the 'grading' of experts were expressed in a comment by Aurbach (1999) "who will be the anointed one or group that determines which evidence is valid?"

There are many strands linking concepts of both evidence and expert-based practice to earlier periods in medical history. One of the earliest references to the use of evidence is attributed to an eighteenth century physician, Thomas Beddoes (17601808), who had called for a more comprehensive approach to the systematic collection and indexing of medical information which would remove "prevailing discontents, imperfections and abuses in medicine" (Porter 1992). The expert-based approach is more traditional, had an earlier genesis and is perhaps typified by a quotation said to be attributable to Hippocrates in which the physician taking the 
Hippocratic oath vows to "regard him who has taught me this technique as equal to my parents", a directive that appears to emphasise the conventionally paternalistic bond between expert and protégé.

As they move into the 'business' side of clinical practice many clinicians will proclaim themselves 'experts' or custodians of the last word on the effectiveness of certain dental treatments, and in support of these not infrequently self-bestowed endorsements will cite years of experience, attendance at frequent refresher courses and subscription to the quality peer reviewed journals. Significantly, history is replete with ill-fated examples where opinion rather than evidence has taken precedence over healthcare decision making. This has been well documented and illustrated in a number of fairly provocative references over the last 20 years, which point to the lack of evidence for the effectiveness of many healthcare interventions and how very few of them are based on high quality or gold standard (the randomized controlled trial) evidence.

One of the most noteworthy of these was an incident referred to by Kerr L White which occurred between himself and Archie Cochrane. Whilst addressing a meeting in 1976 at Wellington Hospital in New Zealand, White stated that "only 15$20 \%$ of physicians' interventions were supported by objective evidence that they did more harm than good", a statement that was interrupted mid-sentence by Cochrane who called him, "a damned liar" and said that he knew "perfectly well that it isn't more than 10\%" (Maynard and Chalmers, 1997, p. 5).

Other sources have provided similarly disconcerting figures, the Institute of Medicine (2-25\%), the US Office of Technology Assessment (10-20\%) (Field and Lohr, 1992). However the fact that an intervention is not supported by high level evidence does not necessarily imply that it is inappropriate, but it does mean that 
clinicians have inadequate grounds for accepting it as effective. The significant point that Cochrane was trying to make was that it is not that most individual clinician's beliefs are unsupported by evidence but that there seemed to be a disconnect between evidence of effectiveness of healthcare interventions, bad outcomes and the clinician.

These causes of bad outcomes of healthcare interventions were attributed to either collective ignorance or individual ignorance by Goodman (2003). Individual ignorance can be implied if the clinician is ignorant of evidence that is freely available and that would affect his/her clinical practice if that evidence has been already acquired by other clinicians. Collective ignorance however applies to a group, where such evidence has not been acquired by anyone and thus no-one in the group has evidence that would affect practice decisions even if the evidence is available. The significance of this distinction lays in the group or herd mentality so often seen in the professions where the expert-based model of learning, to the exclusion of almost any other persists, and which all too often is supported by collective ignorance.

\subsection{Effectiveness and evidence: a paradigm shift}

Evidence has been defined as, "something that tends to prove; grounds for belief' (Webster's New World Dictionary \& Thesaurus 1998). This definition implies a spectrum of rigour from 'grounds for belief' to 'proof', the breadth of latitude of which is important to the evidence-based debate.

The most recent call for more robust evidence of effectiveness in healthcare interventions can be traced back to the efforts of a group of enthusiastic epidemiologists at McMaster University in Canada. This group, the Evidence-Based Medicine Working Group (EBMWG), lead by the enigmatic David Sackett had 
recognized the limitations of 'currency' in clinical knowledge and confirmed that many review articles and journal editorials had no empirical basis and were biased and fallacious (Oxman and Guyatt, 1988). In proclaiming their evidence-based medicine (EBM) 'paradigm' the EBMWG had sought to validate the paradigm shift by invoking the philosophical concept of scientific paradigms described by Kuhn (1970).

These scientific paradigms were portrayed as ways of looking at the world that define addressable problems and the range of admissible evidence that may have an impact on their solution. The EBMWG pronounced that "when defects in an existing paradigm accumulate to the extent that the paradigm is no longer tenable, the paradigm is challenged and replaced by a new way of looking at the world" and that the driving force for this paradigm shift was the changing face of medical practice (EBMWG, 1992).

In this classic paper, they stridently compare "the way of the past" with "the way of the future" and "the former paradigm" with "the new paradigm" and that the foundations of this paradigm shift lie in developments within clinical research and the championing of randomized controlled trials in setting treatment policy. Their views of a Kuhnian paradigm shift were strongly contested on philosophical grounds by Sehon and Stanley (20003, p.2) who argued "that such claims are seriously mistaken and unduly polarize the evidence-based debate". Whilst acknowledging the important differences between the evidence-based and opinion-based approaches and that these have the potential to change medical practice, they sought a more explicit definition of EBM and emphasised that some of their concerns stem from the definition of EBM not merely from an "academic desire for philosophical clarity but from a practical perspective" (Sehon et al. 2003, p.7). 
They maintained that the Kuhnian metaphor is not only inadequate when applied to EBM but that it serves to obscure more than it illuminates. Moreover, they considered that EBM and basic science are so intertwined with no clear dividing line between them and thus there is no point at which changes in theory and clinical practice can illustrate a paradigm shift. They were not content with attacking the conceptualization of the evidence-based approach but also raised one of the tired and old objections to EBM in the priority it gives to the most highly prized form of evidence arising from randomized controlled trials (RCTs). Finally, although they were unwilling to accept EBM as a paradigm shift in relation to the basic science approach to medicine, they recognised that some of the fundamental difficulties lie in the lack of clarity of the Kuhnian notion of a paradigm rather than in the evidencebased concept itself.

It is conceivable that in the early days the disciples of EBM were perhaps a little overzealous, they had created unease within the medical profession by stating that this was a serial change in doctrines and with this new paradigm came an entire set of new values and beliefs, in which the old were to be jettisoned in favour of the new. It is hardly surprising therefore that clinicians may have found this a bitter pill to swallow which led to some defensive retrenchment and an intensification of the natural suspicions of those who feel themselves out of step with the 'new paradigm'.

Clearly, Sehon and Stanley (2003) seem to have missed the earlier concession made by the EBMWG (Haynes 2002). In this paper Brian Haynes had conceded that although there were certainly differences between the approaches of basic and applied research, these concerns were more rhetoric than reality and that the differences were not necessarily mutually exclusive. They were in point of fact opposite ends of the continuum of healthcare research and that they represented its 
progression from bench to bedside. He had also suggested that the two concepts of traditional basic science and modern applied research should be viewed as complementary.

Seemingly the EBMWG had at the outset pitted their 'new paradigm' against the two traditional knowledge foundations of medicine; the basic mechanisms of disease and the clinical experience of 'expert' authority. It is conceivable that these latter concessions, which were offered by Haynes, may have been extracted from the EBMWG to ease the transition of what was seen and is still seen as an abrupt upheaval in the rather cozy and zealously guarded 'fiefdom' of the medical guild. Unquestionably confusion between the objectives of science and those of the practice of medicine has led to much of these earlier misunderstandings which ultimately may have provoked some of the criticism leveled at EBM and possibly delayed its early adoption in certain disciplines of healthcare.

\subsection{The essence of the evidence-based concept}

Sackett and colleagues had announced that the existing paradigm in the practice of medicine was no longer tenable and that it should be challenged and replaced by a new paradigm (EBMWG 1992). At that time rapid developments were taking place in information technology which would eventually drive innovative approaches in the way that medical literature could more effectively guide medical practice. Although Sackett had initially used the term 'critical-appraisal' to describe the application of rules to be used in the evaluation of clinical journals this was superceded in 1991 by the phrase evidence-based medicine (GUYATT 1991).

The term critical appraisal is still used but it is generally applied to the process of evaluating journals, reports or individual studies and although it may have 
been the underlying principle of the earlier definition of EBM it is now accepted that it only forms a constituent part of the EBM triad.

The EBMWG had originally defined EBM as, "the conscientious, explicit and judicious use of current best evidence in making decisions about the care of individual patients" (Sackett 1996). The evidence-based concept was based on the notion that if clinicians are to provide optimal care for their patients, they need to know enough about applied research principles to detect studies published in the medical literature that are both scientifically strong and ready for clinical application. Thus although the initial catalyst in the EBM movement appeared to have been a necessity of keeping 'up to date', the emphasis of the concept has swung away from merely appraising literature towards the assessment and selection of clinically effective and appropriate healthcare interventions and their subsequent implementation.

Four main reasons have been cited for the sudden interest in EBM (SACKETT, 2000):

- the realization of a need for readily accessible and valid information about diagnosis, prognosis, therapy and prevention

- an understanding of the limitations and currency of traditional sources for this information

- an awareness of the discrepancy between diagnostic skills and clinical judgment

- a recognition of the time constraints faced by clinicians to access this information. 
These problems until recently appeared insurmountable but several factors have helped drive the paradigm shift. More recent advances in technology have enabled the rapid and efficient searching for, and appraisal of, evidence of effectiveness of healthcare interventions. The development of robust methodological approaches to the synthesis of evidence has led to the dissemination of an ever widening range of high quality systematic reviews of the effects of healthcare interventions. New strategies have been developed to enhance life-long learning and have given clinicians improved opportunities to ensure they are up to date with the best evidence on healthcare interventions.

The upgraded definition of Evidence-based medicine (EBM) combines the "best research evidence with clinical expertise and patient values" (Sackett, 2000, p.1). Best research evidence is clinically relevant, valid and accurate research, which is patient centered and derived from the basic sciences of medicine. Clinical expertise is a combination of clinical skills, previous experience and ability that an individual clinician uses to assess each patient's unique health state, and the harms and benefits posed to them from potential interventions. Patients' values are the unique expressed preferences, concerns and expectations of each patient and which must be integrated into clinical decisions if they are to provide patient-centred care. The integration of these three components of EBM strives to create a partnership between clinicians and patients with an expectation that it will ultimately optimize clinical outcomes and enhance the quality of life.

The evidence-based approach to healthcare consists of five essential steps.

- the defining of an answerable research question

- searching for the best evidence to answer that question 
- the critical appraisal of that evidence for its validity, size of the effect, and its applicability.

- the integration of that evidence with individual clinical judgment and the patient's preferences and its eventual application.

- an evaluation of the effectiveness and efficiency in completing the process.

These steps will ensure that patient informed decisions can be guided by a comprehensive summary of the best scientific research, appraised systematically, expertly and without bias.

\subsection{Evidence based dentistry}

Much like his medical counterpart the dental clinician would be faced with pressures for change to his clinical practice, and it was these same pressures that would lead to the almost unnoticeable emergence of evidence-based dentistry (EBD) in the early 1990's. Regrettably its early adherents do not appear to have exhibited a similar degree of fervour or missionary zeal as their medical colleagues and a recent pilot study in the UK reinforced the wide gulf between dentists and doctors not only in their level of awareness but also their understanding of the common terminology in the evidence-based concept (BONNER, CLARKSON and McCOMBES, 2001).

Some of the reasons for this mismatch with EBM were outlined by Cooper (2001) who explained how, in the USA, vested interests embodied by organized dentistry; dental education, and insurance companies sought to maintain the status praesens and to which EBD was perceived as a direct and immediate threat. The enthusiasm of the dental profession appeared to be directed towards what he called the "old context of dental care" which was supported by a professional 'guild' 
subdivided into small service units delivering dental care in a fee for service model with the express purpose of making money. Somewhat reassuringly he noted that as "evidence-based medicine is so far down the track it has created a powerful vacuum, pulling evidence-based dentistry right along with it' (Cooper, 2001, p.85) and he remained confident that the tide of evidence-based dentistry was unstoppable. However a study conducted in the less resourced world has illustrated that the mismatch between clinicians in the less and more developed worlds with respect to their knowledge of, perceptions of, and attitudes towards EBD was even more profound and quite significantly extended through undergraduate training and beyond the period of dental internship (FEDOROWICZ, ALMAS And KEENAN, 2004).

Evidence-based dentistry is a reflective approach in the provision of dental care. It does not specifically require the synthesizing of evidence as this may be 'ready made' in the form of clinical guidelines, guidance and clinical decision aids. However, if the evidence sought after is not available 'predigested', the process of EBD may entail the searching for, reviewing and critical appraisal of that evidence. As with EBM, that evidence may be packaged in a number of different formats and strengths of recommendations; in the form of individual studies or trials, systematic reviews, practice guidelines or opinion from 'expert' panels such as the Royal Colleges. The strength of that evidence will depend on the methodological quality of any trials supporting the evidence and on the rigour of the systematic process used in the synthesis of those trials.

As with EBM, evidence-based dentistry only provides guidelines to assist the clinician in making informed decisions, it does not consistently provide definitive, 'cook book' or 'one word' answers. In this way it does not exchange the tyranny of the expert for the tyranny of the literature, nor does it rely solely on 'evidence' but it 
also places a value on clinical expertise and patients' preferences. Expertise is especially critical in dentistry, where the number of randomized controlled trials of specific interventions is very limited.

Patients' preferences and values are also an integral part of EBD and play a significant role in treatment decision making. Changes are gradually occurring in dental care and dental patients are becoming increasingly empowered and their views and preferences are being heard and understood (PITTS, 2003).

\subsection{From traditional hierarchies to the 'Hierarchy of Evidence'}

Evidence can be described as any empirical observation about the relationship between an intervention and an outcome, and, which if it is to be clinically relevant needs to recognize causality between these two events and at the same time to acknowledge the potential influence of systematic error. Clinical observations differ from experimental studies in a number of ways but most specifically in the way that they seek to minimize the effects of systematic error. Unsystematic human inference which is a natural sequel of clinical observation is capable of creating a range of distortions that may affect some of the conclusions reached about the effectiveness of interventions. Conversely, studies that measure variables in response to clinical experimentation are generally less influenced by these systematic distortions.

Evidence may be presented in many forms and strengths. Vital to an understanding of these qualities is the basis on which the evidence is stated; the underlying design of the studies used to generate it and the methods which are used to appraise and synthesise it. A key milestone in the development of methods for critically appraising evidence came in 1979 when the Canadian Task Force on the 
Periodic Health Examination (1979) set about generating 'statements of evidence' for ranking the validity of evidence about the effectiveness of preventative measures. In this way they were able to rate the strength and quality of any investigative studies and by linking these to 'grades of recommendations' they could provide reliable guidance to clinicians. Although the initial focus was on therapeutic or preventative interventions this 'hierarchy of evidence' (Guyatt 1995) is now increasingly being used for levels and grades in diagnosis, prognosis and harms and provides an ordinal ranking of varying levels of evidence in clearly defined terms related to the reliability of relevant studies.

Refinement of this hierarchy of evidence is continuing at the (CEBM) Centre for Evidence-Based Medicine at Oxford (Figure 1). This hierarchy was based on the premise that not all evidence is created equal and that there is a progression in the hierarchy of confidence in evidence. The systematic review was chosen as the reference point as it was considered that a systematic review illustrating homogeneity in the results of a large number of high-quality RCTs (randomized, double-blinded, with complete follow-up and an intention-to-treat analysis) gave the least biased estimate of the effect of an intervention. This was graded as Level 1 with a progression of grading through systematic reviews with heterogeneity, to individual high-quality RCTs, to less rigorous RCTs, to cohort studies, to case-control studies and terminating in expert opinion. There is now fairly wide agreement that the highest levels of evidence in this hierarchy are represented by systematic reviews and randomized controlled trials (Chalmers 1989). The value of this evidence has been ranked according to the following classification in descending order of credibility. 
Figure 1 - Hierarchy of Evidence: Levels I-V Reproduced from: Oxford Centre for Evidence-based Medicine (May 2001) [Note: this has been recently updated (March 2009) to include sub-classifications to each of the levels and now includes additional columns to cover prognosis, diagnosis and economic decision analyses.

\begin{tabular}{|r|l|}
\hline I. & $\begin{array}{l}\text { Strong evidence from at least one systematic review of multiple well-designed } \\
\text { randomized controlled trials. }\end{array}$ \\
\hline II. & $\begin{array}{l}\text { Strong evidence from at least one properly designed randomized controlled trial of } \\
\text { appropriate size. }\end{array}$ \\
\hline III. & $\begin{array}{l}\text { Evidence from well-designed trials such as non-randomized trials, cohort studies, } \\
\text { time series or matched case-controlled studies. }\end{array}$ \\
\hline IV. & $\begin{array}{l}\text { Evidence from well-designed non-experimental studies from more than one centre } \\
\text { or research group. }\end{array}$ \\
\hline V. & $\begin{array}{l}\text { Opinions of respected authorities, based on clinical evidence, descriptive studies or } \\
\text { reports of expert committees. }\end{array}$ \\
\hline
\end{tabular}

Although the CEBM Hierarchy of Evidence is now internationally accepted as the most comprehensive of these 'rules' or categories of evidence, these will only help classify studies based on type of research design whereas their methodological quality will still need to be assessed through the techniques of critical appraisal. Moreover, even though the widespread use of these hierarchies of evidence has helped to illustrate the divergence in trustworthiness of some evidence, their utility has also been challenged. They are said to have three serious disadvantages, according to Glasziou et al. 2004:

- the definitions vary within the different levels of grading,

- they are unable to accommodate the newer hybrid types of research designs

- they can lead to anomalies in rankings.

These authors consider it is time to widen the scope by which evidence is assessed and suggest that "maybe we have something to learn from Michelin guides" (GLASZIOU et al. 2004, p. 41). 
The development by the GRADE (Grading of Recommendations Assessment, Development and Evaluation) Working Group (2004), of a grading system which is able to assess the influence of some of these judgments about evidence and in particular its quality is proving to be a valuable contribution to the resolution of some of these concerns (ATKINS et al. 2005, GUYATT, OXMAN, VIST et al. 2008).

\subsection{Hierarchy of evidence and Dental Public Health}

The hierarchy of evidence is not without its opponents and remains a source of unease particularly in public health (Rychetnik, Hawe, Waters, et al. 2004) where there is a requirement for the strengths of evidence to not only answer questions about clinical effectiveness 'does it work' but also cost effectiveness 'is it worth it'. Studies in which the interventions are of relevance to Public and Dental Public Health may set out to "test less specific hypotheses or simply to explore possible associations of interest; and often in situations where the use of RCTs was not practically or ethically feasible" (Sprod, Anderson and Treasure, 1996). As the strict application of this hierarchy of evidence may not be possible in studies of effectiveness in Public Health, there have been attempts to broaden the scope of the criteria used in systematic reviews of Public Health (RYCHETNIK, FROMMER, HAWE, et al. 2002).

\subsection{A 'gold standard': the randomized controlled trial}

"A randomized controlled trial is a study in which people are allocated at random to receive one of several interventions" (Jadad, 2007, p.1). 
One of the most frequently quoted references to randomized controlled trials is the stinging attack by Archie Cochrane on the medical profession. "It is surely a great criticism of our profession that we have not organized a critical summary, by speciality or subspeciality, adapted periodically, of all relevant randomized controlled trials" (COCHRANE, 1979).

Cochrane had noted the significance of levels of evidence well before their hierarchical structure had been formalized, "observational evidence is clearly better than opinion, but it is thoroughly unsatisfactory." In doing so he also recognised the strength and limitations of the randomized controlled trial (RCT), "the RCT is a very beautiful technique, of wide applicability, but as with everything else there are snags" (Cochrane, 1972, p.22). Although he was a passionate advocate he was not the 'father' of the RCT and along with many other researchers recognised the magnitude of the contribution made by Bradford Hill for his elegant randomized trial on streptomycin for pulmonary TB (MRC 1948). This Medical Research Council trial has been widely acclaimed as the first clinical trial in which random numbers were used to effectively conceal the allocation of interventions to patients. However there had been several earlier reports of alleged randomized trials but in some of these the method of randomization had not been clearly stated and in others, methods of quasirandomization may have been used to assemble the groups.

Tension still exists over who was the rightful 'father' of the RCT. Some of this controversy was highlighted in an Editorial in the British Medical Journal in 1998 entitled "Fifty years of randomized controlled trials". In this issue Doll (1998) referred to a 1948 "watershed" which heralded "the introduction of a new method of conducting clinical trials". A claim which was contested, in the same issue, by Hróbjartsson et al. (1998) who declared that "the controlled clinical trial turns 100 
years" and asserted that in many historical accounts a trial by Fibiger, which predated the one by Bradford Hill, was often not quoted or misquoted.

They stated that because it was published in Danish, references to it often incorrectly quoted the method of randomization but that in general the trial had been "rigorously planned and conducted and was reported with clarity and detail" (Hróbjartsson et al. 1998, p.124). They did however concede that by modern standards it could possibly be classified as a quasi-randomized trial although its most unique feature was a thorough discussion of the avoidance of selection bias by random allocation of participants, an aspect that has been rarely mentioned in any references to this study in the literature. If not the earliest of RCTs then this may have at least been an early warning sign highlighting some of the issues of publication and language bias which have been a cause for concern since the inception of systematic reviews for assessing the effectiveness of healthcare interventions.

Randomized controlled trials are now widely accepted as means of applying experimental methods to a clinical setting and have been advocated as the "gold standard' for comparing and evaluating different treatments. In randomized controlled trials a clearly defined process of randomization ensures that all participants receive an equal chance of being allocated to any one of the treatment arms such that no patient would be advantaged or disadvantaged if allocated to one treatment arm rather than another. As the recognised 'gold standard', RCTs now play a pivotal role in current medical research and are widely considered to be the best way of achieving results that can genuinely increase our knowledge about treatment effectiveness. However, there is still unease amongst some clinical epidemiologists who have dubbed some of the evidence generated by RCTs as "fools gold" (PRINGLE and CHURCHILL, 1995). 
Although there is an increasing requirement for RCTs in guiding health care decision making, the number of reports of RCTs appearing in general heath care journals had peaked by the mid 1980s and by the mid 1990s the number per year had dropped by a third. However although the number of reports may have decreased the number of participants per trial has continued to increase which has been illustrated by larger trial sizes and potentially more powerful studies (McDONALD, WESTBY, CLARKE, et al. 2002).

In dentistry very few interventions fulfill the strict criteria of EBD in having supportive evidence graded as the randomized controlled trial (Cannavina, Cannavina and Walsh, 2000). The best source of this level of evidence is available in the Cochrane Library which has the world's largest collection of reports of randomized controlled and controlled clinical trials (CCTs) with over 586,000 (Issue 3. 2009) included on its CENTRAL database. The Specialized Register maintained by the Oral Health Group of the Cochrane Collaboration (http://www.cochraneoral.man.ac.uk) contains over 20,000 reports of RCTs of dental interventions, many of which are in languages other than English, covering most of the sub specializations within Oral Health.

Many of these RCTs have been accumulated through the Cochrane Collaboration's comprehensive programme of handsearching all of the world's healthcare journals for reports of randomized controlled trials.

This handsearching programme has more recently been extended to the Brazilian oral health and dental journals and has been coordinated by Dr. Raphael Freitas de Souza (Souza, Chaves, Nasser and Fedorowicz 2009; Marchesan, Souza, Pereira-Cenci and Fedorowicz 2008) and colleagues from the Faculdade de Odontologia de Ribeirão Preto, da Universidade de São Paulo in conjunction with 
the Bahrain Branch of the Cochrane Collaboration on behalf of the Cochrane Oral Health Group. The identification of these trials, which may have not previously been readily accessible to the global research community, will heighten an awareness of the extent and quality of clinical trials conducted in Brazil and make a substantial contribution to the evidence base for many interventions not covered by research conducted in other parts of the world.

Randomized controlled trials, apart from being the most precise way of quantifying the level of effect of specific healthcare interventions, have several important design features:

- Random allocation to intervention groups (randomization) which will include any one of the following methods of generation of the allocation sequence: computer generated or table of random numbers, drawing of lots, coin-toss, shuffling cards or throw of a dice.

- Patients and trialists should, if feasible, remain unaware of which intervention they were allocated to (allocation concealment). Methods of allocation concealment include either central randomization or sequentially numbered sealed opaque envelopes.

- All intervention groups are treated identically within each group with the exception of the control group.

- All patients entering the trial should be included in the analysis, irrespective of whether they declined the intervention or withdrew from the study (intention to treat analysis)

Another important strength of RCTs is their capacity to reduce systematic bias such that in a systematic review the summary effects of their individual 
outcomes can, with a certain degree of confidence, provide numerical answers (a meta-analysis) about the effectiveness of a particular intervention.

Bias has been defined as "any process or factor that tends to deviate the results or conclusions of a trial systematically from the truth" (Jadad, 2007, p.29). The elimination of systematic bias (trial design or trial conduct, induced bias) ensures that only random error (the play of chance) and the effect(s) of the intervention can realistically influence the outcome. The application of statistical techniques can allow for the existence of chance or random error whereas the effects of systematic error or bias can only be eliminated through rational study design and robust trial conduct.

The methodological quality of randomized controlled trials is dependent on several key features of their study design. Random allocation ensures that no systematic differences between intervention groups can affect outcomes (selection bias). Double blinding ensures that the personal views of participants and trialist are unable to systematically bias the assessment of outcomes (detection bias). Intention to treat analysis (ITT) maintains the advantages of random allocation, which may be lost if subjects are excluded from analysis through withdrawal or failure to comply (attrition bias).

The effects of systematic bias can be quite significant and it has been shown that failure to randomise participants and conceal allocation can exaggerate the estimate of treatment effect by up to $40 \%$ (Schulz, Chalmers, Hayes, et al. 1995). This form of bias, when patients are knowingly and selectively assigned to treatment interventions is known as selection bias and was explored in a study by Pildal, Chan, Hróbjartsson, et al. (2005).

They investigated how allocation concealment was described in protocols in a series of RCTs and then compared this with the final publications. A staggering 96 
out of the 102 published trials they examined had unclear allocation concealment, and only 15 out of the 96 protocols had adequate allocation concealment. However, they did indicate that their study had excluded trials in dentistry but did not confirm whether this had positive or negative implications.

The subversion of randomized trials, not only in their design and conduct but also in the selective reporting of their results has led to an erosion of both public and academic confidence in them and, poses one of the biggest threats to their validity (SHULTZ et al. 1995).

Not only are trial design and trial conduct important components in trial quality but the completeness in reporting of their results can also significantly influence any subsequent data synthesis (Altman 1996). The CONSORT statement (Consolidation of the Standards of Reporting of Trials) has been developed in an attempt to improve the quality of reporting of RCTs. This statement consists of a checklist of 21 items and a flow diagram which provides a detailed description of the participants entering a clinical trial, and charts their progress through that trial (Altman, Schulz, Moher, et al. 2001). Significantly many journal editors now require that the CONSORT statement has been followed and is included in any reports of randomized trials which are submitted for publication (ALTMAN 2005).

There have also been increasing concerns about the selective reporting of the results of clinical trials (Antes and Chalmers, 2004) which has motivated renewed calls for increased control of trial registration (De Angelis, Drazen, Frizelle, et al. 2004). The alleged concealment of negative results in trials included in two systematic reviews on the effects of selective serotonin reuptake inhibitors (SSRI) for childhood depression (Whittington, Kendall, Fonagy, et al. 2004) and the highly publicised sequelae (Dyer 2004) have emphasised the dangers of non-disclosure of 
trial results, heightened the significance of trial registration and recognised the increased urgency for a globally acceptable method of trial registration (Abbasi 2004). To address these important issues the Ottawa Group is trying to create international consensus on trial registration and in the process is shaping the transition to a new paradigm of health research which is based on transparency, full disclosure and collaboration which is encapsulated in the Ottawa Statement (http://ottawagroup.ohri.ca/index.html).

The WHO has also more recently championed the prospective registration of clinical trials and is working globally through its International Clinical Trials Registry Platform (WHO ICTRP) to develop clinical trials registers in different parts of the world (Ghersi and Pang 2008). In Brazil enforcement of registration which was enacted in 2008 was achieved through national legislation and is a requirement for ethics approval (Agência Nacional de Vigilância Sanitária 2008), many other countries are recognising these benefits and are following suit.

\subsection{Randomized controlled trials in Public and Dental Public Health}

Public health activities are very broadly defined and the effectiveness of their interventions can be evaluated using a variety of study designs not least of all RCTs. Even though RCTs may prove to be a useful source of evidence of effectiveness, their results may have limited generalisability (Black 1996) and their use is often limited by ethical, cost and practical concerns (KELLY, McDAID, LUDBROOK et al. 2005).

In Public Health non RCTs may represent the best available evidence and although they may not address focused issues they are nevertheless able to provide an in depth understanding of patient's experiences and perspectives in the context of 
their personal circumstances and settings. A literature review (Weightman, Ellis, Cullum et al. 2005) confirmed that whilst the RCT design is usually "the best method to demonstrate the effectiveness of individual and group interventions, there is a dominant (if not universal) view that it may not lend itself to evaluating the effectiveness of many complex public health interventions" and that in these types of investigations alternate study designs may be appropriate. It has also been suggested that an insistence on randomized controlled trials when alternative study designs may be applicable, may produce results which are methodologically pure but of limited utility in the clinical setting.

Although this research topic has an element that can be considered relevant to dental public health only a review of clinical experimental studies, for which the randomized controlled trial is considered the most appropriate study design, was considered.

\subsection{Literature and narrative reviews of effectiveness of healthcare}

Clinicians have traditionally sought to maintain their currency through the reading of literature reviews. Although it seems intuitively correct that these types of expert based reviews should be viewed as reliable, they are most commonly conducted by topic-specific experts who use informal and frequently non-systematic methods to interpret the information. Narrative reviews are above all a "compilation of personal opinions and experience and are therefore considered to be fairly subjective" (Jadad, 2007, p.81). Their advantages and the reasons why they are preferred by clinicians are that they are quick and easy to produce; they do not include excessive research jargon and are therefore considered easier to read and more user-friendly. This preference was confirmed by Loke and Derry (2003) who 
surveyed the 'Hit Parade' page of the electronic version of the British Medical Journal (http://bmj.bmjjournals.com/) which records the number of electronic hits in the first week of publication of all articles. Perhaps not surprisingly their findings showed that narrative reviews and editorials are accessed more frequently than primary research papers or systematic reviews. However, as narrative reviews are seen to be a distillation of individual views and preferences in which the reviewer may selectively cite studies to support his opinions, the reader needs to be aware that the results may have been influenced by 'authority selective bias' (OXMAN and GUYATT, 1993).

\subsection{Narrative versus systematic reviews}

The failings of traditional narrative reviews are now well recognized:

- their methodology is rarely explicit

- they lack the a priori statements of how studies will be selected, assessed and integrated

- their lack of precision suggests that small but important 'effects' may be missed

- they are not readily reproducible

- different reviewers are capable of reaching inconsistent conclusions from the same research base.

Furthermore, and quite significantly, there is evidence showing that these types of reviews are not only "incomplete but they can delay the identification of effective or harmful interventions by 10-15 years when compared with more systematic types of reviews" (JADAD, 2007, p.81). 
This lack of rigour in narrative reviews went largely unnoticed until the advent of the evidence-based movement in the 1980s when their fallibility was eventually exposed. The evidence for this came with the publication of two classic papers by Mulrow (1987) and Oxman and Guyatt (1988), which showed that text books and narrative reviews quickly became out of date and were woefully inadequate in summarizing the current state of knowledge. The damning assessment by Mulrow (1987) of 50 narrative reviews published between 1985 and 1986 in the world's best peer reviewed journals proved to be one of the greatest catalysts in research synthesis. Quite surprisingly this study revealed that only one out of the 50 reviews had specified clearly how information was to be identified, selected and validated and that none of the reviews met all of eight criteria considered essential for scientifically sound summaries of evidence.

Additional concerns with traditional and narrative reviews include their tendency to deal with a broader range of issues on a given topic rather than addressing a specific issue in depth and a tenuous connection between their clinical recommendations and the level of evidence. However, having recognised their limitations it is also important to note one of their advantages in that narrative reviews are able to conceptually integrate differing study designs from other fields of research. Consequently recommendations found in narrative reviews often differ quite markedly from recommendations found in systematic reviews.

Possibly the greatest strength of systematic reviews over narrative reviews is that they have the capacity, but not always, to incorporate quantitative techniques to pool data i.e. meta-analyses so that they are better able, than narrative reviews, to detect small but often meaningful benefits of treatments. 


\subsection{Research synthesis: a systematic review, the 'platinum standard'}

A systematic review is a summary of the medical literature that uses explicit methods to systematically search, critically appraise, and synthesize the data on a specific topic. Its goal is to minimize systematic bias and to provide a valid summary of the best available evidence for a specific clinical problem.

Systematic reviews have been dubbed the platinum standard (Tugwell 2004) and are said to be fundamentally different to 'primary research' in that they collate the information presented in primary studies and are frequently, and some believe erroneously, referred to as secondary research. Some researchers even consider that they should be thought of as primary research and that no new piece of research should be done without first conducting a systematic review to find out what is already known (Clarke 2004). Other terms which are in common usage are 'new prospective study' and 'research synthesis' (CHALMERS, HEDGES and COOPER, 2002).

Systematic reviews overcome some of the limitations of narrative reviews but they involve a lengthier and more structured process which combines strategies that aim to limit bias and random error in order that they maximize precision. These strategies are defined by a priori statements which pose a clear research question and set out criteria which will direct a comprehensive search of all relevant articles and the inclusion or exclusion of primary studies. The need for rigour in the production of systematic reviews has led to the development of a formal process for their conduct. This process has clearly designated steps to identify primary studies and the methods which will be employed to assess their methodological quality, the way in which data will be extracted and the statistical techniques that will be used in 
its synthesis. It concludes with a summarizing of the results on which conclusions about the intervention can be based.

Essential to the process is an explicit and detailed description of how the review was conducted so that it may be replicated. In general a systematic review should not include specific recommendations for practice or policy but should be limited to providing a summary of the evidence, its strength, quality and direction made available in the included studies. It should indicate what the implications are of this review for future research and clinical practice and as such it may form a component of clinical practice guidelines related to this specific research question.

\subsection{Systematic reviews and systematic bias}

"In research, as in life, bias is the enemy of truth" (Jacob, 2002, p.61).

Systematic reviews are retrospective observational research which aggregate data from prospective primary clinical studies. In collating this data they are subject to similar forms of systematic and random error that can occur in primary studies. The most important forms of this systematic error that are of relevance to a systematic review are reporting (including publication and language) and selection bias. These types of bias are either knowingly or unknowingly built into the design, conduct, or even the analysis of a review, and as such have the potential to undermine confidence in its results.

\section{Reporting bias}

This includes publication bias, multiple publication bias, language bias, database bias, citation bias and outcome reporting bias (Dickersin 1990). Any one of these forms of reporting bias may hamper the discovery of all relevant studies which 
may result in a review which is incomplete, biased and has misleading results (Chalmers 1990). Reporting bias is generally associated with individual studies that report positive findings and which are:

- more likely to be published than those that find no effect of treatment (Dickersin, Min and Meinert, 1992)

- more likely to be published in English language journals that are indexed in the larger bibliographic databases (Egger, Davey Smith, Schneider, et al.1997)

- more prone to multiple publication (Tramer, Reynolds, Moore, et al. 1997)

- more likely to be cited by other papers (Gøtzsche 1987)

\section{Selection bias}

The selective inclusion of studies with positive findings and the exclusion of studies with negative findings by a reviewer with comprehensive knowledge of the research topic can adversely bias a systematic review (OXMAN and GUYATT, 1993). Clearly, the quality and value of a systematic review of the literature may depend on the extent to which error and bias have been minimized throughout the review process.

\section{Tools to assess biases in systematic reviews}

A range of tools have been developed that can be used to address the suboptimal reporting of meta-analyses and systematic reviews (Oxman 1994). Although it has now been largely superseded the best known of these is the QUOROM Statement (Quality Of Reporting Of Meta-analyses) which evolved out of Oxman and Guyatt's Index of the Scientific Quality of Research Overviews (Oxman and Guyatt 1991). The QUOROM statement (Moher, Cook et al. 1994) has more recently been 
upgraded and replaced by PRISMA (Preferred Reporting Items for Systematic Reviews and Meta-analyses) (Moher, Liberatti, Tetzlaff and Altman 2009). This revision of QUOROM has enabled a wider scope of evaluation of not only metaanalyses but to include systematic reviews in addition to embracing recent conceptual and practical amendments to the process of conducting systematic reviews.

Furthermore, although the conduct and the reporting of reviews may be considered conceptually distinct, these processes are of necessity intertwined. On the one hand methodological quality refers to how well the review was conducted i.e. literature searching, assessment of bias and pooling of data, whilst reporting quality reflects how well the reviewers have reported their methodology and findings.

Methodological quality in the context of comparative research synthesis can be more precisely defined as the extent to which the design of a systematic review will generate unbiased results.

The stated aim of PRISMA is to "help authors improve the reporting of systematic reviews and meta-analyses". Recent methodological research has highlighted the potential importance of language and publication bias in the conduct of systematic reviews and the development of PRISMA is an attempt to address some of these important sources of bias. The PRISMA Group, who are the developers of PRISMA, indicate that although the PRISMA checklist may be useful for critical appraisal of already published systematic reviews and meta-analyses it is not designed to be used as a quality assessment tool to evaluate systematic reviews. Currently there is only one internationally validated instrument available that can be used in the assessment of multiple systematic reviews (AMSTAR). 
AMSTAR is a tool that was designed specifically to assess methodological quality; it is based on previous tools and empirical evidence and was developed through the consensus of a group of experts consisting of clinicians, methodologists, epidemiologists and reviewers (SHEA, GRIMSHAW et al. 2007). This 11-item tool, which has good face and content validity, has recently been validated (Shea et al. 2009) and its importance is increasingly recognised as a keystone in the assessment of quality in systematic reviews. The expectation being that use of this tool can ultimately improve the methodological quality of systematic reviews and thereby contribute to providing the best evidence to inform health care practice and policy.

The quality of reporting of Cochrane Reviews is to a large extent already controlled by robust Cochrane editorial and peer review standards and processes and thus in this comparative effectiveness synthesis we sought to evaluate only the methodological quality of the two included reviews using the AMSTAR checklist (See Appendix 6).

In the context of systematic reviews the GRADE approach defines the quality of a body of evidence as "the extent to which one can be confident that an estimate of effect or association is close to the quantity of specific interest" (Higgins 2008, p361). In considering the quality of a body of evidence such as that in a systematic review a number of within-study criteria need to be addressed. These include limitations of design e.g. risk of bias; directness of the evidence e.g. its external validity, heterogeneity e.g. clinical diversity, precision of effect estimates e.g. low powered studies with wide Confidence Intervals and, risk of publication bias e.g. selective or incomplete reporting of outcomes. 
The GRADE system attempts to evaluate the quality of a body of evidence specifically for each individual outcome across all of the studies and in this way it differs from AMSTAR.

\subsection{Benefits of systematic reviews}

- They provide a clearer picture; small or low powered studies may show no statistical difference between the treated and controlled groups. Aggregating of studies may allow a more complete picture to emerge.

- They can help overcome bias; unsystematic or narrative reviews especially if influenced by the prior beliefs of the reviewer offer plenty of scope for bias.

- They can increase precision; aggregation of data by the synthesis of a number of smaller individual studies can help increase the precision with which the size of any effect can be estimated.

- They are transparent and reproducible; through the documenting of all the decisions taken throughout the process.

\subsection{Clinician perceived disadvantages of systematic reviews}

Systematic reviews can offer significant benefits for busy practitioners but they are still viewed by many clinicians as pure research and since many dental professionals have not been prepared academically to identify and appraise evidence they may experience problems in interpreting and using them. In addition, the common perception of systematic reviews being capable of providing a single answer or the last word may leave clinicians frustrated, disappointed and disillusioned (Berg 1997). These disadvantages are well known but if clinicians are to make the most of 
this type of evidence it has been said that "editors and educators are duty bound to create some kind of evidence-based re-education system" (GOODMAN, 2003, p. 60).

Systematic reviews can aid but never replace sound clinical reasoning which must be based on experience, current best research evidence and even heuristics. Clinicians need to be aware that knowledge of a treatment's effectiveness alone doesn't confer 'title' of how to use that treatment in caring for individual patients. It is increasingly recognised that healthcare decision making is complex and requires an understanding and appreciation of not only the research evidence but the ways in which knowledge, skills and values are integrated in each patient-clinician contact.

\subsection{Systematic reviews in dentistry}

The increasing demand for high level evidence of effectiveness of oral healthcare interventions to inform healthcare decision making has lead to a marked increase in the rate of publication of systematic reviews. The Centre for Reviews and Dissemination (CRD) at the University of York, and the Cochrane Collaboration are two of the leading organisations which maintain databases of systematic reviews in oral health. Unlike the Cochrane Collaboration CRD does not prepare or commission systematic reviews, but it conducts exhaustive monthly searches for completed systematic reviews which are then quality assessed in-house and their abstracts are subsequently published in the DARE database. The most celebrated of these reviews being the systematic review of public water fluoridation (McDONAGH, WHITING, BRADLEY et al. 2000).

Conversely the Cochrane Collaboration prepares, disseminates and maintains systematic reviews with those in oral health coordinated through the Oral Health Group (OHG) based in Manchester (www.cochrane-oral.man.ac.uk). This 
Cochrane Review Group currently has over 20,000 randomized controlled trials in its specialized register which are available to reviewers who are assembling existing evidence into systematic reviews. The range of systematic reviews within the $\mathrm{OHG}$ covers prevention, treatment, and health promotion across the complete range of oral healthcare interventions. The OHG provides support to over 350 reviewers from 40 countries that have so far completed 92 systematic reviews and 76 protocols all of which have been published on the $3^{\text {rd }}$ Issue of The Cochrane Library, July 2009.

\subsection{The background to the research question}

The choice of whether the existing literature in the form of standard clinical reference books alone will help to focus a review or whether to use electronically retrieved information and ignore general background information is a fine balance. $A$ radical solution to this dilemma, suggested by Sackett et al. (2000) in their widely acclaimed monograph, was that traditional textbooks should be "dismissed and burned".

However, they claimed that in order for them to be considered dependable they must satisfy three criteria. Textbooks should be; revised at least annually, be heavily referenced and that evidentiary support for any clinical statements should be achieved through a transparent process and according to explicit principles of evidence. They did concede however that most textbooks are well organized for clinical use and may include some "useful information" about the pathophysiology of certain diseases but "it is best not to use them for establishing the cause, diagnosis, prognosis, prevention or treatment of a disorder" (SACKETT, et al. 2000, p.30).

Undoubtedly the increasing trend towards citation enriched and web linked textbooks will lead to an improvement in the 'currency' of evidence about healthcare 
interventions. However until more recently the likelihood of any textbook satisfying all of Sackett's criteria has been fairly remote but this is likely to change as the number of e-books and other forms of electronic publication become more widely available.

A traditional approach was used in the literature review for this research topic but this was enhanced by a limited electronic search. The objective of this literature review was to provide background information to the research question whereas the foreground questions would be answered by the systematic review after a more comprehensive search of the medical literature which focused on the research question and incorporated the appropriate study design.

Background questions generally "explore broad principles related to diagnosis, prognosis and therapy of the problem, and must include two components" (SACKETT et al. 2000, p15).

1. A question (who, what, were, when, how and why) and a qualifying verb

2. A disorder or disease

\section{My background questions on halitosis were}

I. What are the possible causes of halitosis?

II. What are the clinical symptoms of halitosis?

III. What diagnostic tests can be used to evaluate the extent or degree of halitosis?

IV. What types of interventions are available to treat halitosis?

V. What are the patient-preferred outcomes for halitosis?

VI. What adverse events have been associated with these interventions? 


\subsection{Sources of background information: clinical references and internet resources}

The primary sources that were used to generate background information in these systematic reviews were: several standard clinical references and electronic resources; a 'quick and dirty' electronic search using Google Scholar; my personal collection of relevant bibliographical references and through frequent email contact with several Brazilian researchers.

Assumptions about the effectiveness of any interventions in any studies which have been found in the background scoping searches, and may be potentially included, should not be made prior to conducting the systematic review. Assessment of the methodological quality of these studies was only undertaken after the abstracts from the results of the searches had been evaluated to see if these studies matched the inclusion criteria of the systematic review.

Several premier resources, only one of which matched all of Sackett's three criteria, were consulted for definitions of halitosis, the patho-histology and for relevant clinical information on the diagnosis, prognosis and treatment of oral halitosis. (See Principal clinical references in 'References')

\subsection{Aetiology, clinical symptoms, definitions and diagnostic tests}

Halitosis is an unpleasant odour that emanates from the oral cavity and can be serious enough to cause personal embarrassment. The term halitosis is a general term used to describe any disagreeable odour of expired air, regardless of its origin. The lay term, bad breath, is the generally accepted term for foul smells emanating from the mouth but the term oral malodour is reserved for halitosis originating from the oral cavity (TANGERMAN 2002). 
The reliability of epidemiological data has been questioned, but the prevalence of halitosis has been reported to be as high as 50\% (Yaegaki 2000). In the USA, 10 to $30 \%$ of the population claim to suffer from bad breath (Meskin 1996) whilst a study in Japan showed that $24 \%$ of patients complained of oral malodour (Miyazaki 1995). In France it was reported that between $50 \%$ and $60 \%$ of the population suffer from chronic halitosis (Meningaud 1999). The majority of these patients reporting problems with oral malodour consider it serious enough to cause embarrassment and affect interpersonal social communication (BOSY 1997; BRUNETTE 1998).

The general public and many physicians and dentists are still poorly informed about the causes of halitosis with many still believing that bad breath originates in the stomach and with other sources of halitosis attributed to a range of factors. In $87 \%$ of cases the origin was said to be from oral causes (Delanghe 1999) whilst other possible causes included sinus infections, gastric imbalances, and diet. However it is now fairly widely accepted that halitosis originates from the oral cavity (Ayers 1998) and the tongue is said to act as a reservoir which permits the accumulation and stagnation of bacteria and food residues (BOSY 1994; SCULLY 1997).

Interdental plaque and gingivitis may also play a contributory role, and although periodontal pockets provide an ideal environment for VSC production, their contribution to oral malodour is still unclear (Morita 2001). Halitosis-causing bacteria are the primary sources of volatile sulphur compounds (VSC); the chief components of which are hydrogen sulphide and methyl mercaptans (KLEINBERG 1990; TONZETICH 1977).

These volatile sulphur compounds and other additional odours such as indole, skatole, putrescine and cadaverine (Kleinberg 1995) are produced through the bacterial metabolic degradation of food debris, desquamated cells, saliva proteins, 
dental plaque and microbial putrefaction (RATCLIFF 1999). The intensity of clinical bad breath has been shown to be significantly associated with the amount of intraoral VSC level and to be correlated directly with periodontal health status (BOSY 1994; REPLOGLE 1996; STAMOU 2005).

The periodontal pocket is an ideal environment for VSC production and consequent periodontal tissue destruction, explaining why patients with periodontal disease often complain of oral malodour (MORITA 2001).

Research confirms that the anaerobic and predominantly gram-negative bacteria are involved in degrading amino acids (Persson 1990; Tonzetich 1981) to produce the foul smelling volatile sulphur compounds (ATTIA 1982; ROSENBERG 1996).

A number of other compounds are capable of producing unpleasant smells that originate from the mouth. These include hydrogen sulfide, methanethiol, dimethyl sulphide, n-dodecanol, n-tetradecanol, phenol, diphenylamine and pyridine (Kostelc 1980). The main contributors to oral malodour are now recognised to be the volatile sulfur compounds (VSC: hydrogen sulfide, methyl mercaptan and dimethyl sulfide) (TONZETICH 1964).

\section{Classification of halitosis}

Although this classification has not been universally accepted by all experts in the field there is general agreement that halitosis can be categorised as genuine halitosis, pseudo-halitosis and halitophobia (YAEGAKI 2000; MIYAZAKI 1999).

Genuine halitosis has been further sub-classified as physiologic halitosis or pathologic halitosis. In physiologic halitosis there is no readily apparent disease or pathological condition, whereas pathologic halitosis occurs as a result of an infective 
process of the oral tissues. Pseudo-halitosis is a condition in which there is absence of halitosis but the patient believes that they have oral malodour. Halitophobia can occur when there is no physical or social evidence to suggest that halitosis is present and which can persist after treatment for either genuine halitosis or as pseudohalitosis. Modification of these classifications has been proposed to reflect the perception of halitosis by North American society norms and specifically with reference to halitophobia (YAEGAKI 2000).

\section{Diagnostic Tests}

Methods of assessment of levels of malodour include those which are very simple, highly subjective and others which are complex, time consuming and involve the use of sophisticated equipment:

- organoleptic (TSUNODA 1981);

- portable VSC monitor, the halimeter (ROSENBERG 1991);

- gas chromatography coupled with flame-photometric detection (SOLIS-GAFFAR 1975);

- culture of plaque and periodontal pocket exudates (LOESCHE 1995).

Evaluation of malodour can be complex and subject to the sensitivity and accuracy of equipment used and dependent on individual factors such as heterogeneity in oral hygiene control, circadian variation and smoking habits (Rosenberg 1992). Earlier studies had used trained breath judges and gas chromatography but more recent studies investigating the effectiveness of oral healthcare products to eliminate oral malodour have utilised a portable halimeter (SILWOOD 2001). 
Sulphide monitors although compact, portable and easy to use, have a high sensitivity for hydrogen sulphide, but low sensitivity for the principal cause of malodour methyl mercaptan. The most reliable and practical way of evaluating malodour is claimed to be by organoleptic measurement (human nose) (Rosenberg 1995), but this has been contested by studies showing that measurements with the halimeter appear to be more reproducible than those acquired by subjective, organoleptic methods (SILWOOD 2001).

\section{Interventions}

At present there are no standard and accepted protocols for the treatment of oral malodour (Morita 2001). Patients who are conscious that they have halitosis may attempt to mask it through compulsive brushing or with a range of over the counter methods such as chewing gum, mints, scented liquid drops, and the use of mouthrinses (Borden 2002). Most of these merely provide a competing, and temporary smell that is capable of masking the unfavourable malodour. The success of any halitosis intervention appears to hinge on the reduction of VSC levels and other foul volatiles and consequently the majority focus on mechanical and chemical options.

Mechanical interventions (i.e. brushing, flossing and tongue scraping) aim to reduce the numbers of VSC-producing bacteria, residual food matter and cellular debris from the gingivae and tongue. The limitations of mechanical methods to effectively reach and remove VSC-producing bacteria from all oral ecological sites are acknowledged. The possibility that mouthrinses may be more effective in reaching the less accessible parts of the oral cavity, their greater social acceptance 
and ease of use has led to the development of a large number and range of over the counter mouthrinses (AYERS 1998; RICHTER 1996).

Some mouthrinses contain antibacterial agents in addition to flavouring agents and have been generally categorised into those that neutralize and those that mask the odour. Components which neutralize can further be divided into those that affect the bacteria directly or the chemical compounds they produce and include chlorhexidine, phenol, Triclosan, chlorine dioxide, alcohol and metal ions, the most common of which is zinc (Carvalho 2004; Farrell 2006). The odour-masking agents consist of essential oils, which can also provide a competing and purely temporary smell that is capable of disguising the unfavourable malodour. Some mouthrinses contain components that can neutralize the malodour or the bacteria which produce it. The most common of these include alcohol, zinc, phenol, chlorhexidine, and folic acid.

Reduction of the causative bacteria can also be accomplished through improving oral hygiene (Tonzetich 1978) in addition to cleaning of the tongue (Rosenberg 1996). This can be accomplished by brushing or scraping the dorsum of the tongue to dislodge trapped food, cells, and bacteria from between the filiform papillae. Tongue cleaning has been claimed to reduce oral malodour by decreasing VSC concentration by $20 \%$ to $70 \%$ (Tonzetich 1977 ). A variety of metal and plastic tongue scrapers are commercially available.

\subsection{Electronic scoping search}

Google Scholar (www.scholar.google.com) was used to make a preliminary assessment of the volume of literature on this research topic. Accessing this website enabled a wide scoping search of published and grey literature which includes peer- 
reviewed papers, theses, books, abstracts and reports available from a variety of academic publishers, professional societies and universities. One of the major advantages of Google Scholar is that it includes citations to older works and seminal articles that appear only in books or other offline publications. It is now considered to be the first line in search engines and is used extensively by many research workers. Although it can provide a very comprehensive search, the lack of sophisticated multiline searching and search filters appropriate for healthcare means a lot of irrelevant information is often retrieved.

\subsection{Personal collection of relevant bibliographical references}

The bulk of this personal bibliography, excluding those studies which were included in the two Cochrane systematic review, consisted of papers, reports and historical references which were accumulated during the course of conducting these reviews and only provided 'background' information and did not include studies with a design or content that was relevant for the review question.

\subsection{Summary}

All of the background questions of who, what, where, when, how and why were explored in the literature review. The literature review answered several of these background questions:

- that halitosis was ubiquitous but accurate and reliable prevalence data were hard to obtain;

- that although there was some agreement on the classification of halitosis it still lacked universal acceptance; 
- that the causes and origins of halitosis appear to be well recognised and understood by clinicians albeit not entirely by the lay public;

- that odours other than those produced by volatile sulphur compounds may have a significant role to play in halitosis;

- that whilst organoleptic assessment of halitosis remains the 'gold standard', halimeter readings may not be as reliable as either gas chromatography or organoleptic assessment;

- that there are a wide range of over the counter (OTC) mouthrinses and tongue cleaning tools which have been the subject of clinical trials but whose overall effectiveness has not been assessed in the context of a systematic review.

This work was conducted in order to compare effectiveness research (CER) synthesis of two Cochrane Systematic Reviews on the effects of interventions in treating halitosis. The potential impact of these two systematic reviews on further research can be assessed by examining their rates of citation in the bibliographic references of studies which indicate an average annual citation rate of $(08)-(\underline{\text { See }}$ Appendix 7). 
3. Proposition 



\section{Proposition}

The aim of this work was to perform a Comparative Effectiveness Research (CER) synthesis of two Cochrane systematic reviews on the effects of interventions in treating halitosis and to evaluate their methodological quality against an internationally validated tool that can be used for assessment of multiple systematic reviews (AMSTAR). 

4. Material and Method 



\section{Material and Method}

\subsection{Criteria for considering studies for this review}

\section{Types of studies}

The randomized controlled trial is considered the best study design for assessing the effectiveness of healthcare interventions and thus only randomized controlled trials (RCTs), which includes cross-over trials in which the allocation to interventions was effectively randomized, were considered in this review. Random allocation of participants to either study arm will create groups of participants with similar characteristics at baseline which will help minimize the effect of bias and permit a more accurate assessment of the effect of any intervention. It is essential that the allocation is truly unpredictable and the methods that can be used to ensure random allocation are described in the section on the assessment of risk of bias. (See 4.4. Assessment of risk of bias).

Ascertainment or performance bias in which both trialists and participants know which intervention is being given to which participant can systematically distort the outcomes of a trial. However, although it may not be possible to blind those who would be administering and collecting the outcomes data it may be possible to reduce the effect of ascertainment bias by ensuring that the data analysts are blinded to which data came from which intervention or participant, until the results are ready to be reported.

\section{Types of participants}

Only studies which had recruited adult patients who were over the age of 18 and presented with a clinical or self assessed diagnosis of halitosis, with no 
significant comorbidity or health condition that might lead to increased halitosis (e.g. diabetes) were considered. We excluded studies which had been conducted on participants with refractory and severe chronic periodontal diseases.

\section{Types of intervention and control}

The following interventions and controls were considered for these reviews:

- Tongue scraping versus placebo or nothing.

- Tongue scraping versus mouthwash or other interventions.

Any form of tongue scraper, tongue or toothbrush used to clean the tongue was considered. All mouthrinses which are either available over the counter or those which have been prescribed for halitosis were considered.

- Mouthrinses compared to placebo.

- Mouthrinses against each other.

The active interventions or controls would have been administered over a minimum of one week and with no upper time limit.

We considered all mouthrinses which are either available over the counter or those which have been prescribed by a clinician for the treatment of halitosis. Studies which included single use mouthwashes were not considered for this review.

\section{Types of outcome measures}

\section{Primary}

The primary outcomes considered for this review were self expressed (perceived) (Greenman 2004) and organoleptic (human nose) assessments of halitosis using any validated malodour intensity scale. 


\section{Secondary}

We considered the assessment of halitosis as measured by a halimeter, portable sulphide monitor or gas chromatography coupled with flame-photometric detection.

Additional outcomes which were considered included determination of peak and steady-state volatile sulphur compound levels using a sulphide monitor, prior to and at several time-points after mouthrinsing or tongue scraper.

A minimum follow-up period of 4 weeks was considered for any of the interventions or comparisons.

Adverse effects

We reported on any specific adverse effects related to any clinically diagnosed hypersensitivity or other reactions to the mouthrinses or tongue scrapers. Table 1 shows a summary of the inclusion criteria for identification of relevant studies.

Table 1 - Summary of inclusion criteria for identification of relevant studies.

\begin{tabular}{ll}
\hline Characteristic & \multicolumn{1}{c}{ Criteria } \\
\hline \hline \multirow{3}{*}{ Publication type } & $\begin{array}{l}\text { Clinical studies were included. Emphasis was placed on high quality } \\
\text { studies. Abstracts were excluded where no clinical outcomes were } \\
\text { reported, or where the paper was a review, editorial, or a laboratory or } \\
\text { animal study. } \\
\text { Due to difficulties in appraising risk of bias, conference abstracts were } \\
\text { generally excluded unless they reported specific adverse events. }\end{array}$ \\
& $\begin{array}{l}>18 \text { yrs with a clinical or self assessed diagnosis of halitosis, with no } \\
\text { significant comorbidity }\end{array}$ \\
Interventions & $\begin{array}{l}\text { Tongue scraping versus placebo or nothing. } \\
\text { Tongue scraping versus mouthwash or other interventions. } \\
\text { Mouthrinses compared to placebo. } \\
\text { Mouthrinses against each other. }\end{array}$ \\
\hline Language & $\begin{array}{l}\text { Full text copies were retrieved if the abstract contained information } \\
\text { relevant to the effectiveness and/or safety of the interventions. }\end{array}$ \\
\hline & $\begin{array}{l}\text { Non-English language articles were eligible and were translated as } \\
\text { required. }\end{array}$ \\
\hline
\end{tabular}




\subsection{Search Strategy for identification of studies}

\section{The aims of the search}

The overarching aim of the search was to ensure that an exhaustive scrutiny of the literature created as comprehensive a list as possible of published and unpublished primary studies which were deemed relevant to answering the research question.

Factors that are crucial to and could have an impact on the identification of studies include:

- a comprehensive and unbiased search strategy,

- a sufficiently large enough number of studies,

- a recognition of the influence of publication and language bias.

Although these three factors are interrelated they are nevertheless separately and uniquely capable of affecting the results of a search and thus directly influencing the outcome of a systematic review.

Whilst maintaining that an exhaustive search may prove unrealistic White, Cooper and Hedges (1994, p.41) also expressed doubt about its necessity. They declared that the main objective of the search was not solely to track down every relevant paper but rather to avoid bias by not missing a useful reference through the use of established search methods. The comparative simplicity of effecting electronic searches means that it is now quite possible to ensure a full and fairly comprehensive search. However, there is no consensus and currently very little evidence comparing the results of exhaustive and non exhaustive searches in identifying reports of randomized trials. Concerns have been expressed about exhaustive searches in that they are more likely to locate trials of lower 
methodological quality, which raises the possibility that rather than preventing, they might introduce bias (EGGER, JÜNI, BARTLETT, et al. 2003).

The Centre for Reviews and Dissemination Report (CRD4) emphasized that there was a strong correlation between the validity of review findings and the comprehensiveness of the search, and reinforced support for a thorough and unbiased search strategy which they deemed was crucial for the identification of all relevant studies (Khan K, ter Riet G, Glanville J, et al. 2001). The requirement for thoroughness in the identification of studies entails the development of a broad search strategy and the mandatory iterative testing and refining of the appropriate search terms (EGGER, et al. 2003).

The volume of information within a systematic review is directly related to the quantity of included studies and the quality of their reporting, both of which may ultimately affect the precision of the review and reflect the degree of confidence in the range or Confidence Interval $(\mathrm{Cl})$ around the effect estimate. The width of the $\mathrm{Cl}$ provides information on how big or small the true effect might possibly be and will therefore correlate with the size and number of included studies. In this way a wider range in $\mathrm{Cl}$ will reflect a more diverse range of effect sizes resulting in less precision, and conversely a narrow $\mathrm{Cl}$ infers a smaller range of effect size and thus greater precision which can permit greater confidence in the outcome of the review.

Language and publication bias are two of the important sources of bias to be considered in the dissemination and ultimately identification of research (Dickersin 1990). Publication bias has been described as the publication or non publication of research findings depending on the nature and the direction of the results, and language bias as the publication of research findings in a particular language depending on the nature and direction of the results (Egger, Dickersin and Davey- 
Smith, 2001). Where and when studies were published, in which language and if and how they were written up may facilitate or impede their identification.

Trials which are 'buried' in journals which are not indexed to the major databases are likely to be missed even in the most comprehensive of searches (Egger and Davey-Smith, 1998). A range of personal, academic and editorial factors are also known to play a role in the publication or non publication of research. Some of these factors are supported by strong evidence which confirms that trialists tend to write and submit, and editors are willing to accept, manuscripts based on the significance and direction of study results (DICKERSIN 1997).

Thus research findings with statistically significant or positive result have been shown to be more likely published than those reporting less significant results (loannidis, 1998). Language bias, a variation of publication bias, can be inferred when the direction of the results of a study dictate its publication in other languages. Thus studies which show positive results tend to be published in English language journals (Egger, Zellweger-Zahner, Schneider, et al. 1997) and are often published earlier (STERN and SIMES, 1997).

In addition searches which are restricted by language may exclude studies showing a non-significant result, which may have implications for the overall quality of a review particularly if the summary outcomes effect is small. The extent of language bias was illustrated in a study of ten German language dental journals which found that nearly half of the randomized trials in these journals were not included in MEDLINE (Türp, Schulte and Antes, 2002). These authors could find no justification for this form of bias and emphasised that the assumption of differences in quality and conduct of RCTs between reports published in English and other European languages was not justified and confirmed the earlier views of Moher, 
Fortin, Jadad, et al. (1996). It was interesting to note that as Türp et al. (2002) had published their criticism in an English language journal, their action although highlighting the problems of language bias, could be conceived as contributing further to that bias by not being co-published in a German language journal.

Databases such as LILACS (Latin American and Caribbean Health Sciences Literature), represent a geographical region, are the main reference index of technical and scientific literature in Health sciences in Latin America and the Caribbean and may often be omitted from search strategies and in this way can contribute to publication bias. The extent and ability of publication bias to influence systematic reviews can be assessed through statistical methods or graphical tests called funnel plots (EGGER, DAVEY SMITH, SCHNEIDER et al. 1997). These tests are an important component of the review process however they are more specifically relevant if quantitative analysis of the data is proposed.

Thus if the aims of the search are to minimize bias due to the selective availability of data, steps must be taken to ensure that the search identifies as wide a range and as many relevant studies as possible to provide reliable evidence on which healthcare decisions can subsequently be based.

\section{Generating a search strategy}

The development of a search strategy involves a repetitive process of selecting appropriate search terms and appropriate data bases and testing and retesting of these search terms in a series of trial searches to ensure a comprehensive coverage of the literature. The most significant attributes of a search strategy are its sensitivity (ability to identify relevant articles) and specificity (ability to exclude irrelevant articles) or precision. In systematic reviews of healthcare 
interventions sensitivity is of paramount importance such that specificity may often be sacrificed in favour of sensitivity. The key components in developing a search strategy are: (See Appendix 1)

- Defining the searchable question by breaking down the question into facets or Groups.

(Group 1) P: problem/topic, patient. (Group 2) I: intervention.

(Group 3) C: comparison. (Group 4) O: outcome

The group of search terms covering each facet should include a range of text words (free text), which may be found in the title and abstract of potential studies, as well as any subject indexing terms.

- Identifying any synonyms, spelling variants and subject headings associated with each facet, using text terms and Medical subject headings $(\mathrm{MeSH})$.

- Study design is a facet of importance to search strategies which can include terms to identify randomized controlled trials or other study designs.

- Identifying the databases to be searched. There is a wide range of specialised databases and specialised registers which are specific for RCTs, the largest of which is the Cochrane Central Register of Controlled Trials (CENTRAL). (www.cochrane.org)

- Conducting a scoping test search

- Assessment of the test results. This will help confirm the specificity of the search terms used. 
- Refining the search terms and retesting accordingly.

- Executing the MEDLINE search and identifying of other resources

- Running the searches

\section{Searchable question and search terms}

The searchable question for this research topic was, "The comparative effectiveness of mouthrinses and tongue scraping for the treatment of halitosis". The main search term used was based on the MeSH indexing term:

\section{Halitosis}

\section{Scoping search}

Scoping searches were conducted on MEDLINE using the subject term to merely provide an overview of the volume of potentially eligible studies. These were conducted prior to the fully comprehensive searches which are documented below.

\section{Databases searched}

One of the cardinal features of a systematic review is that the search strategy should be reproducible and therefore this must be documented and described in sufficient detail to facilitate its repetition by any researcher. Documentation should include the main sources that were used to locate the studies, the search strategy for each database, the date of the search and include any language or other constraints.

There is no single electronic database that is comprehensive enough to cover all medical journals but general medical databases such as MEDLINE and EMBASE are considered to be useful starting points in developing the search strategy. These databases use thesaurus-derived indexing terms to facilitate 
searching in addition to a structured vocabulary known as MeSH (Medical Subject Headings) which can be used to help identify appropriate keywords. The MEDLINE database is located in the USA, and to ensure comprehensive coverage in this systematic review it was searched in conjunction with its European equivalent EMBASE. There is a recognised degree of overlap of reports in journals covered by both MEDLINE and EMBASE and which has been estimated at $34 \%$, with a range of $10-75 \%$ depending on the topic.

For the identification of studies included or considered for this review, detailed search strategies were developed for each database to be searched. These were based on the search strategy developed for MEDLINE but were revised appropriately for each database.

\section{Electronic searches}

Searches were conducted by the Cochrane Collaboration's Oral Health Group Trials Search Coordinator, for the tongue scrapers review in September 2005 and updated in February 2009 and for the mouthrinses review in August 2008. The following databases were searched on the dates indicated: (See Appendix 2)

For the MEDLINE search (and in the updates) we ran the subject search with the Cochrane Highly Sensitive Search Strategy (CHSSS) for identifying randomized trials in MEDLINE: sensitivity maximising version (2008 revision) as referenced in Chapter 6.4.11.1 and detailed in box 6.4.c of The Cochrane Handbook for Systematic Reviews of Interventions Version 5.0.1 [updated September 2008] (HIGGINS 2008).

\section{\# Tonque scraping for treatment of halitosis}

- the Cochrane Oral Health Group Trials Register (to 15th September 2005) 
- the Cochrane Central Register of Controlled Trials (CENTRAL) (The Cochrane Library 2005, Issue 3)

- MEDLINE (from 1966 to 15th September 2005)

- EMBASE (from 1974 to 19th September 2005)

Amendments were made to these earlier search strategies and updated searches were re-run. The most recent searches were carried out on 3rd February 2009.

\section{\# Mouthrinses for treating halitosis}

The following databases were searched on the dates indicated:

- Cochrane Oral Health Group Trials Register (to August 2008).

- (CENTRAL) (The Cochrane Library 2008, Issue 3)

- MEDLINE (1950 to August 2008)

- EMBASE (1980 to August 2008)

- CINAHL (1982 to August 2008)

The last searches were carried out on the $11^{\text {th }}$ August 2008.

\section{Handsearching}

No additional handsearching was conducted other than examination of the reference lists of the studies.

\section{Language}

There were no language or date restrictions in the electronic searches and we arranged to translate any relevant non-English papers. 


\subsection{Finding the trials}

The search strategies identified a combined total of 990 references, 435 potentially relevant to the tongue scrapers and 555 potentially relevant to the mouthrinses, review questions. These references were de-duplicated and all titles and abstracts were further assessed independently by two reviewers against the inclusion criteria stipulated for the two systematic reviews. As only study designs that randomized the participants to either mouthrinses or tongue scrapers versus the prespecified controls were to be considered, any reports that did not describe a randomized controlled trial were excluded. After this preliminary assessment of study design any remaining references which did not match the inclusion criteria of this review were excluded from further study. For a summary of the search results across the databases, see Figure 2. 


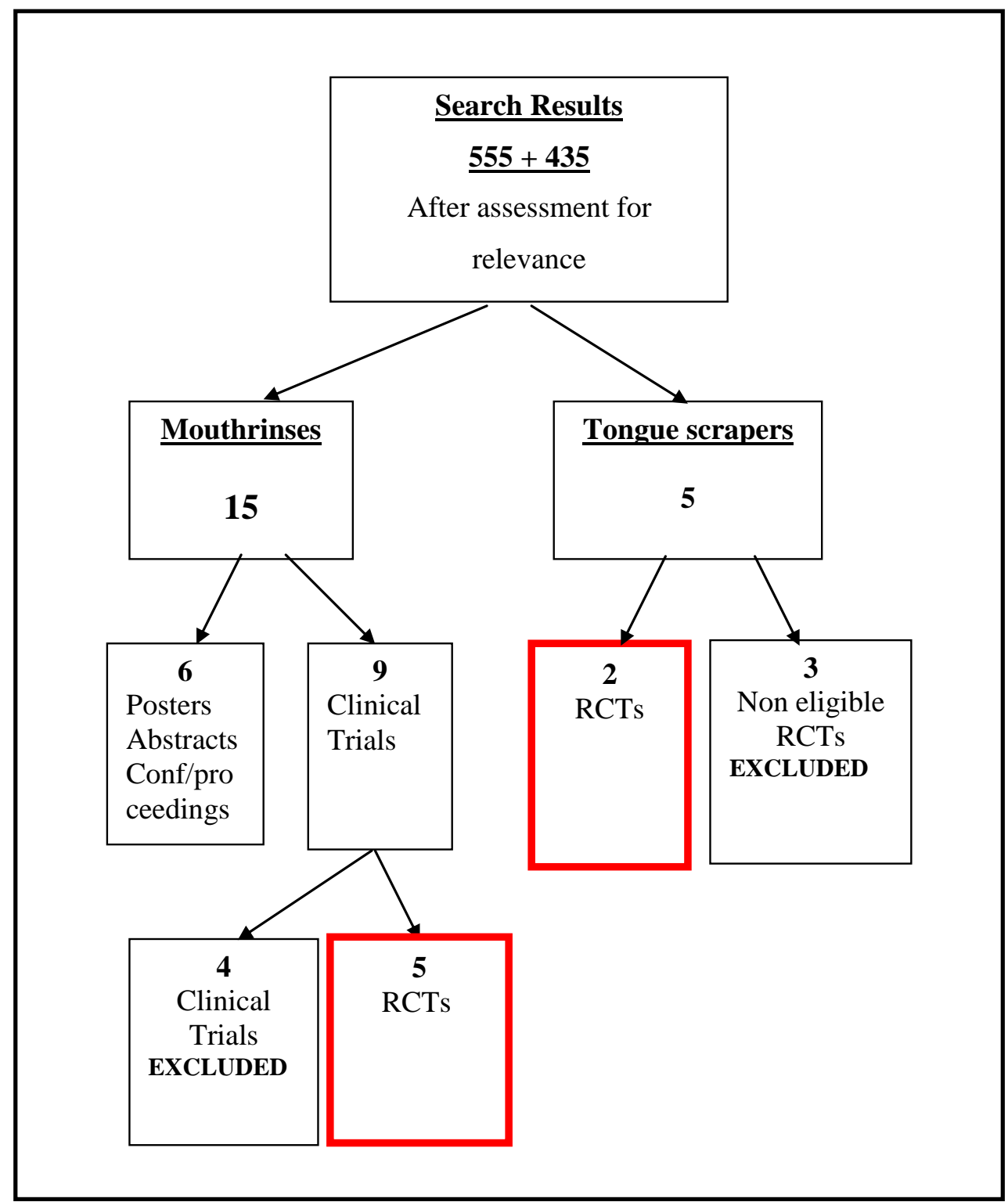

Figure 2 - Summary of the search results across the four databases.

A total of 20 reports of randomized controlled trials were identified as being potentially eligible for inclusion in the two reviews, full text copies of these 20 reports were obtained from various sources to enable further assessment.

\section{Tongue scraping for treatment of halitosis}

Full text copies of the five papers were obtained from the Cochrane Oral Health Group (OHG). An unpublished trial which matched our inclusion criteria was 
discovered by searching on Google Scholar (Chotai 2003). The investigators have been contacted several times by e-mail and requested to supply further study details but no reply has been received until the present (Table 2).

Table 2- Study awaiting classification. Tongue scrapers.

\begin{tabular}{ccc}
\hline Author & Study design & Interventions/treatment \\
\hline \hline Chotai 2003 & RCT & Tongue brush/scrapers \\
\hline
\end{tabular}

We excluded the Suarez (2000) trial as there was no randomization of the participants, the allocation sequence of the interventions was not explicit and the interventions were only used for a single day. The Williams (2004) trial was a crossover design which compared 3 different types of toothbrushes with a new toothbrush. In this study the trialists only permitted tongue brushing with the new toothbrush. It was considered that the restriction of tongue brushing to this new toothbrush might bias any results of lowered VSC levels in favour of this toothbrush. In addition this study compared the products of three other manufacturers with the toothbrush manufactured by the sponsors of this trial. In view of the potential for bias within this study we excluded it from further review. The Yonezawa (2003) study was excluded as it included participants with a range of health and oral/dental status and a variety of confounding variables which would preclude the making of accurate and valid comparisons of the primary interventions being studied (Table 3).

Table 3 - Excluded studies for tongue scrapers.

\begin{tabular}{|c|c|c|c|}
\hline Author & Study design & Interventions/ treatment & Reason for exclusion \\
\hline Suarez 2000 & Non RCT & Applied for 1 day only & $\begin{array}{c}\text { Study design, ineligible } \\
\text { intervention period }\end{array}$ \\
\hline Williams 2004 & $\mathrm{RCT}$ & $\begin{array}{c}\text { Toothbrush versus } \\
\text { toothbrush }\end{array}$ & $\begin{array}{l}\text { Tongue brushing only } \\
\text { permitted with one of the } \\
\text { toothbrushes }\end{array}$ \\
\hline Yonezawa 2003 & $\mathrm{RCT}$ & Sponge brushes & $\begin{array}{c}\text { Wide range of baseline } \\
\text { characteristics }\end{array}$ \\
\hline
\end{tabular}


Finally only two studies (Pedrazzi 2004; and Seemann 2001) met the majority of our inclusion criteria and were included in this review. The criteria specified in the outcomes measures section of the protocol for this review required a follow-up period of 1 month but as we were unable to locate any trials with this length of follow up we amended this criterion to allow for any length of follow up and also set no time limits on the duration of the intervention. Thus, although these two studies did not totally match our inclusion criteria it was considered that the reporting of their results might go some way towards providing evidence to answer this research question (Table 4).

Table 4 - Included studies for tongue scrapers.

\begin{tabular}{|c|c|c|}
\hline Author & Study design & Participants \\
\hline Pedrazzi 2004 & RCT & 10 (age 20-50yrs) \\
\hline & $\begin{array}{c}\text { (cross-over) } \\
\text { RCT }\end{array}$ & $\begin{array}{c}2 \text { arouns } \\
30 \text { (age unspecified) }\end{array}$ \\
\hline 2001 & (cross-over) & 3 groups \\
\hline
\end{tabular}

'References to included studies ' - (

\section{\# Mouthrinses for treating halitosis}

The 15 references that were identified as potentially eligible studies included six citations (Borden 2001; Kozak 1994; Nachnani 1998; Ono 2002; Pitts 1981; Witt 1998) to papers and poster presentations from conference proceedings.

Full text copies of nine of the studies (Borden 2002; Carvalho 2004; Codipilly 2004; Kozlovsky 1996; Peruzzo 2007; Quirynen 2002; Rassameemasmaung 2007; van Steenberghe 2001; Winkel 2003) were obtained and subjected to further evaluation. 
The abstracts of the six papers from conference proceedings were also acquired for more detailed examination, and two (Pitts 1981; Witt 1998) of which were subsequently eliminated and the reasons for their exclusion noted (Table 5).

Table 5 - Excluded studies for mouthrinses.

\begin{tabular}{|c|c|c|c|}
\hline Author & Study design & Interventions/treatment & Reason for exclusion \\
\hline Carvalho 2004 & RCT & 4-day intervention & $\begin{array}{c}\text { Intentionally induced } \\
\text { halitosis }\end{array}$ \\
\hline Peruzzo 2007 & RCT & 4-day intervention & $\begin{array}{c}\text { Intentionally induced } \\
\text { halitosis }\end{array}$ \\
\hline Pitts 1981 & RCT & $\begin{array}{c}\text { Single rinse of } \\
\text { mouthwash }\end{array}$ & $\begin{array}{l}\text { Ineligible period of } \\
\text { administration of } \\
\text { intervention }\end{array}$ \\
\hline Quirynen 2002 & $\mathrm{RCT}$ & Mouthrinses or slurry & $\begin{array}{l}\text { Participants with healthy } \\
\text { periodontium and not } \\
\text { assessed as having } \\
\text { halitosis }\end{array}$ \\
\hline $\begin{array}{c}\text { van Steenberghe } \\
2001\end{array}$ & $\mathrm{RCT}$ & $\begin{array}{l}\text { Intervention to test } \\
\text { suppression of morning } \\
\text { breath. }\end{array}$ & $\begin{array}{c}\text { Participants with healthy } \\
\text { periodontium and not } \\
\text { assessed as having } \\
\text { halitosis }\end{array}$ \\
\hline Witt 1998 & Non RCT & Commercial mouthrinse & No control or placebo \\
\hline
\end{tabular}

In the remaining four abstracts to conference proceedings the lack of trial details did not permit their further evaluation and these await a more complete assessment as soon as further information becomes available from the investigators (Table 6).

Table 6 - Studies awaiting classification. Mouthrinses.

\begin{tabular}{ccc}
\hline Author & Study design & Interventions/treatment \\
\hline \hline Borden 2001 & RCT & 3 mouthrinses \\
Kozak 1994 & RCT & Mouthrinse \\
Nachnani 1998 & RCT & Mouthrinse \\
Ono 2002 & RCT & Mouthrinse \\
\hline
\end{tabular}


Of the nine remaining studies, five (Borden 2002; Codipilly 2004; Kozlovsky 1996; Rassameemasmaung 2007; Winkel 2003) were parallel group and four (Carvalho 2004; Peruzzo 2007; Quirynen 2002; van Steenberghe 2001) were crossover trials. Examination of the bibliographical references of their full text reports did not provide any further citations to potentially eligible studies.

Following discussion with the Cochrane Oral Health Group editorial team it was agreed that although two (Carvalho 2004; Peruzzo 2007) of the trials met most of our inclusion criteria, because the intervention periods did not match our stipulated criterion of a minimum of 1 week these were excluded (See 4.1 Criteria for considering studies for this review).

A further two studies (Quirynen 2002; van Steenberghe 2001), investigated the effects of mouthrinses on morning breath odour in volunteers with a healthy periodontium and low organoleptic scores and volatile sulphur compounds (VSC) ratings. As routine oral hygiene procedures were prohibited during all of the experimental periods in these studies it could be inferred that halitosis had been artificially induced, and consequently these were also excluded from this review.

Organoleptic scores of $\geq 3$ which correspond to VSC levels in excess of 75 parts per billion (ppb) are generally accepted as diagnostic indicators of halitosis and were the minimum acceptable characteristics of participants enrolled in any of the studies to be considered eligible for inclusion in this review.

After discussion between the review authors, any remaining uncertainties on the eligibility of any of the studies were resolved by consensus, and subsequently five trials involving 293 participants were included in this review (Table 7). 
Table 7 - Included studies for mouthrinses.

\begin{tabular}{|c|c|c|c|}
\hline Author & $\begin{array}{c}\text { Study } \\
\text { design }\end{array}$ & Participants & Interventions/treatment \\
\hline Borden 2002 & $\mathrm{RCT}$ & $\begin{array}{c}99 \text { enrolled, } 3 \\
\text { withdrawals, } n=95 \text { (29 } \\
\text { males, } 66 \text { females age } \\
19 \text { to } 65 \text { years), } 22-25 \\
\text { participants/intervention } \\
\text { group. }\end{array}$ & $\begin{array}{l}\text { 1: Listerine, 2: Breath Rx- } \\
\text { cetylpyridinium chloride, } 3 \text { : } \\
\text { placebo, 4: Oxygene- } \\
\text { chlorine dioxide + zinc, } \\
\text { Twice daily rinsing/ } 4 \text { weeks. } \\
\text { Toothbrush use permitted. }\end{array}$ \\
\hline Codipilly 2004 & $\mathrm{RCT}$ & $\begin{array}{c}\mathrm{n}=48 \text { (20 males, } 28 \\
\text { females, age } 21 \text { to } 69) \text {, } \\
\text { Three groups: } 80-90 \\
\text { ppb, } 91-135 \text { ppb, }>135 \\
\text { ppb. }\end{array}$ & $\begin{array}{c}\text { 1: control (no active } \\
\text { ingredients), } 2 \text { : zinc chloride } \\
\text { minus sodium chlorite, } 3 \text { : } \\
\text { zinc chloride plus sodium } \\
\text { chlorite (TriOral), Twice daily } \\
\text { rinsing for } 4 \text { weeks, Routine } \\
\text { oral hygiene measures } \\
\text { permitted. }\end{array}$ \\
\hline
\end{tabular}

Kozlovsky $1996 \quad$ RCT females, mean age 24 years).
1: Two-phase oil-water

$(0.05 \%$ cetylpyridinium chloride) $n=26,2$ : essential oils (Listerine) $n=24$, Twice daily rinsing for 6 weeks,

Routine oral hygiene measures permitted

\begin{tabular}{|c|c|c|c|}
\hline $\begin{array}{l}\text { Rassameemasmaung } \\
\qquad 2007\end{array}$ & $\mathrm{RCT}$ & $\begin{array}{c}\mathrm{n}=60,(12 \text { male, } 48 \\
\text { female, } 17 \text { to } 37 \mathrm{yr} \\
\text { mean } 26.15)\end{array}$ & $\begin{array}{l}\text { 1: Pericarp extract of } \\
\text { Garcinia mangostana L, } 2 \text { : } \\
\text { Placebo mouthwash, Twice } \\
\text { daily rinse for } 2 \text { weeks, } \\
\text { Routine oral hygiene } \\
\text { measures permitted. }\end{array}$ \\
\hline Winkel 2003 & $\mathrm{RCT}$ & $\begin{array}{c}\mathrm{n}=40(\mathrm{n}=20 \\
\text { Amsterdam, } \mathrm{n}=20 \\
\text { Madrid }),(21 \mathrm{males}, 19 \\
\text { females, } 21-84 \mathrm{yr}), 8 / 40 \\
\text { smokers }\end{array}$ & $\begin{array}{c}\text { 1: } 0.05 \% \text { chlorhexidine }+ \\
0.05 \% \text { cetylpyridinium } \\
\text { chloride }+0.14 \% \text { zinc lactate } \\
\text { mouthrinse, } 2 \text { : placebo, } \\
\text { Twice daily rinse for } 2 \\
\text { weeks, Routine oral hygiene } \\
\text { measures permitted }\end{array}$ \\
\hline
\end{tabular}

\section{References to studies}

'References to included studies' (See: Appendix 3)

'References to excluded studies' (See: Appendix 4)

'Studies awaiting assessment' (See: Appendix 5) 


\subsection{Assessment of risk of bias}

All of the studies that reported a randomized trial were graded independently by two reviewers according to the domain-based evaluation described in the Cochrane Handbook for Systematic Reviews of Interventions 5.0.0 (Higgins 2008). The gradings were compared and any inconsistencies between the reviewers were discussed and resolved.

The following domains were assessed as 'Yes' (i.e. low risk of bias, plausible bias unlikely to seriously alter the results), 'Unclear' (uncertain risk of bias, plausible bias that raises some doubts about the results) or 'No' (i.e. high risk of bias, plausible bias that seriously weakens confidence in the results):

1. sequence generation;

2. allocation concealment;

3. blinding (of participants, personnel and outcomes assessors);

4. incomplete outcome data;

5. selective outcome reporting

These assessments are reported for each individual study in: 5.2. Assessment of risk of bias in the included studies.

\subsection{Data collection}

Study details and extracted data were entered into the 'Characteristics of included studies' table in RevMan (Review Manager - the software used for preparing and maintaining Cochrane Reviews) and (any disagreements were resolved by consensus. 
The following details were extracted:

(1) Trial methods:

(a) method of allocation

(b) masking of participants, trialists and outcomes

(c) exclusion of participants after randomization and proportion of losses at follow up.

(2) Participants:

(a) country of origin

(b) sample size

(c) age

(d) sex

(e) inclusion and exclusion criteria.

(3) Intervention:

(a) type and dose

(b) duration and length of time in follow up.

(4) Control:

(a) type and dose

(b) duration and length of time in follow up.

(5) Outcomes:

(a) primary and secondary outcomes mentioned in the outcome measures section of this review.

Any sources of funding declared by the investigators were also recorded. This information was used to help assess heterogeneity (clinical diversity) and the external validity of the trials. 


\subsection{Data synthesis}

An important step in a systematic review is the careful consideration of whether it is appropriate to combine studies, in a meta-analysis, to provide a summary statistic (together with its confidence intervals) that is capable of summarizing the effectiveness of a particular treatment. In the absence of substantial clinical diversity between studies, statistical investigation of the range of variation in treatment effect between studies can help with guiding decisions on the feasibility and appropriateness of combining results from these individual studies.

However although some divergence in patient groups, clinical settings and the methods of delivery of the interventions between the trials is inevitable, significant differences may increase the variability of results between trials, and a meta-analysis under these circumstances may be implausible and potentially misleading. The pooling of data from clinically diverse studies has been likened to the combination of apples with oranges which may be deemed inappropriate unless of course the expectation is of producing a fruit salad.

In view of the wide clinical heterogeneity between the included studies it was not possible to perform a synthesis or pooling of the data and only relevant data for each outcome is presented in a Forest plot where appropriate together with a narrative synthesis of the results.

\subsection{Sensitivity analysis}

It is customary to perform a sensitivity analysis in a systematic review to assess the robustness of the review results especially where there may be "some uncertainty or disagreement involving inclusion of studies, data extraction, missing data and choice of statistical method" (Khan, et al. Stage II p.14, 2001). This consists 
of repeating the analysis with either of the following adjustments: exclusion of studies of lower methodological quality and unpublished studies. In this way sensitivity analyses can help inform the robustness of the reviewers' conclusions to these disagreements and uncertainties. However in view of the paucity of clinical trials and the clinical diversity between those included in the systematic reviews, sensitivity analyses were not carried out.

\subsection{Evaluation of the reviews using (AMSTAR)}

The use of scales for assessing the methodological quality or risk of bias in Cochrane reviews is now explicitly discouraged by the Cochrane Collaboration. Although comparisons of quality using numerical scores would appear to be appealing in terms of their simplicity this approach, which involves calculating a summary score and the assigning of weights to different items in the scale, is not supported by empirical evidence (Schulz, Chalmers et al. 1995). Not only are there inherent difficulties in weighting of items but these weights have also been shown to be unreliable assessments of validity (Jüni 1999), and are less likely to be transparent to users of reviews. Criterion or domain based evaluations, albeit qualitative assessments are more readily interpretable and less likely to suffer from the generic problems of scales.

Evaluation of the systematic reviews against the 11-item AMSTAR instrument was on the basis of responses [YES/NO/CAN'T ANSWER/NOT APPLICABLE] to each question and this assessment is reported in the results (See Results). 
5. Results 



\section{RESULTS}

\section{Description Of StUdies}

\subsection{Summary of trial details}

\section{\#Tonque scraping for treatment of halitosis}

\section{Methods}

The two included studies were randomized cross-over clinical trials conducted in Germany and Brazil. The total sample size comprised 40 adult participants; Pedrazzi 2004 (10); Seemann 2001 (30).

\section{Characteristics of the participants and setting}

The Seemann (2001) trial was conducted on 30 adult volunteers, 15 males and 15 females, whose ages were not specified and who had been recruited from a bad breath consultation clinic at the Humboldt University in Berlin. Ten dental students or employees at the University of São Paulo Brazil, with ages ranging from 20-50 years, were enrolled in the Pedrazzi (2004) study.

The two studies were conducted over different time periods. In the Pedrazzi study each of the two intervention periods of one week each were interspersed with a 48 hour washout whilst the participants in the Seemann study were seen at four morning appointments with a "waiting period of one week between appointments".

All of the participants enrolled in Seemann had morning VSC levels in excess of 130 parts per billion ( $\mathrm{ppb}$ ) which had been measured by a portable sulfide halimeter (Halimeter, Interscan) in addition to having oral malodour which had been organoleptically detected by a designated individual trialist. 
Active smokers were excluded from this study as well as participants who had systemic diseases, removable dentures, dental caries, active periodontitis or mucosal lesions as well as patients on long term medication. Participants who regularly used a mouthwash or had received a professional dental prophylaxis in the preceding 2 months were also considered ineligible.

There were no restrictions on routine oral hygiene measures during the course of the study but participants were instructed to refrain from any tongue cleaning for the preceding 24 hours before each intervention if this was their usual practice. Two participants, one male and one female, were eventually excluded from the analysis in this trial as they had VSC levels below the baseline minimum of 130 ppb.

Although the inclusion criteria were not pre-specified in the Pedrazzi study, all of the participants achieved the maximum reading on the handheld sulfide monitor (Breath Alert, Model HC201E Tanita ${ }^{\text {TM }}$ Corporation, Tokyo Japan) at baseline. Active smoking, periodontal disease, gastric conditions or the presence of hard or soft oral tissue lesions or tonsils were reasons for exclusion. Participants in this study were required to refrain from any tongue cleaning for the preceding 48 hours and any oral hygiene measures, eating or drinking only on the morning of the intervention.

Characteristics of the interventions

In the Seemann study one of the three types of tongue cleaning devices; the One Drop Only Tongue Cleaner (a brush and scraper), the Tongue-Putzer (a tongue scraper) and a regular tooth brush, was used for the whole group. A different intervention was used on each group at each of the succeeding weekly appointments while the fourth appointment was used as a control with no intervention. 
Only one trialist was designated to carry out all of the procedures and these were performed according to the following protocol. The toothbrush and the tongue scraper were used to brush the tongue 10 times from the back to the tip of the tongue, whilst the tongue cleaner was used with 5 strokes brushing and 5 strokes scraping from the back to the tip of the tongue. After the intervention and before the VSC level measurement the participants were permitted to rinse their mouth with tap water.

The interventions in the Pedrazzi study were self administered, with one group of participants using a polystyrene scraper for the first week and a nylon soft bristle toothbrush for the second week. This sequence was reversed for the second group which used a soft bristle toothbrush for the first week and a polystyrene scraper for the second week. In both groups there was a 48 hour wash out period between each of the weeks. The participants were instructed to use the cleaners for 3 minutes in the morning and after every meal according to the directions of the tongue scraper manufacturer.

\section{Characteristics of outcomes measures}

Only one of the included trials, Seemann (2001), partially addressed the primary outcome for this review, the self expressed (perceived) and organoleptic (human nose) assessments of halitosis. However, it was reported that these organoleptic measurements were only taken at the start of the study but no relevant data were provided by the trialists.

Both trials reported VSC levels as measured by a portable sulfide meter. The VSC levels of each participant in Seemann were recorded before each tongue cleaning session (Table 5.3), immediately after and at 5 minute intervals for up to a 
minimum of 35 minutes after the procedure or until the readings had returned to baseline levels within a range of $\pm 5 \%$.

Baseline data as reported in Pedrazzi are available in (Table 8). Breath odour levels were measured on a scale of 1 to 4 , with $1=$ odorless, $2=$ light odor, $3=$ moderate odor/ bad breath-perceptible and $4=$ strong odor. At the conclusion of this trial the participants were requested to complete a questionnaire in which they provided a subjective self assessment of the two tongue cleaners and were required to report any adverse effects which they may have experienced with any of the tongue cleaning devices.

\section{\# Mouthrinses for treating halitosis}

\section{Characteristics of the trial setting and investigators}

One of the trials was conducted in Thailand (Rassameemasmaung 2007), one in Israel (Kozlovsky 1996), one was a multicentre trial in Holland and Spain (Winkel 2003) and a further two were conducted in the USA (Borden 2002; Codipilly 2004). Two trials were supported by government or scientific foundation funding and three acknowledged assistance from pharmaceutical or oral care products manufacturers.

The providers and assessors of the treatments, with the exception of one trial (Borden 2002) in which the researchers were from a consumer products testing division of a private research organisation, were mainly university research staff.

\section{Characteristics of the participants}

Only adults were recruited for these trials which excluded participants with significant periodontal disease, extensive dental caries or chronic oral neglect in 
addition to those wearing any form of dentures. All but one of the trials (Winkel 2003) excluded smokers but participants in this trial were prohibited from smoking for 12 hours prior to any assessment. Participants were also excluded if they had taken systemic antibiotics before the study period, or had any systemic disease likely to have an influence on the outcome of the trial.

One study (Winkel 2003) only enrolled participants with a VSC score of $>170$ ppb who had been referred to a halitosis clinic, and Borden 2002 screened out participants with organoleptic ratings of $<3$ (scale 0 to 5 ). A further study (Codipilly 2004) screened potential participants, only enrolled those with mean halimeter assessed VSC levels of $>80 \mathrm{ppb}$ and further grouped them into three categories based on ranges of VSC levels (i.e. 80 to $90 \mathrm{ppb}, 91$ to $135 \mathrm{ppb}$ or > $135 \mathrm{ppb}$ ). In Rassameemasmaung 2007, the mean (standard deviation (SD)) VSC levels of participants at baseline were 248.35 (172.30) ppb in the intervention and 237.45 (114.15) ppb in the placebo groups.

\section{Characteristics of the interventions}

The interventions included herbal as well as several over the counter mouthrinses: two-phase oil and water/cetylpyridinium chloride; a chlorhexidine with cetylpyridinium chloride and zinc lactate formulation; an essential oil; and a chlorine dioxide based product. All of the mouthrinses were used twice daily with intervention periods ranging from 2 to 6 weeks and there were no restrictions on routine oral hygiene measures during the course of these studies. Assessment of participants' compliance and usage of the mouthrinses were reported in all of the studies with the exception of Kozlovsky 1996. 


\section{Treatment of halitosis}

- essential oils $\left(\right.$ Listerine $\left.^{\circledR}\right)$; cetylpyridinium chloride + essential oils + chlorine dioxide + zinc (Breath $\left.R x^{\circledR}\right)$; chlorine dioxide + zinc $\left(\right.$ Oxygene $\left.{ }^{\circledR}\right)$ mouthrinses versus placebo (Borden 2002);

- zinc chloride + sodium chlorite $\left(\right.$ TriOral $\left.^{\circledR}\right)$; zinc chloride minus sodium chlorite (Breath $\mathrm{Rx}^{\circledR}$ containing cetylpyridinium chloride) mouthrinses versus control containing neither zinc chloride nor sodium chlorite (Codipilly 2004);

- two-phase oil-water ( $0.05 \%$ cetylpyridinium chloride) mouthrinse versus control referred to as "a mouthrinse which has been previously shown to be effective in reducing levels of odour related organisms" i.e. Listerine ${ }^{\circledR}$ (Kozlovsky 1996);

- pericarp extract of Garcinia mangostana L mouthrinse versus placebo (Rassameemasmaung 2007);

- $0.05 \%$ chlorhexidine $+0.05 \%$ cetylpyridinium chloride $+0.14 \%$ zinc lactate mouthrinse versus placebo (Winkel 2003).

\section{Characteristics of outcome measures}

\section{Treatment of halitosis}

Three of the studies assessed halitosis organoleptically as well as by halimeter/portable sulphide monitor. The investigators in Rassameemasmaung relied solely on halimeter assessed VSC levels while Codipilly undertook indirect surrogate salivary organoleptic assessments in addition to recording halimeter scores.

Organoleptic assessments of mouth odour (scale 0 to 5 with 5 as most severe) were conducted according to standard and internationally recognised 
procedures which involved two trained and independent organoleptic odour judges. Identical portable sulphide monitors, the Halimeter ${ }^{\circledR}$ Interscan Corporation Chatsworth $\mathrm{Ca}$, were used in all of the studies. In all of the studies, with the exception of Kozlovsky in which the assessments were conducted in the late afternoon (< 8 hours after rinsing), VSC levels and organoleptic scores were recorded in the morning after rinsing. In two of the studies (Borden 2002; Kozlovsky 1996) in which an alcohol-containing mouthrinse was used, the investigators ensured that halimeter recordings were conducted at least 2 hours after rinsing.

Restrictions on eating, drinking and tooth brushing prior to assessment varied between trials and ranged from 2 hours (Rassameemasmaung 2007; Winkel 2003), to 12 hours (Codipilly 2004). Although the actual measurement periods varied between studies any data collected were used to calculate mean organoleptic ratings and halimeter scores, and if appropriate the percentage changes of VSC from baseline for each study. Peak VSC values were recorded in all of the studies but at differing times throughout the experimental periods. No self assessments of halitosis were reported but participants in one trial (Winkel 2003) completed post-treatment questionnaires. There were no outcomes reported in which gas chromatography coupled with flame-photometric detection was used to assess halitosis.

\section{Adverse events}

Two of the five studies took note of adverse events but only one reported any side effects. 


\subsection{Assessment of risk of bias in the included studies}

We assessed each included study for risk of bias. For the methods that were used for these assessments (See: 4.4. Assessment of risk of bias). Judgements of each domain across all of the included studies were made for each review question (See: Risk of bias graphs Figures 3, 4, 5\& 6).

\section{\# $\underline{\text { Tongue scraping for treatment of halitosis }}$}

\section{Allocation}

\section{Randomization}

After communication by electronic mail with the investigators in Pedrazzi 2004 we were able to clarify the method used to generate the allocation sequence and thus this domain was judged 'clear'.

The investigators in Seemann 2001 only indicated that the participants were randomly assigned to three groups but the method of randomization was not specified and we were unable to clarify further details with the investigators, and therefore we graded this domain as 'unclear'.

Albeit the method of sequence generation was clarified by the investigators in the Pedrazzi study we were unable to clarify how foreknowledge of the upcoming assignment was concealed from the investigators and together with the absence of relevant trial details in Seemann, concealment of the allocation sequence was graded as 'unclear' in both studies.

\section{Blinding}

In view of the nature of the interventions blinding of the participants in both of the included studies was not feasible, and although it was not possible to blind the 
investigators, who were the care givers, in Seemann the outcomes assessments were taken operator blind. In Pedrazzi the healthcare providers were also the outcomes assessors but blinding of the data analysts was confirmed in electronic mail communication with the investigators. These domains were judged 'clear' for both studies.

\section{Incomplete outcome data}

The absence of data for the organoleptic assessments which were conducted in Seemann 2001 but not reported, resulted in this domain being graded as 'unclear', whereas all of the outcome data reported in Pedrazzi 2004 were complete.

\section{Selective reporting}

Albeit the Seemann 2001 trial failed to report any organoleptically determined oral malodour scores it was not clear if these were selectively withheld from publication.

\section{Other potential sources of bias}

No other potential sources of bias were identified (Tables 8 \& 9). 
Table 8- Pedrazzi 2004 - Risk of Bias Judgments.

\begin{tabular}{ccc} 
Item & Judgment & Description \\
\hline $\begin{array}{c}\text { Adequate } \\
\text { sequence } \\
\text { generation? }\end{array}$ & Yes & $\begin{array}{r}\text { Quote: "The } 10 \text { individuals were randomized into two groups of } \\
\text { five". Quote (from correspondence): "randomization of the } \\
\text { participants was through a computer based programme named } \\
\text { GMC (Geraldo Maia Campos)". Comment: Probably done. }\end{array}$ \\
$\begin{array}{c}\text { Allocation } \\
\text { concealment? }\end{array}$ & Unclear & No information available in the report. \\
\hline
\end{tabular}

Participants: Not possible to blind participants as the interventions were self administered. The healthcare providers were also the outcomes assessors. Comment: Not feasible.

Outcomes assessors \& Data analysts: Quote (from correspondence): " the individuals were coded by characters Blinding? Yes and numbers, i.e. A1, A2, B1, etc. and the collected data were sent to another researcher, one of the trialists, who performed the statistical analysis, but was blinded to participants and outcomes". Comment: Although outcomes assessment may not have been blinded, masking of the data analysts was confirmed in electronic mail communication with the investigators.

Probably done.

\begin{tabular}{ccc}
\hline $\begin{array}{c}\text { Incomplete } \\
\text { outcome data } \\
\text { addressed? }\end{array}$ & Yes & $\begin{array}{r}\text { There were no losses to follow-up or withdrawals and all } \\
\text { outcome data were addressed. }\end{array}$ \\
\hline $\begin{array}{c}\text { Free of selective } \\
\text { reporting? }\end{array}$ & Yes & $\begin{array}{c}\text { No evidence of selective choice of data for outcomes. } \\
\text { Outcomes listed in the methods section comparable to the } \\
\text { reported results. }\end{array}$ \\
\hline $\begin{array}{c}\text { Free of other } \\
\text { bias? }\end{array}$ & Yes & The study appears to be free of other sources of bias. \\
\hline
\end{tabular}


Table 9- Seemann 2001 - Risk of Bias Judgments.

\begin{tabular}{|c|c|c|}
\hline Item & Judgment & Description \\
\hline $\begin{array}{c}\text { Adequate } \\
\text { sequence } \\
\text { generation? }\end{array}$ & Unclear & $\begin{array}{c}\text { Quote: "We randomly assigned subjects to three groups". } \\
\text { Comment: Method of sequence generation unclear and not } \\
\text { clarified by investigators. }\end{array}$ \\
\hline $\begin{array}{c}\text { Allocation } \\
\text { concealment? }\end{array}$ & Unclear & No details available in the report. Comment: Unclear. \\
\hline Blinding? & Yes & $\begin{array}{c}\text { Participants/Healthcare providers: Not possible to blind } \\
\text { participants or the investigators who administered the } \\
\text { interventions but the outcomes assessments were blinded. } \\
\text { Outcomes assessors \& Data analysts: Quote: "All VSC } \\
\text { measurements were taken operator blind". Comment: Probably } \\
\text { done. }\end{array}$ \\
\hline $\begin{array}{l}\text { Incomplete } \\
\text { outcome data } \\
\text { addressed? }\end{array}$ & Yes & $\begin{array}{l}\text { Quote: "We excluded two of the study's subjects from our } \\
\text { analysis, because they had baseline VSCs lower than 130ppb } \\
\text { during the study period". Comment: Although not explicitly } \\
\text { stated these participants appear to have been excluded early in } \\
\text { the study, albeit after randomization, because their baseline } \\
\text { assessments did not match the inclusion criteria. }\end{array}$ \\
\hline $\begin{array}{c}\text { Free of selective } \\
\text { reporting? }\end{array}$ & Unclear & $\begin{array}{l}\text { Quote: "We organoleptically determined these subjects' oral } \\
\text { malodour". Comment: No data were reported for this initial } \\
\text { assessment and no other assessments were mentioned by the } \\
\text { investigators. It was unclear if the organoleptic assessments } \\
\text { mentioned in the 'Materials and Methods' section of this report } \\
\text { were selectively withheld. }\end{array}$ \\
\hline $\begin{array}{c}\text { Free of other } \\
\quad \text { bias? }\end{array}$ & Yes & The study appears to be free of other sources of bias. \\
\hline
\end{tabular}




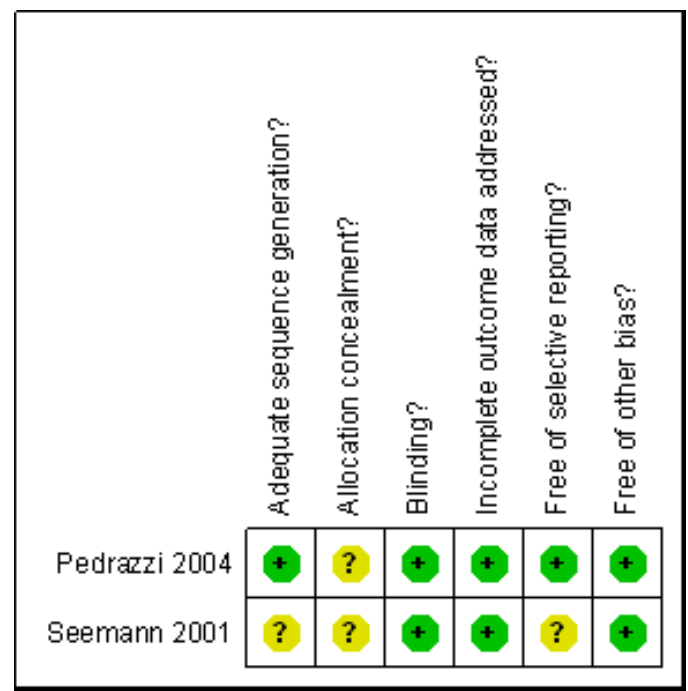

Figure 3 - Risk of Bias summary (Tongue scraping). Methodological quality summary: review authors' judgements about each methodological quality item for each included study.

The validity of each study was assessed as at low, moderate or high risk of bias. One of the studies was rated as at low risk of bias (A) (Pedrazzi 2004) and the remaining study (Seemann 2001) as at moderate risk of bias (B).

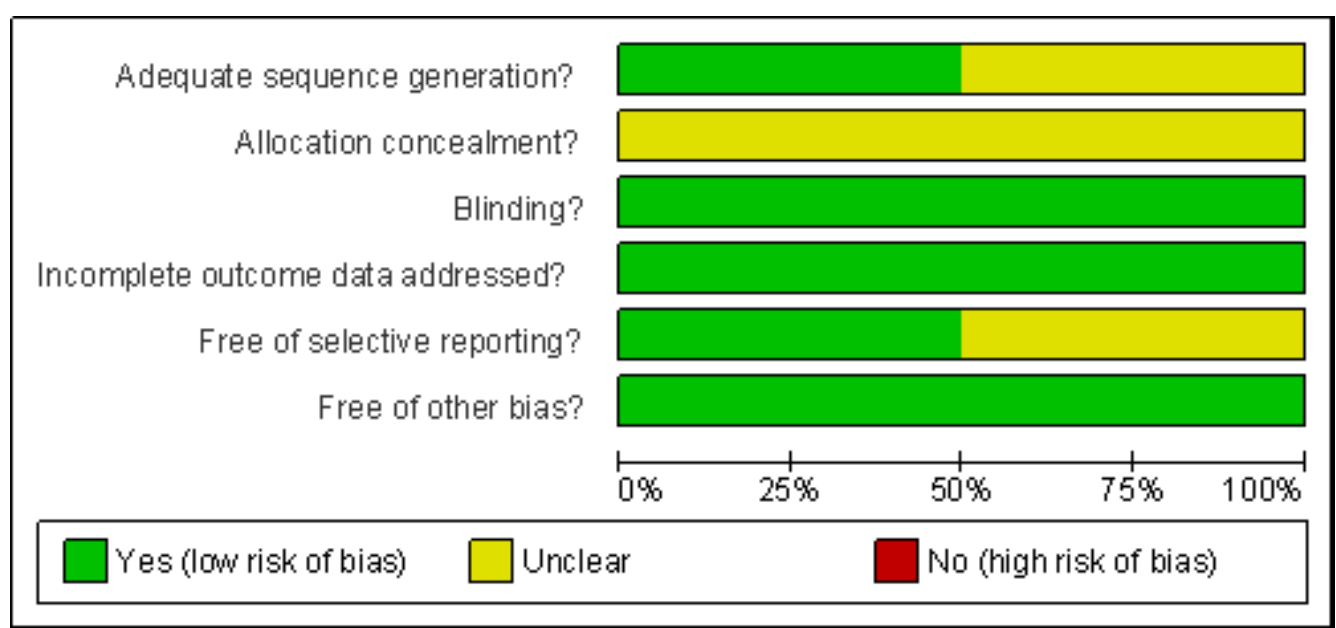

Figure 4 - Risk of Bias graph (Tongue scraping). Methodological quality graph: review authors' judgments about each methodological quality item presented as percentages across all included studies. 


\section{\# Mouthrinses for treating halitosis}

\section{Allocation}

\section{Randomization}

The methods used to randomise participants were only clearly described in one study (Winkel 2003), and the method of randomization in (Rassameemasmaung 2007) was only confirmed after e-mail contact with the investigators.

Concealment of the allocation sequence was adequate $(A)$ in only two (Borden 2002; Rassameemasmaung 2007) of the five trials, unclear (B) for the remaining three (Codipilly 2004; Kozlovsky 1996; Winkel 2003) but in no trials was it considered inadequate $(\mathrm{C})$.

\section{Blinding}

Methods used to blind participants to the interventions were clearly described in four of the five trials. Blinding of outcomes assessment was reported in only two of the trials (Rassameemasmaung 2007; Winkel 2003).

\section{Incomplete outcome data}

There were several withdrawals in the included trials; four participants in Borden of which three with low organoleptic scores were subsequently excluded and one dropped out in the first week of the study. Additionally in this trial, with the exception of the cetylpyridinium chloride (Breath $R x^{\circledR}$ ) mouthrinse group, several participants failed to attend for the last assessment at week 4. Two participants dropped out in one trial (Codipilly 2004) and no reasons were given.

Attempts were made to contact several of the investigators by e-mail to seek clarification of missing trial details and only one reply was received 
(Rassameemasmaung 2007), which enabled a change in the assessment of concealed randomization from unclear to adequate to be made for this study.

The validity of each of the included studies was assessed as at low, moderate or high risk of bias. Two of the studies were rated as at low risk of bias (A) (Rassameemasmaung 2007; Winkel 2003), and the remaining three studies (Borden 2002; Codipilly 2004; Kozlovsky 1996) as at moderate risk of bias (B). This assessment is based solely on the details as reported by the investigators in these three trials.

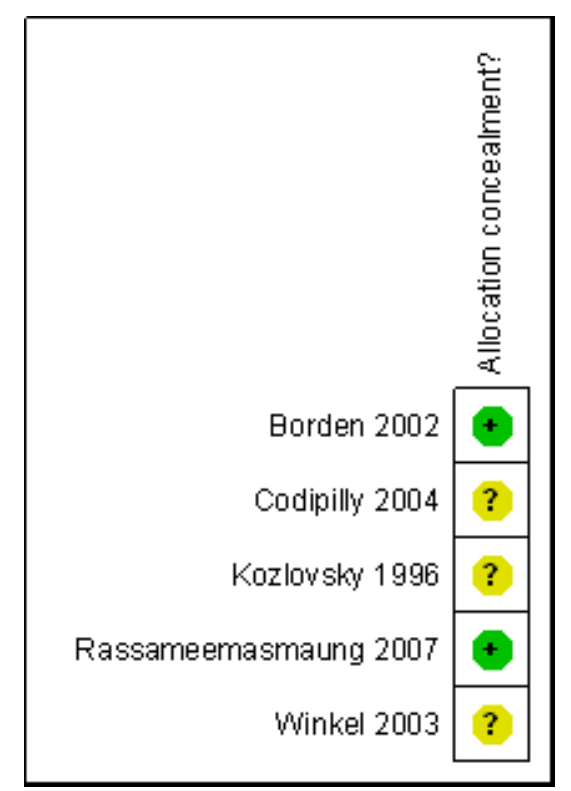

Figure 5 - Risk of Bias summary (Mouthrinses). Methodological quality summary: review authors' judgements about each methodological quality item for each included study.

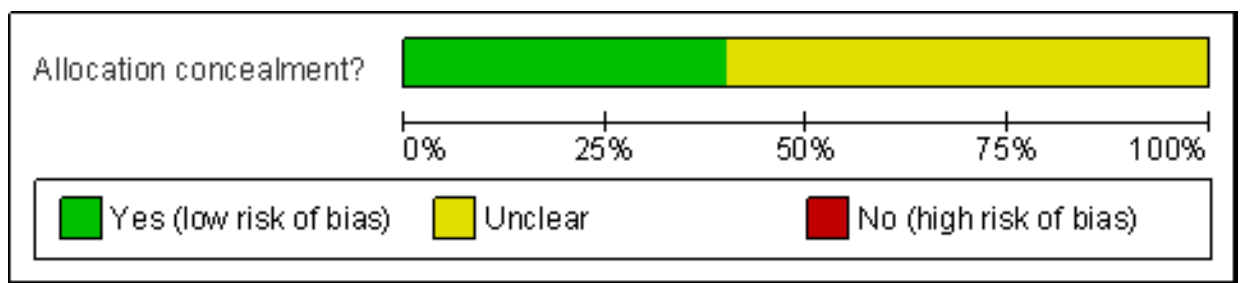

Figure 6 - Risk of Bias graph (Mouthrinses). Methodological quality graph: review authors' judgments about each methodological quality item presented as percentages across all included studies. 


\subsection{Effects of interventions}

\section{\#Tonque scraping for treatment of halitosis}

Baseline data in the Seemann trial illustrated that all of the participants entering the study had similar VSC levels ranging from 194 to 197 ppm (Table 10).

Table 10 - VSC ppb: Baseline/ Mean value/ percentages (SD) (Seemann 2001).

\begin{tabular}{|c|c|c|c|c|}
\hline & Tongue Cleaner & Tongue Scraper & Toothbrush & $P$ value \\
\hline \multirow[t]{2}{*}{ Baseline } & $194(80)$ & $197(81)$ & $195(83)$ & \\
\hline & $\begin{array}{c}\text { Mean (SD) } \\
\%(S D)\end{array}$ & $\begin{array}{c}\text { Mean (SD) } \\
\%(S D)\end{array}$ & $\begin{array}{c}\text { Mean (SD) } \\
\%(S D)\end{array}$ & \\
\hline $\begin{array}{c}\text { Immediately } \\
\text { after }\end{array}$ & $\begin{array}{c}115(61) \\
58(11)\end{array}$ & $\begin{array}{c}122(67) \\
60(12)\end{array}$ & $\begin{array}{c}133(68) \\
67(9)\end{array}$ & $<.001^{*}$ \\
\hline 5 minutes & $\begin{array}{c}125(65) \\
63(11)\end{array}$ & $\begin{array}{c}132(72) \\
65(12)\end{array}$ & $\begin{array}{c}143(71) \\
72(7)\end{array}$ & $<.001^{*}$ \\
\hline 10 minutes & $\begin{array}{c}133(66) \\
67(12)\end{array}$ & $\begin{array}{l}147(81) \\
72(12)\end{array}$ & $\begin{array}{c}155(74) \\
78(7)\end{array}$ & $<.001^{*}$ \\
\hline 15 minutes & $\begin{array}{l}148(72) \\
75(12)\end{array}$ & $\begin{array}{l}162(86) \\
80(11)\end{array}$ & $\begin{array}{c}171(80) \\
87(6)\end{array}$ & $<.001^{*}$ \\
\hline 20 minutes & $\begin{array}{l}165(75) \\
84(10)\end{array}$ & $\begin{array}{c}181(89) \\
90(9)\end{array}$ & $\begin{array}{c}189(84) \\
96(5)\end{array}$ & $<.005^{\star}$ \\
\hline 25 minutes & $\begin{array}{c}186(80) \\
95(6)\end{array}$ & $\begin{array}{c}194(86) \\
98(6)\end{array}$ & $\begin{array}{c}197(83) \\
100(1)\end{array}$ & $>.05(\mathrm{~ns})$ \\
\hline 30 minutes & $\begin{array}{c}196(79) \\
100(2)\end{array}$ & $\begin{array}{c}198(81) \\
101(1)\end{array}$ & $\begin{array}{c}197(83) \\
101(1)\end{array}$ & $>.05(\mathrm{~ns})$ \\
\hline 35 minutes & $\begin{array}{c}198(82) \\
101(1)\end{array}$ & $\begin{array}{c}199(82) \\
101(1)\end{array}$ & $\begin{array}{c}197(83) \\
101(1)\end{array}$ & $>.05(\mathrm{~ns})$ \\
\hline
\end{tabular}

All of the participants in the Pedrazzi trial had the maximum score possible of 4 (VSCI range 1 to 4 ) at baseline (Table 11). 
Table 11 - Baseline and Final VSC Index: Scale 1-4. (Pedrazzi 2004).

\begin{tabular}{cccccc}
\hline Participant & \multicolumn{2}{c}{ Soft Toothbrush } & & \multicolumn{2}{c}{ Tongue Scraper } \\
\cline { 2 - 3 } \cline { 5 - 6 } \cline { 5 - 6 } & Baseline & Final & & Baseline & Final \\
\hline A1 & 4 & 2 & & 4 & 1 \\
A3 & 4 & 3 & & 4 & 1 \\
$A 4$ & 4 & 1 & & 4 & 1 \\
$A 5$ & 4 & 3 & & 4 & 1 \\
$B 1$ & 4 & 2 & & 4 & 1 \\
$B 2$ & 4 & 2 & & 4 & 1 \\
$B 3$ & 4 & 3 & & 4 & 1 \\
$B 4$ & 4 & 2 & & 4 & 1 \\
$B 5$ & 4 & 4 & & 4 & 1 \\
\hline
\end{tabular}

The clinical heterogeneity between the studies with respect to baseline characteristics at enrolment; the providers and receivers of care who administered the intervention; the exact procedure; the duration of the intervention and the lack of follow up in either study precluded any possibility of synthesising the data from these studies and therefore only the published outcomes data are reported as extracted from the two reports together with a descriptive summary of their results.

\section{Primary outcomes}

Neither of the two included trials provided any data for the self expressed or organoleptic scores which were the primary outcomes specified in the inclusion criteria for this systematic review.

\section{Secondary outcomes}

Both studies (Pedrazzi 2004; Seemann 2001) only provided data relevant to some of the secondary outcomes as specified in the inclusion criteria for the 
review. Assessment of secondary outcomes in both trials was through the use of two different types of portable sulphide meter. One trial presented results as mean values of VSCs expressed as ppbs and percentages (Seemann 2001) whilst the other trial (Pedrazzi 2004) only provided breath odor values registered on an analogue scale within a range of 1 to 4 .

The Seemann trial assessed peak values as ppb sulphide equivalents which were expressed as the mean values of two consecutive measurements. In this trial the reduction of VSC levels with the tongue cleaner, which was a combination of scraper and brush, was $42 \%$, whilst with the tongue scraper of $40 \%$ and the toothbrush of $33 \%$. The mean values of the VSCs in ppb and as percentages (Table 10) and their differences were assessed as inter-group comparisons by the Friedman and the Wilcoxon signed rank tests with the level of significance set at $p<0.05$.

The tongue cleaner showed a tendency $(p=.06)$ towards an improved reduction of VSC levels over the tongue scraper at 15 minutes post intervention, in addition to statistically significant lower VSC values, and a higher percentage VSC level reduction than the toothbrush for up to 25 minutes after tongue cleaning (Table 10).

The reduced VSC levels also persisted longer with the tongue cleaner than with either of the two other interventions, however the trialists noted that the reduced levels of VSCs could not be detected for more than 30 minutes after the intervention in any of the groups. At the fourth appointment the trialists detected no statistically significant differences between baseline values and the control measures. The trialists did not provide any data for the fourth or control appointment and thus it was not possible to compare data for any of the interventions against control, but they did 
indicate that there was no significant difference between baseline levels and those at the fourth appointment.

The Pedrazzi 2004 trial showed a reduction of VSC levels compared with baseline measurements for both of the interventions. The rank sum differences of the initial and final volatile sulfur compounds indexes (VSCI) between the two interventions were compared and assessed by the Dunn method with a significance level set at $p<.01$. Comparison of the averages of VSCls at baseline and the final assessments showed a reduction of VSCs of $75 \%$ with the tongue scraper and $45 \%$ with the toothbrush (See: Table 11).

\section{Adverse events}

Data from the self assessment questionnaire revealed that six $(60 \%)$ of the participants in the Pedrazzi study complained of nausea and one participant reported tongue trauma with the toothbrush but all of the participants were receptive to the tongue scraper. In the Seemann study the trialists did not report any adverse effects to any of the three interventions.

The individual data from the two trials provided weak and unreliable evidence that there is a small but statistically significant difference in favour of tongue cleaners and tongue scrapers at reducing VSC levels when compared with toothbrushes.

\section{\# Mouthrinses for treating halitosis}

\section{Primary and secondary outcomes}

\section{Borden 2002}

At the end of this 4-week trial the cetylpyridinium chloride + essential oils + chlorine dioxide + zinc $\left(\right.$ Breath $\left.R x^{\circledR}\right)$ mouthrinse produced a larger reduction in mean 
organoleptic score of -0.41 from baseline when compared with essential oils $\left(\right.$ Listerine $\left.^{\circledR}\right) \quad 0$; chlorine dioxide + zinc $\left(\right.$ Oxygene $\left.^{\circledR}\right) \quad 0.06$; and placebo 0.16 mouthrinses, and these results were supported by a reduction in halimeter assessed mean VSC readings of $-77.87,-68.90,-53.28$ and -36.77 respectively as showed in Table 12.

Table 12 - (Borden 2002) Change in organoleptic \& halimeter ratings.

\begin{tabular}{|c|c|c|c|c|c|c|}
\hline \multirow{2}{*}{$\begin{array}{c}\text { baseline to } \\
\text { week } 2 \text { \& } 4 \\
\text { Mouthrinse } \\
(\boldsymbol{n}=95) \\
(n=22-25 \\
\text { each group) }\end{array}$} & \multicolumn{3}{|c|}{$\begin{array}{c}\text { Mean change } \\
2 \text { weeks }\end{array}$} & \multicolumn{3}{|c|}{$\begin{array}{c}\text { Mean change } \\
4 \text { weeks }\end{array}$} \\
\hline & Organoleptic & $\begin{array}{l}\text { Halimeter } \\
\text { (ppb) }\end{array}$ & $\begin{array}{c}\% \\
\text { decrease }\end{array}$ & Organoleptic & $\begin{array}{l}\text { Halimeter } \\
\text { (ppb) }\end{array}$ & $\begin{array}{c}\% \\
\text { decrease }\end{array}$ \\
\hline $\begin{array}{c}\text { Listerine } \\
\text { (essential oil) }\end{array}$ & 0.02 & -43.22 & 48.54 & 0 & -68.90 & 77.39 \\
\hline $\begin{array}{c}\text { Breath Rx } \\
\text { (cetylpyridinium } \\
\text { chloride) }\end{array}$ & -0.52 & -66.84 & 67.65 & -0.41 & -77.87 & 78.82 \\
\hline Placebo & 0.23 & -39.86 & 45.25 & 0.16 & -36.77 & 41.75 \\
\hline $\begin{array}{c}\text { Oxygene } \\
\text { (chlorine dioxide } \\
+ \text { zinc) }\end{array}$ & 0 & -47.63 & 64.97 & 0.06 & -53.28 & 72.67 \\
\hline
\end{tabular}

\section{Codipilly 2004}

Unfortunately, the outcomes presented as graphplots in the 4-week comparison of zinc chloride plus sodium chlorite $\left(\right.$ TriOral $\left.^{\circledR}\right)$; zinc chloride minus sodium chlorite (Breath $\mathrm{Rx}{ }^{\circledR}$ containing cetylpyridinium chloride) versus control mouthrinses did not permit the extraction of precise data from the report. In addition the organoleptic ratings reported were of indirect surrogate salivary organoleptic scores and not organoleptic breath scores and it was also not possible to make any accurate deductions from the absolute results which were presented as halimeter VSC ratings. However the investigators in this trial did report that VSC reductions from baseline at 2 weeks were: $55 \%(P<0.01)$ in the zinc chloride plus sodium 
chlorite $\left(\right.$ TriOral $\left.^{\circledR}\right)$, and $38 \%(P<0.05)$ in the zinc chloride minus sodium chlorite (Breath $\mathrm{Rx}{ }^{\circledR}$ containing cetylpyridinium chloride) mouthrinses, and that at 4 weeks the TriOral $^{\circledR}$ mouthrinse achieved a VSC reduction of $60 \%(P<0.01)$.

\section{Kozlovsky 1996}

In this 6-week comparison, the two-phase oil-water $(0.05 \%$ cetylpyridinium chloride) mouthrinse achieved a reduction in mean baseline organoleptic scores of $80 \%(2.14 \pm 0.88$ to $0.42 \pm 0.55)$ and peak VSC levels of $<40 \%$ versus Listerine $\AA$ with a reduction in organoleptic scores of $2.40 \pm 1.00$ to $0.71 \pm 0.64$ and a mean VSC reduction of $29 \%$ (See: Table 13 ).

Table 13 - (Kozlovsky 1996) Organoleptic ratings \& peak VSC levels: week 0 to 6.

\begin{tabular}{|c|c|c|c|c|c|c|c|c|}
\hline \multirow{2}{*}{$\begin{array}{c}\text { Type of } \\
\text { Mouthrinse } \\
(n=50)\end{array}$} & \multicolumn{2}{|c|}{$\begin{array}{c}\text { Baseline } \\
(\text { Mean } \pm \text { SD) }\end{array}$} & \multicolumn{2}{|c|}{$\begin{array}{c}\text { Week } 1 \\
(\text { Mean } \pm \text { SD) }\end{array}$} & \multicolumn{2}{|c|}{$\begin{array}{c}\text { Week } 3 \\
\text { (Mean } \pm \text { SD) }\end{array}$} & \multicolumn{2}{|c|}{$\begin{array}{c}\text { Week } 6 \\
(\text { Mean } \pm \text { SD) }\end{array}$} \\
\hline & Org. & $\begin{array}{l}\text { Peak } \\
\text { VSC } \\
\text { ppb }\end{array}$ & Org. & $\begin{array}{c}\text { Peak } \\
\text { VSC ppb }\end{array}$ & Org. & $\begin{array}{l}\text { Peak } \\
\text { VSC } \\
\text { ppb }\end{array}$ & Org. & $\begin{array}{c}\text { Peak } \\
\text { VSC } \\
\text { ppb }\end{array}$ \\
\hline $\begin{array}{c}\text { 2-phase oil- } \\
\text { water }(0.05 \% \\
\text { CPC) } n=26\end{array}$ & $\begin{array}{c}2.14 \\
\pm \\
0.88\end{array}$ & $\begin{array}{c}94 \\
\pm 36\end{array}$ & $\begin{array}{c}0.85 \\
\pm \\
0.83\end{array}$ & $\begin{array}{c}58 \\
\pm 14\end{array}$ & $\begin{array}{c}0.69 \\
\pm 0.69\end{array}$ & $52 \pm 11$ & $\begin{array}{c}0.42 \\
\pm \\
0.55\end{array}$ & $\begin{array}{r}56 \\
\pm 10\end{array}$ \\
\hline $\begin{array}{c}\text { Control: } \\
\text { essential oils } \\
\text { (Listerine) } n \\
=24\end{array}$ & $\begin{array}{c}2.40 \\
\pm \\
1.00\end{array}$ & $\begin{array}{c}79 \\
\pm 40\end{array}$ & $\begin{array}{c}1.38 \\
\pm \\
0.84\end{array}$ & $\begin{array}{r}69 \\
\pm 33\end{array}$ & $\begin{array}{r}1.29 \\
\pm 0.78\end{array}$ & $58 \pm 16$ & $\begin{array}{c}0.71 \\
\pm \\
0.64\end{array}$ & $\begin{array}{r}56 \\
\pm 16\end{array}$ \\
\hline
\end{tabular}

Notes: Org. = Organoleptic scale $(0$ to 5$), \mathrm{ppb}=$ parts per billion, SD = standard deviation, VSC = volatile sulphur compounds

$\mathrm{CPC}=$ cetylpyridinium chloride

\section{Rassameemasmaung 2007}

The extract of Garcinia mangostana L mouthrinse reduced VSC levels by $59.68 \%$ from baseline $248.35 \pm 172.30$ to $100.54 \pm 69.37$ at 15 days $(P<0.05)$, 
compared with $25.74 \%(237.45 \pm 114.15$ to $176.83 \pm 123.6, \mathrm{P}<0.05)$ in placebo (See: Table 14).

Table 14 - (Rassameemasmaung 2007) VSC levels at baseline \& day 15.

\begin{tabular}{cccc}
\hline Mouthrinse & $\begin{array}{c}\text { Baseline } \\
\text { (Mean } \pm \text { SD) }\end{array}$ & $\begin{array}{c}\text { Day 15 } \\
\text { (Mean } \pm \text { SD) }\end{array}$ & $\begin{array}{c}\text { Change from } \\
\text { baseline }\end{array}$ \\
\hline $\begin{array}{c}\text { Garcinia mangostana L } \\
\mathrm{n}=30\end{array}$ & $248.35 \pm 172.30$ & $100.54 \pm 69.37$ & $59.68 \%$ \\
$\begin{array}{c}\text { Placebo } \\
\mathrm{n}=30\end{array}$ & $237.45 \pm 114.15$ & $176.83 \pm 123.6$ & $25.74 \%$ \\
\hline
\end{tabular}

Notes: SD = standard deviation, VSC = volatile sulphur compounds

\section{Winkel 2003}

In this 2 -week comparison of $0.05 \%$ chlorhexidine $+0.05 \%$ cetylpyridinium chloride $+0.14 \%$ zinc lactate mouthrinse versus placebo, the mean change (standard deviation (SD)) of organoleptic scores from baseline was $-1.13(1.1) \mathrm{P}<0.005$ with the chlorhexidine cetylpyridinium chloride zinc lactate mouthrinse versus -0.2 (0.7) in the placebo group. The mean change (SD) in peak level of VSC was -120 (92) parts per billion (ppb) in the mouthrinse group versus 8 (145) ppb in the placebo group, as show in Table 15. 
Table 15 - (Winkel 2003) Organoleptic and VSC scores: baseline \& week 2.

\begin{tabular}{|c|c|c|c|c|c|c|}
\hline \multirow[b]{2}{*}{ Mouthrinse } & \multicolumn{3}{|c|}{$\begin{array}{l}\text { Organoleptic score } \\
\text { (scale } 0 \text { to } 5 \text { ) }\end{array}$} & \multicolumn{3}{|c|}{ Peak VSC (ppb) } \\
\hline & Baseline & $\begin{array}{c}\text { Baselin } \\
\text { e }\end{array}$ & Baseline & Baseline & Day 14 & $\begin{array}{c}\text { Mean } \\
\text { change } \\
\pm S D\end{array}$ \\
\hline $\begin{array}{c}0.05 \% \\
\text { chlorhexidine + } \\
0.05 \% \mathrm{CPC}+ \\
0.14 \% \text { zinc lactate } \\
\mathrm{n}=20\end{array}$ & $\begin{array}{r}2.8 \\
\pm 0.5\end{array}$ & $\begin{array}{l}1.5 \\
\pm 1.0\end{array}$ & $\begin{array}{l}-1.3 \pm 1.1 \\
P<0.005\end{array}$ & $\begin{array}{r}292 \\
\pm 141\end{array}$ & $\begin{array}{r}172 \\
\pm 104\end{array}$ & $\begin{array}{c}-120 \\
\pm 92 \\
P<0.005\end{array}$ \\
\hline $\begin{array}{l}\text { Placebo } \\
n=20\end{array}$ & $\begin{array}{l}2.7 \\
\pm 0.8\end{array}$ & $\begin{array}{l}2.5 \\
\pm 1.1\end{array}$ & $\begin{array}{l}-0.2 \\
\pm 0.7\end{array}$ & $\begin{array}{r}352 \\
\pm 161\end{array}$ & $\begin{array}{r}360 \\
\pm 254\end{array}$ & $\begin{array}{c}8 \\
\pm 145\end{array}$ \\
\hline
\end{tabular}

Notes: SD = standard deviation

$\mathrm{CPC}=$ cetylpyridinium chloride

\section{Adverse events}

There were 13 adverse events reported in one of the trials (Borden 2002) but the investigators concluded that none were likely to be related to product usage. In one trial (Winkel 2003) significantly more tongue $(P<0.001)$ and tooth $(P<0.002)$ staining was noted with the chlorhexidine cetylpyridinium chloride zinc lactate mouthrinse rather than placebo. There were no reported adverse effects in the herbal mouthrinse study (Rassameemasmaung 2007) or in either of the two other studies.

\section{Evaluation of the reviews using (AMSTAR)}

The reviews were evaluated individually against the 11-item AMSTAR checklist, because the instrument does not allocate pass or fail scores therefore the cumulated responses are presented as a narrative synthesis.

Published protocols of both reviews included; a priori statements regarding inclusion/exclusion criteria and the use of duplicate study selection, extraction of data 
and consensus procedures for disagreements and these were implemented during the conduct of the reviews.

The completed reviews reported the comprehensive searching of several (more than two) electronic databases and the relevant keywords, MeSH terms that were used. The searches were supplemented by examination of the Cochrane Oral Health Groups Specialised Register and the bibliographical references of identified studies were examined for further potentially eligible studies.

There were no exclusions on publication type, language or date of publication and lists of included and excluded studies together with the reasons for exclusion were provided.

Tables of the characteristics of included studies were provided and the scientific quality, to include 'risk of bias' assessment, of the studies was documented.

The limitations in terms of methodological rigour of the included studies were considered and reported in the conclusions of the reviews but no pooling of data was feasible in view of the clinical heterogeneity between the studies in terms of participants included and the diversity in the interventions.

The lack of a sufficient of number included studies for any one specific intervention did not permit assessment of publication bias, and in view of the high level of commercial interest in this topic there is a possibility that some studies may not have been published therefore we cannot discount the likelihood of publication bias. Moreover, although we did not identify any multiple or duplicate publications the most likely sources of this form of bias if any would be as a result of decisions to publish or not publish research findings depending on the nature and direction of the results. 
The review authors attested that they had neither financial or other conflicts of interest nor any associations with any parties who may have vested interests in the results of the reviews.

\section{$\underline{\text { Addendum }}$}

\section{Updating of searches and identification of additional included studies}

The electronic searches were re-run and updated to April $4^{\text {th }} 2014$ by Dr Jan Schoones, an Information Specialist based at the Leiden University Medical Center Leiden the Netherlands.

The search strategy employed was identical to the one used in the previous searches carried out by the Cochrane Oral Health Group Trials Search Coordinator on $11^{\text {th }}$ August 2008 (updated $3^{\text {rd }}$ February 2009). (See: Appendix 2)

Identical search criteria such as limitations on language and date of publication were applied and no additional handsearching was conducted other than examination of the reference lists of any potentially eligible studies.

After de-duplication, the searches delivered 278 references to mouthrinses and 189 unique references to tongue scraping. The titles and abstracts of these references were assessed against the pre-specified inclusion criteria and studies which were clearly ineligible were excluded from the review. The assessments for potential eligibility were undertaken using a newly developed data-mining tool; Rayyan http://rayyan.qcri.org/ supported by the Qatar Computing Research Institute (Qatar Foundation) Doha Qatar.

No relevant studies matching the inclusion criteria were identified for tongue scraping and only 3 reports of randomized controlled trials were considered potentially eligible for mouthrinses for halitosis and full text copies of these were 
obtained for further evaluation. Assessment of these full reports revealed that the intervention in one of them (Saad 2011) was a single rinse of five test formulations and therefore this study was excluded. (See 4.1 Criteria for considering studies for this review).

The updated searches provided two potentially eligible studies (WiggerAlberti 2010; Dadamio 2013) which are added to the existing included studies.

\section{\# Mouthrinses for treating halitosis}

Table of additional included studies (Update 2014)

\begin{tabular}{|c|c|c|c|}
\hline Author & $\begin{array}{l}\text { Study } \\
\text { design }\end{array}$ & Participants & Interventions/treatment \\
\hline $\begin{array}{l}\text { Wigger-Alberti } \\
2010\end{array}$ & RCT & $\begin{array}{c}\mathrm{N}=174, \text { (32 males, } 142 \\
\text { females age } 43.1 \pm 12.3 \text { ). } \\
\text { Unclear how many } \\
\text { participants/intervention } \\
\text { group. "stratified } \\
\text { according to their } \\
\text { Organoleptic Rating" } \\
\text { OR >2, VSC > 50ppb }\end{array}$ & $\begin{array}{c}\text { 1: Experimental halitosis } \\
\text { mouthrinse (ASF- amine } \\
\text { fluoride/stannous fluoride), 2: } \\
\text { Halita ( } \mathrm{CHX} / \mathrm{CPC} / \mathrm{Zn} \text { lactate), } \\
\text { 3: PerioAid (CHX), 4: Tap } \\
\text { water. Twice daily rinsing for } 3 \\
\text { weeks. Toothbrush use } \\
\text { permitted. }\end{array}$ \\
\hline Dadamio 2013 & RCT & $\begin{array}{c}\mathrm{N}=98 ; 8 \text { lost to follow-up } \\
\text { (56 males, } 34 \text { females, } \\
\text { age } 48.2 \pm 11.2 \text { yrs, OR } \\
>2, \\
\text { VSC 150-1343 ppb) }\end{array}$ & $\begin{array}{c}\text { 1: Colgate Fluorigard (sodium } \\
\text { fluoride } 0.05 \% \text { ), } 2 \text { : Perio-plus } \\
\text { (CHX 0.12\%), 3: Halita (CHX } \\
\quad 0.05 \%), 4: \text { Meridol } \\
\text { (amine+stannous fluoride), 5: } \\
\text { Meridol+Zn (zinc lactate). } \\
\text { Once daily rinsing for } 7 \text { days, } \\
\text { Routine oral hygiene } \\
\text { measures permitted. }\end{array}$ \\
\hline
\end{tabular}

'References to included studies' (See: Appendix 3)

'References to excluded studies' (See: Appendix 4) 


\section{Summary of trial details}

\section{Methods}

The two studies were described as randomized, double blind and included positive and negative control groups.

Characteristics of the participants and setting

The total sample size consisted of 272 adult participants; Dadamio 2013 (98) but the report in Wigger-Alberti 2010 was unclear whether there were 174 or 176 participants. The participants in Dadamio (2013) were recruited over a period of 4 years, between April 2007 and July 2011, from a breath odour clinic at the UZ Leuven in Belgium. No such details were reported by Wigger-Alberti 2010 only that the participants were volunteers.

The inclusion criteria were similar in both studies and the exclusion criteria were in agreement with most breath odour studies and specifically those which were most likely to have an impact on assessment of the outcomes. In both studies participants were required to refrain from eating spicy foods, garlic, onions one week before and alcohol in the 12 hours prior to any assessment. For further details. See Table of additional included studies (Update 2014).

\section{Characteristics of the interventions}

For further details. See Table of additional included studies (Update 2014).

\section{Characteristics of outcomes measures}

Both studies addressed the primary and secondary outcomes that were prespecified for this systematic review. 
Self-reported adverse events were recorded in Dadamio (2013). In WiggerAlberti (2010) the participants also completed a questionnaire with a VAS rating which assessed the "product features" ie taste, mouth numbness feeling. Discolouration of the teeth was investigator evaluated in this study.

Outcomes were assessed in (Dadamio 2013) 15 minutes after the first rinse, day 8 , and 12 hours after the last rinse. Organoleptic scores (OLS) were undertaken by trained and calibrated judges and rated 0-5 (Greenman 2004). VSC measurement was carried out with the Halimeter $^{\circledR}$ and a portable gas chromatograph (OralChroma $^{\mathrm{TM}}$ ) was used for further analysis of the expired air. Similar assessments were made in Wigger-Alberti (2010) on days 1,7,14 and 21 in addition to evaluation of tooth discolouration at the final visit.

\section{Assessment of risk of bias in the included studies}

These assessments followed the steps outlined in 4.4. Assessment of risk of bias

\section{Randomization}

The method used to randomize participants and conceal the allocation sequence was only clearly described in one study (Dadamio 2013). This trial employed block randomization (23 blocks of 5 participants) and the sequence was generated independent of the trial investigators ie 'by the sponsor'. Sealed and coded envelopes were used and the codes were concealed until completion of the study. Conversely the other study (Wigger-Alberti 2010) although described as "randomized", the investigators provided no details on this aspect of trial conduct. 
The trialists only mentioned that the participants "were divided into four groups" and were "stratified according to their organoleptic ratings".

On the basis of the details reported, the domains of sequence generation and concealment were considered satisfactory in only one of these studies (Dadamio 2013), and inadequate and judged to be 'high risk of bias' in the other (Wigger-Alberti 2010).

\section{Blinding}

The trialists in (Dadamio 2013) indicated that the "formulations were provided by the sponsor in undistinguishable bottles", and thus the method used to blind participants and investigators was considered adequate and the domain was judged to be 'low risk'. Nothing was reported for this trial quality item in the other study (Wigger-Alberti 2010) which raises the possibility of an element of selection and performance bias and therefore this domain was judged 'unclear risk of bias'.

\section{Incomplete outcome data}

Losses to follow-up and discontinuation of treatment (8/98) were low and the reasons were fully reported in (Dadamio 2013). Although the analysis in this study was per-protocol, the low numbers (8\%) were not considered to pose a threat to its internal validity and therefore this domain was judged as at 'low risk of bias'. In the other study (Wigger-Alberti 2010) the number of participants allocated to each of the individual intervention groups and how these correlated with their corresponding outcomes were not reported at all. Mean Differences were reported for each group as box-and-whisker plots but little or no information was provided about the participants 
representing these data. In addition, the trialists in this study frequently referred to an ITT and PP population and that "the results did not deviate".

Clearly these comments would appear to indicate that there were losses to follow-up and/or most probably incomplete outcome data but these were not reported or commented on anywhere by the investigators. In view of the absence of these key data, several attempts were made to contact the study investigators by email. The contact author did respond finally and said he was unable to answer any questions at all about the study. The potential for attrition bias cannot be discounted and therefore this domain received a judgement of 'high risk' in this study (Wigger-Alberti 2010).

\section{Selective reporting}

The protocol for neither of the studies was available but the pre-specifed outcomes and those defined in the methods section in one of the studies appear to have been reported (Dadamio 2013). Reporting of pre-specified outcomes in (Wigger-Alberti 2010) was marred by the lack of information on the number of participants per intervention group and thus the possibility of selective reporting bias remains uncertain and this domain was judged as 'unclear risk of bias'.

\section{Other potential sources of bias}

There was a degree of concern with the potential impact of study support and sponsorship in (Wigger-Alberti 2010). It was reported that this study, which was conducted by proDERM, was funded by GABA International which is the manufacturer of the mouthrinse under investigation, and thus the possible impact of any conflicts of interest of the trialists and their employment by proDERM remains unclear. 
The authors in (Dadamio 2013) reported that support was provided by GABA International, and that although the nature of the support was not specified, they had no conflicts of interest nor did they appear to be employed by the supporting body.

The assessments of overal risk of bias of these two additional studies in this update were based on the details as reported and according to the pre-specified methods. (See: 4.4. Assessment of risk of bias). The summative assessments of risk of bias across the domains were judged to be 'low to unclear' for (Dadamio 2013) and 'high to unclear' for (Wigger-Alberti 2010). In this instance a low risk of bias indicates plausible bias that is unlikely to seriously alter the results, whereas a high risk seriously weakens our confidence in the results.

\section{Effects of interventions}

Wigger-Alberti (2010): The incompleteness of reporting of key data in this study in conjunction with concerns with its overall methodological quality and the apparent unwillingness by the contact author to respond to the most basic queries, presented challenges in how best to evaluate the effectiveness of the interventions that were examined. Although it remains unclear to what extent the incomplete reporting of data can be construed as selective reporting in favour of the "newly developed mouthrinse product", it does nevertheless mean that the data as reported cannot be adequately interpreted or presented in an equipoised and balanced manner. Based on the data presented we can neither say that the interventions are effective nor ineffective as fair comparisons cannot be made without a fuller dataset.

This study was initially presented as a poster [Ref no: EUABS065363] at Europerio 6 ( $6^{\text {th }}$ Congress of the European Federation of Periodontology) in June 2009. 
No additional information was available in this poster, no contact could be made with the investigators and therefore re-analysis of the study data proved impossible and thus this study is designated as having unusable or potentially unreliable data and will not be discussed further.

Dadamio (2013): The baseline data showed no statistically significant difference ( $p$-value $>0.05$ ) between the 5 intervention groups.

\section{Primary and secondary outcomes}

This study examined the 'masking effect' i.e. the immediate (15 minutes after rinsing) based on OLS and Halimeter readings and the 'therapeutic effect' which was evaluated similarly but at the completion of the study at Day 7.

For the masking effect Halita, Meridol and Meridol with zinc lactate (2\%) showed greater reductions in OLS (0.8 to 1.9 scores) than the two controls (sodium fluoride $0.05 \%$; $\mathrm{CHX} 0.12 \%$ ) which were both statistically significant and clinically meaningful. Reductions in VSC levels in the Halita and Meridol with zinc lactate intervention groups were more significant than in the other groups.

The longer term therapeutic effects of the interventions which were assessed at seven days, revealed the possibly increased effectiveness of mouthrinses which incorporated antimicrobial components although the differences between them were not distinctive.

No serious adverse events were reported with any of the mouthrinses only of what were described as "unpleasant feelings" with; sodium fluoride $(0.05 \%), \mathrm{CHX}$ $(0.12 \%)$ and Halita $(0.05 \% \mathrm{CHX}+\mathrm{CPC})$ with accompanying tooth staining. 

6. Discussion 



\section{Discussion}

\subsection{Summary of main results (the effects: benefits and harms)}

Although the smaller (Pedrazzi 2004) of the two studies on tongue scrapers had statistically significant results $(p<0.01)$ and the larger trial (Seemann 2001) had an extremely short intervention time the results from both of these studies should still be interpreted with some degree of caution. One of the trials (Seemann 2001) showed that the VSC levels returned to baseline after a very short period even with what appeared to be the most effective of the instruments. As tongue coating is generally associated with higher VSC levels the reason for this rapid return to baseline levels after removal of the tongue coating was unclear.

A small amount of tongue trauma induced by 1 week of tongue scraping was reported in the (Pedrazzi 2004) trial and thus the potential for adverse effects with long-term use of tongue scrapers should be set against the possibly limited duration of the benefits of VSC reduction.

Chlorhexidine-containing mouthrinses have been shown to be successful in reducing antibacterial activity in supragingival plaque as well as the bacterial load on the tongue and thus are seen as potentially effective agents in controlling halitosis. The clinical benefits of a mouthrinse combining $0.05 \%$ chlorhexidine with cetylpyridinium chloride and zinc lactate were demonstrated in one of the included studies (Winkel 2003). In this mouthrinse, the antibacterial properties of chlorhexidine and cetylpyridinium chloride (i.e. in reducing the number of VSC-producing bacteria), are combined with the ability of zinc ions to transform volatile sulphur compounds into non-odiferous breakdown products. Unfortunately chlorhexidine, as was noted in 
this trial, also has some disadvantages principally with the increased tooth and tongue staining, bad taste and some reduction in taste sensation.

The effectiveness of a two-phase oil-water mouthrinse containing $0.05 \%$ cetylpyridinium chloride was illustrated by favourable reductions of organoleptically assessed mouth odour scores in three of the included trials. In one of the trials, as the principal constituent of Breath $\mathrm{Rx}^{\circledR}$, it was the only mouthrinse that reduced organoleptic scores at both 2 and 4 weeks. Organoleptic scores were significantly reduced in a further comparison of this mouthrinse with an essential oil mouthrinse at the end of a 6-week trial. A combination of this mouthrinse with chlorhexidine in a 2week study of participants with moderate to severe halitosis also achieved a reduction of $50 \%$ in mean organoleptic scores.

Albeit the herbal extract of Garcinia mangostana has shown some effectiveness in reducing salivary mutans streptococci, this appears to be the first such study of this extract as a mouthrinse to combat halitosis, and whilst the lack of organoleptic mouth odour assessments may be an important oversight this study did nevertheless show significant reduction in halimeter assessed mean VSC levels and little or no reported adverse effects over a 2-week period. The potential benefits of this intervention warrant further investigation and the trialists have indicated their willingness to work with a Brazilian research team to further explore this naturally occurring product.

Chlorine dioxide based mouthrinse formulations were examined in two trials, one mouthrinse $\left(\right.$ TriOral $^{\circledR}$ ) delivered VSC reductions of up to $60 \%$ at 4 weeks which were said to be consistent with surrogate organoleptically assessed salivary odour scores, but conversely in the second trial daily use of a similar mouthrinse $\left(\right.$ Oxygene $\left.{ }^{\circledR}\right)$ did not appear to reduce organoleptic scores from baseline over a 4- 
week period although the reduction in halimeter assessed VSC levels was reportedly similar (72\%).

\subsection{Overall completeness and applicability of evidence}

The primary outcome for both of the reviews specified the self assessed measurement of halitosis which, albeit is the outcome of relevance to patients, is said to be inaccurate and 'the least reliable'. The 'gold standard' for the measurement of oral malodour is considered to be by organoleptic assessment and these scores have been shown to correlate fairly well with assessments from portable sulfide monitors [Spearman $r_{s}=0.64, p<0.001$ ] (Rosenberg 1995) and thus the data presented as secondary or surrogate outcomes in some of the included trials may provide some indication of the effectiveness of tongue scraping or mouthrinses for reducing VSC levels. All of the included trials for both reviews conducted halimeter assessments of VSC levels, but because no additional organoleptic breath odour assessments were conducted in several trials (Codipilly 2004; Rassameemasmaung 2007), caution must be exercised in interpreting relevant outcomes in these trials and specifically in comparisons showing substantial reductions in VSC levels.

There is a large market for over the counter mouthwashes for controlling mouth odour and thus the somewhat unexpected lack of randomized controlled trials comparing the effectiveness of mechanical tongue cleaning with mouthwashes proved to be disappointing. It was however rewarding to find two trials which compared the effectiveness of several types of scrapers and brushes which are available for mechanical cleaning of the tongue.

Although neither of these trials had a follow-up period of 1 month as specified in the protocol they nevertheless provided some evidence (if limited and weak) for 
the effectiveness of tongue scrapers. Significant clinical heterogeneity between the studies included in the mouthrinses review was illustrated by the inclusion of participants with low organoleptic and baseline volatile sulphur compounds (VSC) scores in addition to those with significantly higher scores who had been referred to halitosis clinics. The presence of this clinical diversity precluded any pooling of the data which might have been of value in strengthening the effects measured in each separate study.

A far wider range of mouthrinses than tongue scrapers are available for controlling mouth odour and although there have been a large number of studies conducted over the last 30 years, it was somewhat surprising to find so few high quality randomized controlled trials comparing the effectiveness of some of these mouthrinses. The reduction of bacterial levels in sites such as the tongue that might serve as reservoirs for odour-producing bacteria is of paramount importance in controlling halitosis. Two randomized controlled trials provided some weak and unreliable evidence for the use of tongue scraping as a means of controlling halitosis.

Mouthrinses containing antibacterial agents such as chlorhexidine and cetylpyridinium chloride can play an important role in reducing bacterial levels on the tongue but the effectiveness of chlorine dioxide and zinc containing mouthrinses in neutralisation of odoriferous sulphur compounds should not be underestimated. There would therefore appear to be a place in the management strategy of halitosis for formulations which include and combine some of these constituents.

Although the review of mouthrinses provided some evidence for the comparative effectiveness of several different mouthrinses the results must be weighed carefully against the diversity in baseline characteristics of the participants included in these studies as well as the methods used to assess their outcomes. 
This rather limited evidence emphasised the gaps that are present and did not enable an overall judgment to be made about the external validity of this comparative effectiveness research synthesis.

\subsection{Quality of the evidence}

A GRADE assessment of the quality of evidence for individual outcomes across the included studies is an integral part of a review these days. This would include an evaluation of the limitations in study design; unexplained heterogeneity and inconsistency of results; indirectness of evidence; imprecision of results and an estimation of any publication bias (GRADE Working Group 2004). In view of the clinical diversity (heterogeneity) between the studies it was not possible to construct a 'Summary of Findings' table in which to report these quality assessments for the primary outcomes across the included studies and therefore only a descriptive summary.

\subsection{Potential biases in the review process}

Strident attempts were made to limit bias during the review process by ensuring a comprehensive search for potentially eligible studies which included searching in several specialised databases. The effects of language bias in the identification and selection of studies is widely recognised and therefore attempts were made to ensure that all potentially eligible studies were either translated or assessed for relevance with the help of a native language speaker.

However it is accepted that the incompleteness of some of the reports of studies and the inability to obtain clarification of trial details or resolve ambiguities in 
the reports may have contributed to bias but where these conditions applied this was explicitly stated in the review.

\subsection{Agreements and disagreements with other studies or reviews}

The only other study available is an evidence summary published by BMJ Clinical Evidence (Scully and Porter 2007) and whilst there is general harmony in the results and conclusions there were points of divergence in the methodological approaches used and in particular those related to transparency and reproducibility.

The authors of the BMJ evidence summary did not provide a protocol and only stated that the "selected studies were sent to the authors for additional assessment against predetermined criteria". The report did not include a flow chart or any explicit detail on the process of selection or exclusion of studies nor did the authors provide a complete list of the excluded studies and the reason for their exclusion.

No assessments of risk of bias were reported by the authors and it was unclear if these had been conducted, the authors did however declare their potential competing conflicts.

Although a formal assessment, using AMSTAR, of this evidence summary was not conducted it was clear that a large number of the items would be graded as 'Can't answer'.

\subsection{Implications for research}

There are long standing concerns about the variability and somewhat subjective nature of organoleptic assessment but it nevertheless remains the 'gold standard' principally because direct assessment of breath malodour is a reflection of 
what the breath recipient actually encounters and is therefore of the most relevance to the haltosis sufferer.

Organoleptic scores might appear to correlate favourably with portable sulfide meter assessment, but the correlations indicate that the VSCs measured by a halimeter may only account for $18 \%$ to $41 \%$ (Rosenberg 1995 ) of the organoleptic score with other not detected odorants contributing to the remainder of the score.

Future research should attempt to determine what role these other important odorants might play in oral malodour. Moreover in light of the fact that the findings from these reviews have reinforced the well held belief that discrepancies can occur between organoleptic and halimeter breath odour assessment investigators should ensure that organoleptic assessments are routinely conducted for this research question.

Synthesis of the results from the included studies has indicated the short lived effect of tongue scraping on reducing VSC levels and the diversity in effectiveness of some of the more popular over the counter mouthrinses in treating halitosis, thus further trials should be conducted. These future randomized controlled trials should aim to compare the portable sulfide monitor's discriminatory ability to detect some of the important odorants against gas chromatography, in addition to including a larger sample, a longer intervention and follow-up period, and be well designed and reported according to the Consolidated Standards of Reporting Trials (CONSORT) statement (http://www.consort-statement.org). 


\subsection{Discussion after the addendum}

The updated searches added only one single study to the CER and that was to the mouthrinses component. The single trial which examined the effects of different mouthrinse formulations added-value by investigation of the masking effect of these rinses in addition to their longer term effects. Halita and Meridol with zinc lactate appeared to show improved masking effects in both assessments over the other rinses which may in part be due to the ability of zinc ions to capture VSC. The longer term effectiveness of mouthrinses containing chlorhexidine or amine fluoride and stannous fluoride in reducing halitosis was confirmed, an effect which was largely attributable to their antimicrobial properties.

Inadequate reporting continues to be a problem in clinical trials in general but there appear to be lingering concerns with those conducted in dentistry as was illustrated by the one trial that was included in this update. Compliance with CONSORT by trialists and ultimately a more rigorous enforcement of this in the submission requirements by journal editors will do much to elevate oral healthcare research. 
7. Conclusions 



\section{CONCLUSIONS}

After the development of the Comparative Effectiveness Research (CER) synthesis of the two Cochrane systematic reviews for treating halitosis, and the employment of AMSTAR tool, it can conclude that:

1. Some concerns about the quality of systematic reviews in dentistry were raised by Richards (2004) who recommended that if future clinical decisions are to be based upon systematic reviews, it is imperative that these reviews are focused, address clinically relevant questions, and follow a transparent, well-designed protocol. Specific areas of weakness which were identified included poorly designed search strategies, inadequate attempts to identify all relevant studies, inconsistent screening and quality assessment of studies, inappropriate pooling of data, incomplete exploration of heterogeneity and incorrect interpretation of findings.

2. These two systematic reviews sought to answer important patientrelevant questions which span the continuum of treatment options for halitosis. Undoubtedly their quality in terms of clear and explicit statements in their inclusion criteria and consistency in the application of those criteria to the selection of relevant studies was to a certain extent endorsed by the methodological rigour expected of Cochrane reviews. And whilst the lack of sufficient numbers of high quality trials placed a restriction on any major explicit clinical recommendations, the conclusions in terms of the strength and direction of current best 
evidence are reinforced by the results of the methodological quality evaluation of these reviews using the AMSTAR instrument.

3. A personal communication from lain Chalmers, the founder of the Cochrane Collaboration provides a suitable footnote to this research topic.

"If the research question is important and there are no reliable data available with which to address it, then the world needs to know that. There are several potentially useful consequences of doing this. Firstly, a reader may draw attention to a trial, which has been overlooked. Secondly, a patient may realise that their preferences should dominate in any decisions about choice of treatment, and thirdly, researchers and research funding organisations will see that there is an important gap in reliable evidence and take steps to plug it. Cochrane reviews can be - 
8. References 



\section{REFERENCES ${ }^{1}$}

Abbasi K. (2004) Compulsory registration of clinical trials. British Medical Journal 329:637-638.

Agencia Nacional de Vigilância Sanitária. Resolução RDC $n^{0} 39$, de 05 de junho de 2008. (2008.) Available at: http://elegis.anvisa.gov.br/leisref/public/showAct.php?id=31279.

Altman DG. Better reporting of randomized controlled trials: the CONSORT statement. British Medical Journal 1996; 313:570-1.

Altman DG, Schulz KF, Moher D, Egger M, Davidoff F, Elbourne D, et al. The revised CONSORT statement for reporting randomized trials: explanation and elaboration. Annals of Internal Medicine 2001; 134:663-94.

Altman DG. Endorsement of the CONSORT statement by high impact medical journals: survey of instructions for authors. British Medical Journal 2005; 330:7 1056.

Antes G, Chalmers I. Under-reporting of clinical trials is unethical. Lancet 2004; 361(9362):978.

Antman EM, Lau J, Kupelnick B, Mosteller F, Chalmers TC. A comparison of results of meta-analysis of randomized controlled trials and recommendations of clinical experts. Journal of the American Medical Association 1992; 268:240-248.

Atkins D, Briss PA, Eccles $M$ et al. Systems for grading the quality of evidence and the strength of recommendations. 11; Pilot study of a new system. BMC Health Services Research 2005; Available on-line at: http://www.biomedcentral.com/1472$\underline{6963 / 5 / 25}$.

Attia EL, Marshall KG. Halitosis. Canadian Medical Association Journal 1982; 126(11):1281-5.

Aurbach FE. Evidence based dentistry. A practitioner's perspective. The Journal of the American College of Dentists 1999; 66:17-20.

Ayers KM, Colquhoun AN. Halitosis: causes, diagnosis, and treatment. The New Zealand Dental Journal 1998; 94(418):156-60.

Berg, M. Problems and promises of the protocol. Social Science and Medicine 1997; 44: 1081-8.

Bero LA, Grilli R, Grimshaw JM, Harvey E, Oxman AD, Thomson MA. Closing the gap between research and practice: an overview of systematic reviews of interventions to promote the implementation of research findings. The Cochrane

\footnotetext{
1 De acordo com: International Committee of Medial Journal Editors - padrão ANSI, adaptado pela U.S. National Library of Medicine (estilo VANCOUVER). Disponível em: http://www.ncbi.nlm.nih.gov/bookshelf/br.fcgi?book=citmed (acessado em $15 \mathrm{de}$ outubro de 2015).
} 
Effective Practice and Organization of Care (EPOC) Review Group. British Medical Journal 1998; 317:465-8.

Black N. Why we need observational studies to evaluate the effectiveness of health care. British Medical Journal 1996; 312:1215-8.

Bonner BC, Clarkson JE, McCombes W. General dental practitioners view on the pursuit and practice of evidence-based dentistry: The results of a questionnaire. Tuith Online 2001. Available at: http://www.dundee.ac.uk/tuith/Articles/rt05.htm.

Borden LC, Chaves ES, Bowman JP, Fath BM, Hollar GL. The effect of four mouthrinses on oral malodour. Compendium of Continuing Education in Dentistry 2002; 23(6):531-6.

Bosy A, Kulkarni GV, Rosenberg M, McCulloch CA. Relationship of oral malodour to periodontitis: evidence of independence in discrete subpopulations. Journal of Periodontology 1994; 65(1):37-46.

Bosy A. Oral malodour: philosophical and practical aspects. Journal of the Canadian Dental Association 1997; 63(3):196-201.

Brunette D M. Critical thinking: understanding and evaluating dental research. Chicago: Quintessence; 1996.

Brunette DM, Proskin HM, Nelson BJ. The effects of dentifrice systems on oral malodour. Journal of Clinical Dentistry 1998; 9(3):76-82.

Canadian Task Force on the Periodic Health Examination: The periodic health examination. CMAJ 1979; 121:1193-1254.

Cannavina CD, Cannavina G, Walsh TF. Effects of evidence-based treatment and consent on professional autonomy. British Dental Journal 2000; 188:302-306.

Carvalho MD, Tabchoury CM, Cury JA, Toledo S, Nogueira-Filho GR. Impact of mouthrinses on morning bad breath in healthy subjects. Journal of Clinical Periodontology 2004; 31(2):85-90.

Centre for Evidence-Based Medicine at Oxford. Levels of evidence. Available online at: http://www.cebm.net/levels of evidence.asp.

Chalmers I. Evaluating the effects of care during pregnancy and childbirth. In: Effective care in pregnancy and childbirth. (Eds). Chalmers I, Enkin M \& Keirse MJNC. Oxford: Oxford University Press; 1989.

Chalmers I. Underreporting research is scientific misconduct. Journal of the American Medical Association 1990; 263:1404-8.

Chalmers I, Hedges LV, Cooper H. A brief history of research synthesis. Evaluation and the Health Professions 2002; 25(1):12-37.

Chinnock P, Siegfried N, Clarke M. Is Evidence-based Medicine Relevant to the Developing World? Public Library of Science Medicine 2005; 2 (25):e107. 
Clarke M. Doing new research? Don't Forget the Old. Public Library of Science Medicine 2004; 1(2):e35.

Cochrane AL. The history of the measurement of ill health. International Journal of Epidemiology 1972; 1:89-92.

Cochrane AL. 1931-1971: a critical review, with particular reference to the medical profession. In: Medicines for the year 2000. London: Office of Health Economics 1$11 ; 1979$.

Cook DJ, Mulrow CD, Haynes RB. Systematic Reviews: Synthesis of Best Evidence for Clinical Decisions. Annals of Internal Medicine 1997; 126(5):376-380.

Cooper MB. The context of evidence-based dentistry. Journal of Evidence Based Dental Practice 2001; 1; 83-86.

CRD (Centre for Reviews and Dissemination) University of York, UK. Available online at: http://www.york.ac.uk/inst/crd.

DARE (Database of Reviews of Effect). University of York, UK. Available on-line at: http://www.york.ac.uk/inst/crd.

De Angelis C, Drazen JM, Frizelle FA, Haug C, Hoey J, Horton R, et al. Clinical trial registration: a statement from the International Committee of Medical Journal Editors. Lancet 2004; 364 (9438): 911-2.

Delanghe G, Bollen C, Desloovere C. Halitosis--foetor ex ore. Laryngo- RhinoOtologie 1999; 78(9):521-4.

Dickersin K. The existence of publication bias and risk factors for its occurrence. Journal of the American Medical Association 1990; 263(10):1385-9.

Dickersin K, Min YI, Meinert CL. Factors influencing publication of research results. Follow-up of applications submitted to two institutional review boards. Journal of the American Medical Association 1992; 267(3):374-8.

Dickersin K. How important is publication bias? A synthesis of available data. AIDS Education and Prevention 1997; 9 (suppl A):15-21.

Doll R. Controlled trials: the 1948 watershed. British Medical Journal 1998; 317(7167):1217-1220.

Dyer O. Glaxo Smith Kline faces US lawsuit over concealment of trial results. British Medical Journal 2004; 328(7453):1395.

Egger M, Davey Smith G, Schneider M, Minder C. Bias in meta-analysis detected by a simple, graphical test [see comments]. British Medical Journal 1997; 315(7109): 629-34.

Egger M, Davey Smith G. Bias in location and selection of studies. British Medical Journal 1998; 316(7124):61-66. 
Egger M, Dickersin K, Davey-Smith G. Problems and limitations in conducting systematic reviews. In Egger M, Smith DG, Altman DG, editors. Systematic reviews in health care: meta-analysis in context. London: BMJ Books, pp 43-68; 2001.

Egger $M$, Jüni $P$, Bartlett $C$, Holenstein F, Sterne J. How important are comprehensive literature searches and the assessment of trial quality in systematic reviews? Empirical study. Health Technology Assessment 2003; 7:1-76.

Egger M, Zellweger-Zahner T, Schneider M, Junker C, Lengeler C, Antes G. Language bias in randomized controlled trials published in English and German. Lancet 1997; 350: 158-162

Eisinga A, Lefebvre C. (2004) Closing the gap - identifying reports of randomized trials in EMBASE for inclusion in CENTRAL [abstract]. In: $\mathbf{1 2}^{\text {th }}$ Cochrane Colloquium 2004 Oct 2-6; Ottawa, Ontario, Canada: 150-1.

Evidence-based Medicine Working Group: Evidence-based medicine: a new approach to teaching the practice of medicine. Journal of the American Medical Association 1992; 268:2420-2425.

Farrell S, Baker RA, Somogyi-Mann M, Witt JJ, Gerlach RW. Oral malodour reduction by a combination of chemotherapeutical and mechanical treatments. Clinical Oral Investigations 2006; 10(2):157-63.

Fedorowicz Z, Keenan JV. Eminence or evidence based dentistry....... whither Homo evidensis? Brazilian Journal of Oral Sciences 2003; 2(7):337-8.

Fedorowicz Z, Almas K, Keenan JV. Perceptions and attitudes towards the use of Evidence-based dentistry (EBD) among Final year students and Interns at King Saud University College of Dentistry in Riyadh Saudi Arabia. Brazilian Journal of Oral Sciences 2004; 3(9):470-474.

Field MJ, Lohr KN. Guidelines for Clinical Practice: From Development to Use. Institute of Medicine. Washington, DC: National Academy Press; 1992.

GDC. (2002) The First Five Years - A Framework for Undergraduate Dental Education. Available on-line at: http://www.gdc-uk.org/news+publications

Ghersi D, Pang T. En route to international clinical trial transparency. Lancet 2008; 372(9649):1531-32.

Glasziou P, Vandenbroucke J, Chalmers I. Assessing the quality of research. British Medical Journal 2004; 328:39-41

Goldstein GR, Preston JD. Therapy. Anecdote, Experience, or Evidence. Dental Clinics of North America 2002; 46(1):21-28.

Goodman KW. Ethics and Evidence-Based Medicine. Cambridge: Cambridge University Press; 2003.

Google Scholar. Available on-line at: http://www.scholar.google.com. 
Gøtzsche PC. Reference bias in reports of drug trials. British Medical Journal (Clinical Research Edition) 1987; 295: 654-6.

GRADE Working Group. Grading quality of evidence and strength of recommendations. British Medical Journal 2004; 328:1490-4.

GRADE Working Group. Available on-line at: www.gradeworkinggroup.org.

Greenman J, Duffield J, Spencer P, Rosenberg M, Corry D, Saad S et al. Study on the organoleptic intensity scale for measuring oral malodour. Journal of Dental Research 2004; 83(1):81-5.

Guyatt G. Evidence-based medicine. American College of Physicians Journal Club 1991; 114 : A-16.

Guyatt G, Sackett DL, Sinclair J, Hayward R, Cook D, Cook R. A new method of grading healthcare recommendations. Journal of the American Medical Association 1995; 274(22): 1800-4.

Guyatt $\mathrm{GH}$, Oxman $A D$, et al. GRADE: an emerging consensus on rating quality of evidence and strength of recommendations. British Medical Journal 2008; 336: 924-926.

Haynes RB. (2002) What kind of evidence is it that Evidence-Based advocates want health care providers and consumers to pay attention to? British Medical Journal Health Services Research Available on-line at: http://www.biomedcentral.com/1472$\underline{6963 / 2 / 3}$.

Higgins JPT, Green S. (2008) Editors. Cochrane Handbook for Systematic Reviews of Interventions Version 5.0.1 [updated September 2008]. The Cochrane Collaboration, 2008. Available on-line at: www.cochrane-handbook.org.

Hróbjartsson A, Gøtzsche PC, Gluud C. The controlled clinical trial turns 100 years: Fibiger's trial of serum treatment of diphtheria. British Medical Journal 1998; 317:1243-1245.

loannidis JP. Effect of the statistical significance of results on the time to completion and publication of randomized efficacy trials. Journal of the American Medical Association 1998; 279:281-286.

Jacob RF. Bias in dental research can lead to inappropriate treatment selection. Dental Clinics of North America 2002; 46(1):61-78.

Jadad A. Randomized Controlled Trials: Questions, Answers and musings. $2^{\text {nd }}$ Edition. British Medical Journal Books London: UK; 2007.

James Lind Library [online]. Available on-line at: www.jameslindlibrary.org.

Juni $P$, Witschi $A$, Bloch $R$, Egger $M$. The hazards of scoring the quality of clinical trials for meta-analysis. Journal of the American Medical Association 1999; 282:1054-1060. 
Kelly MP, Mc Daid D, Ludbrook A, Powell J. (2005) Economic appraisal of public health interventions. Briefing paper. London: Health Development Agency.

Available on-line at: www.hda.nhs.uk.

Khan K, ter Riet G, Glanville J, Sowden A, Kleijnen J. (2001) Undertaking Systematic Reviews of Research on Effectiveness. CRD's Guidance for those Carrying Out or Commissioning Reviews. CRD Report Number 4 ( $2^{\text {nd }}$ Edition). CRD. York. [Updated 2009 and available at: http://www.york.ac.uk/inst/crd/systematic reviews book.htm]

Kleinberg I, Westbay G. Oral malodour. Critical Reviews in Oral Biology and Medicine 1990; 1(4):247-59

Kleinberg I, Codipilly M. In: Rosenberg M, editor(s). (1995). The biological basis of oral malodour formation. Bad Breath: research perspectives.Tel Aviv: Ramot Publishing, 13-40.

Kostelc JG, Preti G, Zelson PR, Stoller NH, Tonzetich J. Salivary volatiles as indicators of periodontitis. Journal of Periodontal Research 1980; 15(2):185-92.

Kuhn TS. The Structure of Scientific Revolutions. Chicago III: University of Chicago Press; 1970.

LILACS (Latin American and Caribbean Health Sciences Literature). Available online at: www.bireme.br/bvs/l/ihome.htm.

Loesche WJ, De Boever EH. Strategies to identify the main microbial contributors to oral malodour. In: Rosenberg M, editor(s). Bad Breath: research perspectives. Tel Aviv: Ramot Publishing: 41-69; 1995.

Loesche WJ. Microbiology and treatment of halitosis. Current Infectious Disease Reports 2003; 5(3):220-26.

Loke YK, Derry S. (2003) Does anybody read "evidence-based" articles? BMC Medical Research Methodology. Available on-line at: http://www.biomedcentral.com/1471-2288/3/14

Marchesan M A, Souza RF, Pereira-Cenci T, Fedorowicz Z (2008) Carnival time: a mapping exercise of Brazilian oral health journals. [abstract]. In: $16^{\text {th }}$ Cochrane Colloquium 2008 Oct 3-7; Freiburg, Germany: P88.

Maynard A, Chalmers I. Non-random Reflections on Health Services Research. British Medical Journal Books Plymouth: UK. Latimer Trend \& Co; 1997.

McDonagh $M$, Whiting $P$ et al. Treasure $E$, Kleijnen J. A systematic review of public water fluoridation. University of York: Centre for Reviews and Dissemination. York; 2000. 
McDonald S, Lefebvre $\mathrm{C}$ et al. The contribution of handsearching European general healthcare journals to the Cochrane Controlled Trials Register. Evaluation and the Health Professions. 2002; 25(1):65-75.

McDonald S, Westby M, Clarke M, Lefebvre C. Number and size of randomized trials reported in general health care journals from 1948 to 1997 International Journal of Epidemiology 2002; 31(1):125-127.

Medical Research Council. Streptomycin treatment of pulmonary tuberculosis: a Medical Research Council investigation. British Medical Journal 1948; 2:769-782.

Meningaud JP, Bado F, Favre E, Bertrand JC, Guilbert F. Halitosis in 1999. Revue de Stomatologie et de Chirurgie Maxillo-Faciale 1999; 100(5):240-4.

Meskin LH. A breath of fresh air. Journal of the American Dental Association 1996; 127(9):1282, 1284, 1286 passim

Miyazaki H, Sakao S, Katoh Y, Takehara T. Correlation between volatile sulphur compounds and certain oral health measurements in the general population. Journal of Periodontology 1995; 66(8):679-84.

Miyazaki H, Arao M, Okamura K, Kawaguchi Y, Toyofuku A, Hoshi K et al. Tentative classification of halitosis and its treatment needs. Niigata Dental Journal 1999; 32:7-11.

Moher D, Cook DJ, Eastwood S, Olkin I, Rennie D et al. Improving the quality of reporting of meta-analysis of randomized controlled trials: The QUOROM statement. Lancet 1994; 354:1896-1900.

Moher D, Fortin $\mathrm{P}$ et al. Completeness of reporting of trials published in languages other than English: implications for conduct and reporting of systematic reviews. Lancet 1996; 347: 363-366.

Moher D, Liberati A, Tetzlaff J, Altman DG; PRISMA Group. Preferred reporting items for systematic reviews and meta-analyses: the PRISMA statement. Annals of Internal Medicine 2009; 151(4):264-9,

Moore T. Deadly Medicine: Why Tens of Thousands of Heart Patients Died in America's Worst Drug Disaster. Simon \& Schuster: Adult Publishing Group; 1995.

Morita M, Wang HL. Association between oral malodour and adult periodontitis: a review. Journal of Clinical Periodontology 2001; 28(9):813-9.

Mulrow CD. Rationale for systematic reviews. British Medical Journal 1984; 309: 597-9.

Mulrow CD. The Medical Review Article: State of the Science. Annals of Internal Medicine 1987; 106:485-8.

Oral Health Group of the Cochrane Collaboration. Available on-line at: http://www.cochrane-oral.man.ac.uk. 
Ottawa Statement. Available on-line at: http://ottawagroup.ohri.ca/index.html.

Oxman A D, Guyatt G. Guidelines for reading literature reviews. Canadian Medical Association Journal 1988; 138:697-703.

Oxman A D, Guyatt G. Validation of an index of the quality of review articles. Journal of Clinical Epidemiology 1991; 44: 1271-8

Oxman AD, Guyatt GH. The science of reviewing research. Annals of the New York Academy of Sciences 1993; 703:125-131.

Oxman AD. Checklists for review articles. British Medical Journal 1994; 309:64865.

Pedrazzi V, Sato S, de Mattos MG, Lara EH, Panzeri H. Tongue-cleaning methods: a comparative clinical trial employing a toothbrush and a tongue scraper. Journal of Periodontology 2004; 75(7):1009-12.

Persson S, Edlund MB, Claesson R, Carlsson J. The formation of hydrogen sulfide and methyl mercaptan by oral bacteria. Oral Microbiology and Immunology 1990; 5(4):195-201.

Pildal J, Chan A, Hróbjartsson A, Forfang E, Altman DG, Gøtzsche PG. Comparisons of descriptions of allocation concealment in trial protocols and the published reports. British Medical Journal 2005; 330:1049.

Pitts N. Options for change. British Dental Journal 2003; 195: 631-635.

Porter R. The rise of medical journalism in Britain to 1800. In Medical Journals and Medical Knowledge: Historical Essays. Ed. W.F. Bynum, S. Lock and R. Porter, pp6-28. London and New York: Routledge; 1992.

Pringle M, Churchill R. Randomized controlled trials in general practice: Gold standard or fool's gold? British Medical Journal 1995; 311:1382-1383.

QUOROM Statement. Available on-line at http://www.thelancet.com.

Ratcliff PA, Johnson PW. The relationship between oral malodour, gingivitis, and periodontitis: A review. Journal of Periodontology 1999; 70(5):485-9.

Replogle WH, Beebe DK. Halitosis. American Family Physician 1996; 53(4):12158, 1223.

Richards D. The quality of systematic reviews in dentistry. Evidence-Based Dentistry 2004; 5 (1):17.

Richter JL. Diagnosis and treatment of halitosis. Compendium of Continuing Education in Dentistry 1996; 17(4):370-2, 374-6 passim.

Rosenberg $\mathrm{M}$ et al. Halitosis measurement by an industrial sulphide monitor. Journal of Periodontology 1991; 62(8):487-9. 
Rosenberg M, McCulloch CA. Measurement of oral malodour: current methods and future prospects. Journal of Periodontology 1992; 63(9):776-82.

Rosenberg M. Introduction. In: Rosenberg M, editor(s). Bad breath: research perspectives. Tel Aviv: Ramot Publishing. 1-12; 1995.

Rosenberg M. Clinical assessment of bad breath: current concepts. Journal of

Rychetnik L, Frommer M, Hawe P, Shiell A. Criteria for evaluating evidence on public health interventions. Journal of Epidemiology and Community Health 2002; 56 (2):119-27.

Rychetnik L, Hawe P, Waters E, Barratt A, Frommer M. A glossary for evidence based public health Journal of Epidemiology and Community Health 2004; 58 (7): 538-545.

Sackett DL, Rosenberg W, Gray JA, Haynes RB, Richardson WS. Evidence based medicine: what it is and what it isn't. British Medical Journal 1996; 312:71-2.

Sackett DL, Strauss SE, Richardson W S, Rosenberg W, Haynes R B. Evidencebased medicine: How to practice and teach EBM. London: Churchill Livingstone; 2000.

Schulz KF. Subverting randomization in controlled trials. Journal of the American Medical Association 1995; 274:1456-8.

Schulz KF, Chalmers I, Hayes RJ, Altman DG. Empirical evidence of bias: dimensions of methodological quality associated with estimates of treatment effect in controlled trials. Journal of the American Medical Association 1995; 271: 408-12.

Scully C, el-Maaytah M, Porter SR, Greenman J. Breath odor: etiopathogenesis, assessment and management. European Journal of Oral Sciences 1997; 105(4):287-93.

Scully C, Porter S. (2007) Halitosis BMJ Clinical Evidence BMJ Publishing Group

Available on-line at: http://clinicalevidence.bmj.com/ceweb/conditions/orh/orh/jsp.

Sehon SR, Stanley DE. () A philosophical analysis of the evidence-based medicine debate. BMC Health Services Research 2003; 3:14 [online]. Available on-line at: http://www.biomedcentral.com/1472-6963/3/14.

Shea BJ et al. Development of AMSTAR: a measurement tool to assess the methodological quality of systematic reviews. BMC Medical Research Methodology 2007; 15(7):10.

Shea BJ et al. (2009) AMSTAR is a reliable and valid measurement tool to assess the methodological quality of systematic reviews. Journal of Clinical Epidemiology. 2009; Feb 18. [Epub ahead of print] 
Silwood CJ, Grootveld MC, Lynch E. A multifactorial investigation of the ability of oral health care products (OHCPs) to alleviate oral malodour. Journal of Clinical Periodontology 2001; 28(7):634-41.

Solis-Gaffar MC, Niles HP, Rainieri WC, Kestenbaum RC. Instrumental evaluation of mouth odor in a human clinical study. Journal of Dental Research 1975; 54(2):3517.

Souza RF, Chaves CAL, Nasser M, Fedorowicz Z. An evaluation of the quantity and quality of clinical trials in six Brazilian dental journals accessible through the Scientific Electronic Library Online (SCIELO). Journal of Applied Oral Science (In Press); 2009.

Sprod A, Anderson R, Treasure E. Effective oral health promotion. Literature Review. Cardiff: Health Promotion Wales; 1996.

Stamou E, Kozlovsky A, Rosenberg M. Association between oral malodour and periodontal disease-related parameters in a population of 71 Israelis. Oral Diseases 2005; 11 (Suppl 1):72-4.

Stern J, Simes R. Publication bias: evidence of delayed publication in a cohort study of clinical research projects. British Medical Journal 1997; 315:640-645.

Tangerman A. Halitosis in medicine: a review. International Dental Journal 2002; 52(Suppl 3):201-6.

Tonzetich J, Richter VJ. Evaluation of volatile odoriferous components of saliva. Archives of Oral Biology 1964; 16:39-46.

Tonzetich J. Production and origin of oral malodour: a review of mechanisms and methods of analysis. Journal of Periodontology 1977; 48(1):13-20.

Tonzetich J. Oral malodour: an indicator of health status and oral cleanliness. International Dental Journal 1978; 28(3):309-19.

Tonzetich J, McBride BC. Characterization of volatile sulphur production by pathogenic and non-pathogenic strains of oral Bacteroides. Archives of Oral Biology 1981; 26(12):963-9.

Tramer MR, Reynolds DJ, Moore RA, McQuay HJ. Impact of covert duplicate publication on meta-analysis: a case study. British Medical Journal 1997; 315:635640.

Tsunoda M, Sato H, Ohkushi T. The experimental study for the effect of sodium copper chlorophyllin in halitosis. Nippon Shishubyo Gakkai Kaishi - Journal of the Japanese Association of Periodontology 1981; 23(3):490-8.

Tudiver $\mathrm{F}$ et al. What influences family physicians' cancer screening decisions when practice guidelines are unclear or conflicting? Journal of Family Practice 2002; $51(9) 760$. 
Tugwell $\mathrm{P}$ et al. (editors). Evidence-based Rheumatology. London: BMJ Books; 2004.

Türp JC, Schulte JM, Antes G. Nearly half of dental randomized controlled trials published in German are not included in Medline. European Journal of Oral Sciences 2002; 110:405-411.

Webster's New World Dictionary \& Thesaurus. Accent Software. Macmillan Publishers Version 2; 1998.

Weightman A, Ellis S, Cullum A, Sander L, Turley R. (2005) Grading evidence and recommendations for public health interventions: developing and piloting a framework. Health Development Agency. Available on-line at: www.hda.nhs.uk.

White HD, Cooper H, Hedges LV. Editors. Scientific communication and literature retrieval. In: The handbook of research synthesis. New York: Russell. Sage Foundation; 1994.

Whittington CJ, Kendall T, Fonagy P, Cottrell D, Cotgrove A, Boddington E. Selective serotonin reuptake inhibitors in childhood depression: systematic review of published versus unpublished data. Lancet 2004; 363:1341-5.

WHO. The meaning of "health for all by the year 2000" World Health Forum 1981. $1981 ; 1: 5-22$.

WHO. (ICTRP).International Clinical Trials Registry Platform. Available on-line at: http://www.who.int/ictrp/about/details/en/index1.html.

Yaegaki K, Coil JM. Examination, classification, and treatment of halitosis; clinical perspectives. Journal of the Canadian Dental Association 2000; 66(5):257-61. 

Appendix 



\section{APPENDIX - 1}

\section{Search strategy flow chart}

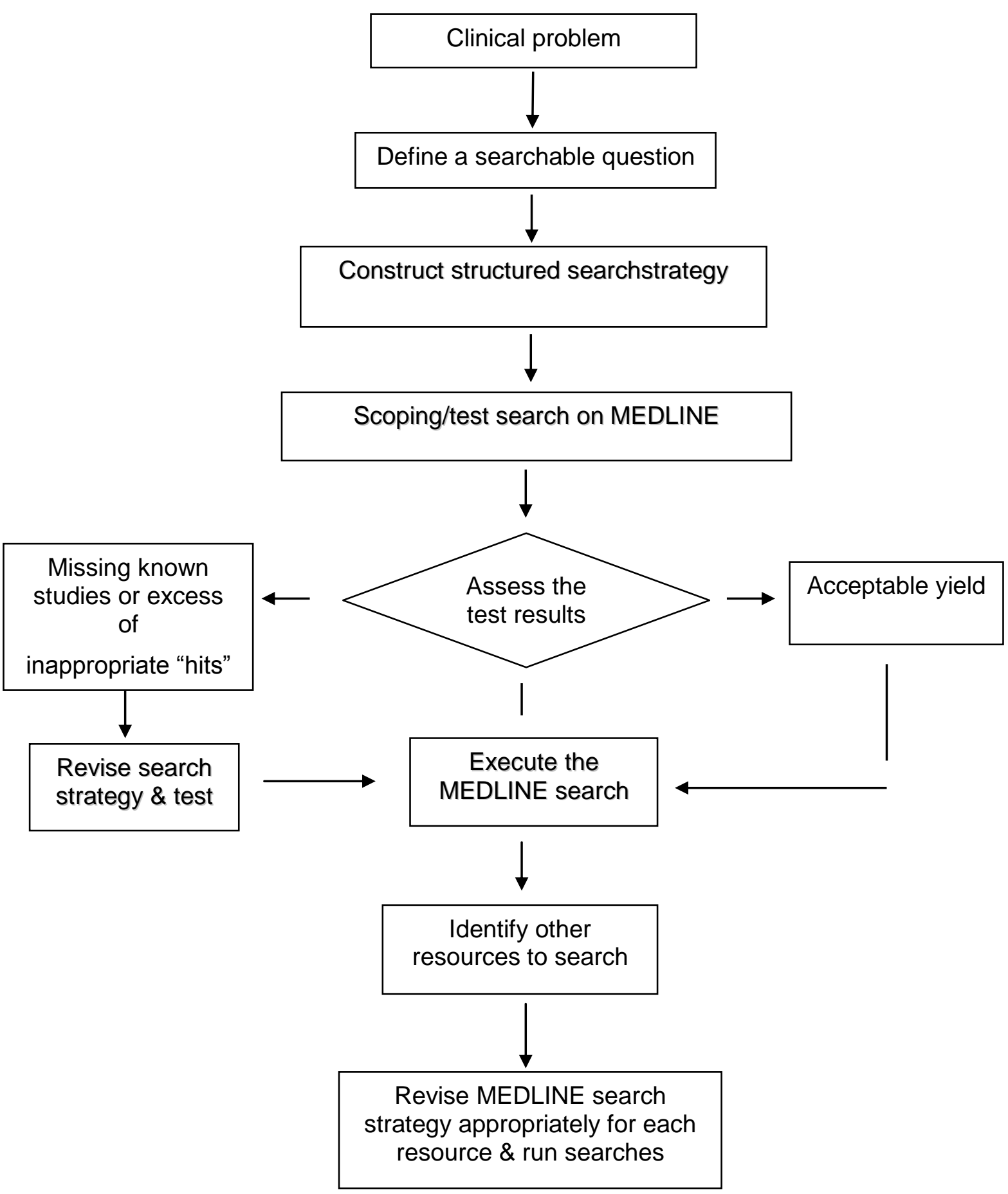




\section{Appendix - 2}

\section{Electronic Database Search Strategies}

\section{1) Cochrane OHG TRIALS REGISTER SEARCH STRATEGY}

halitosis or halitose* or "oral malodour*" or "oral malodour" or (breath AND odor*) or "bad breath" or (breath AND odour*) or (breath and smell*) or (breath AND offensive) or (mouth AND odor ${ }^{*}$ ) or (mouth AND odor ${ }^{*}$ ) or (mouth AND malodour ${ }^{\star}$ ) or (mouth AND malodour") or "volatile sulphur compound" or "volatile sulfur compound" or "fetor oris" or "foetor oris" or "fetor ex ore" or "foetor ex ore" or "foul breath" or "fetid breath" or "putrid breath"

\section{2) CENTRAL}

\section{\#1.HALITOSIS/}

\#2.halitosis or halitose*

\#3. "oral malodour*" or "oral malodour*"

\#4. ((breath near/3 odor*) or "bad breath*" or (breath NEAR/4 odour*") or (breath NEAR/4 smell*) or (breath NEAR/4 offensive) or (mouth NEAR/4 odour*) or ("mouth odor $^{*}$ ) or (mouth NEAR/4 malodour*) or (mouth NEAR/4 malodour*)) \#5. ("volatile sulphur compound" or "volatile sulfur compound"" \#6. "fetor oris" or "foetor oris" or "fetor ex ore" or "foetor ex ore" or "foul breath" or "fetid breath" or "putrid breath"

\#7 OR/1-6 


\section{3) MEDLINE via OVID SEARCH STRATEGY}

Ovid MEDLINE(R) In-Process, Other Non-Indexed Citations, Ovid MEDLINE(R) [with filter]:

1 Halitosis/

2 (halitosis or halitose $\$$ ).mp. [mp=ti, ot, ab, nm, hw]

3 ((oral adj malodour\$) or (oral adj malodour\$)).mp. [mp=ti, ot, ab, nm, hw]

4 ((breath adj3 odor\$) or (bad adj breath) or (breath adj4 odour\$) or (breath adj4 smell\$) or (breath adj4 offensive) or (mouth adj4 odour\$) or mouth adj4 odor4 or (mouth adj4 malodour\$) or (mouth adj4 malodour\$)).mp. [mp=ti, ot, ab, nm, hw]

5 (volatile sulphur compound $\$$ or volatile sulfur compound\$).mp. [mp=ti, ot, ab, nm, hw]

6 (fetor oris or foetor oris or fetor ex ore or foetor ex ore or foul breath or fetid breath or putrid breath).mp. [mp=ti, ot, ab, $\mathrm{nm}, \mathrm{hw}]$

7 or/1-6

[mp=title, original title, abstract, name of substance word, subject heading word]

\section{Cochrane Search filter for MEDLINE via OVID}

1. randomized controlled trial.pt.

2. controlled clinical trial.pt.

3. randomized.ab.

4. placebo.ab.

5. drug therapy.fs.

6. randomly.ab. 
7. trial.ab.

8. groups.ab.

9. or/1-8

10. animals.sh. not (humans.sh. and animals.sh.)

11.9 not 10

\section{4) EMBASE via OVID SEARCH STRATEGY}

1. Halitosis/

2. (halitosis or halitose\$).mp.

3. ((oral adj malodour\$) or (oral adj malodour\$)).mp

4. ((breath adj3 odor\$) or (bad adj breath) or (breath adj4 odour\$) or (breath adj4 smell\$) or (breath adj4 offensive) or (mouth adj4 odour\$) or (mouth adj odor\$) or (mouth adj4 malodour\$) or (mouth adj4 malodour\$)).mp.

5. (volatile sulphur compound $\$$ or volatile sulfur compound $\$$ ).mp

6. (fetor oris or foetor oris or fetor ex ore or foetor ex ore or foul breath or fetid breath or putrid breath).mp.

7. or/1-6

[mp=title, abstract, subject headings, drug trade name, original title, device manufacturer, drug manufacturer name] [\$ = wild card symbol/truncated text]

EMBASE filter:

1. random $\$ . t i, a b$.

2. factorial\$.ti,ab.

3. (crossover\$ or cross over\$ or cross-over\$).ti,ab.

4. placebo\$.ti,ab. 
5. (doubl\$ adj blind\$).ti,ab.

6. (singl\$ adj blind $\$) . t i, a b$.

7. assign\$.ti,ab.

8. allocat\$.ti,ab.

9. volunteer\$.ti,ab.

10. CROSSOVER PROCEDURE.sh.

11. DOUBLE-BLIND PROCEDURE.sh.

12. RANDOMIZED CONTROLLED TRIAL.sh.

13. SINGLE BLIND PROCEDURE.sh.

14. or/1-13

15. ANIMAL/ or NONHUMAN/ or ANIMAL EXPERIMENT/

16. HUMAN/

17. 16 and 15

18. 15 not 17

19. 14 not 18

Additional database searched for the Mouthrinses for the treatment of halitosis

\section{5) CINAHL (OVID) search strategy}

1. Halitosis/

2. (halitosis or halitose\$).mp.

3. ((oral adj malodour\$) or (oral adj malodour $\$)$ ).mp.

4. ((breath adj3 odor $\$$ ) or (bad adj breath) or (breath adj4 odour $\$$ ) or (breath adj4 smell\$) or (breath adj4 offensive) or (mouth adj4 odour\$) or (mouth adj odor\$) or (mouth adj4 malodour\$) or (mouth adj4 malodour\$)).mp.

5. (volatile sulphur compound $\$$ or volatile sulfur compound\$).mp. 
6. (fetor oris or foetor oris or fetor ex ore or foetor ex ore or foul breath or fetid breath or putrid breath).mp.

[mp=title, subject heading word, abstract, instrumentation]

\section{CINAHL filter:}

1. Random Assignment/

2. single-blind studies/

3. Double-Blind Studies/

4. Triple-Blind Studies/

5. Crossover Design/

6. Factorial Design/

7. (multicentre study or multicenter study or multi-centre study or multi-center study).mp.

8. random $\$ . t i, a b$.

9. latin square.ti,ab.

10. cross-over.mp. or crossover.ti,ab.

11. Placebos/

12. ((singl\$ or doubl\$ or trebl\$ or tripl\$) adj25 (blind $\$$ or mask $\$)$ ).ti,ab.

13. placebo\$.mp.

14. Clinical Trials/

15. (clin\$ adj25 trial\$).mp.

16. or/1-15

[mp=title, cinahl subject headings, abstract, instrumentation] 


\section{APPENDIX - 3}

\section{REFERENCES TO INCLUDED STUDIES}

Pedrazzi V, Sato S, de Mattos Mda G, Lara EH, Panzeri H. Tongue-cleaning methods: a comparative clinical trial employing a toothbrush and a tongue scraper. Journal of Periodontology 2004; 75(7):1009-12.

Seemann R, Kison A, Bizhang M, Zimmer S. Effectiveness of mechanical tongue cleaning on oral levels of volatile sulfur compounds. Journal of the American Dental Association 2001; 132(9):1263-7.

Borden LC, Chaves ES, Bowman JP, Fath BM, Hollar GL. The effect of four mouthrinses on oral malodour. Compendium of Continuing Education in Dentistry 2002; 23(6):531-6.

Codipilly DP, Kaufman HW, Kleinberg I. Use of a novel group of oral malodour measurements to evaluate an anti-oral malodour mouthrinse (TriOralTM) in humans. The Journal of Clinical Dentistry 2004; 15(4):98-104.

Kozlovsky A, Goldberg S, Natour I, Rogatky Gat A, Gelernter I, Rosenberg M. Efficacy of a 2-phase oil: water mouthrinse in controlling oral malodour, gingivitis, and plaque. Journal of Periodontology 1996; 67(6):577-82.

Rassameemasmaung S, Sirikulsathean A, Amornchat C, Hirunrat K, Rojanapanthu $P$, Gritsanapan W. Effects of herbal mouthwash containing the pericarp extract of Garcinia mangostana $L$ on halitosis, plaque and papillary bleeding index. Journal of the International Academy of Periodontology 2007; 9(1):19-25.

Winkel EG, Roldan S, Van Winkelhoff AJ, Herrera D, Sanz M. Clinical effects of a new mouthrinse containing chlorhexidine, cetylpyridinium chloride and zinc-lactate on oral halitosis. A dual-center, double-blind placebo-controlled study. Journal of Clinical Periodontology 2003; 30(4):300-6. 


\section{REFERENCES INCLUDED IN 2014}

Wigger-Alberti W, Gysen K, Axmann EM, Wilhelm KP. Efficacy of a new mouthrinse formulation on the reduction of oral malodour in vivo. A randomized, double-blind, placebo-controlled, 3 week clinical study. Journal of Breath Research 2010;4(1):017102. doi: 10.1088/1752-7155/4/1/017102.

Dadamio J, Van Tournout M, Teughels W, Dekeyser C, Coucke W, Quirynen M. Efficacy of different mouthrinse formulations in reducing oral malodour: a randomized clinical trial. Journal of Clinical Periodontology 2013;40(5):505-13 


\section{APPENDIX - 4}

\section{REFERENCES TO EXCLUDED STUDIES}

Suarez FL, Furne JK, Springfield J, Levitt MD. (2000) Morning breath odor: influence of treatments on sulfur gases. Journal of Dental Research 79(10):1773-7.

Williams MI, Vazquez J, Cummins D. (2004) Clinical comparison of a new manual toothbrush on breath volatile sulfur compounds. Compendium of Continuing Education in Dentistry 25(10 Suppl 2):22-7.

Yonezawa H, Takasaki K, Teraoka K, Asaka T, Sato C, Tsuchiya K. (2003) Effects of tongue and oral mucosa cleaning on oral Candida species and production of volatile sulfur compounds in the elderly in a nursing home. Journal of Medical \& Dental Sciences 50(1):1-8.

Carvalho MD, Tabchoury CM, Cury JA, Toledo S, Nogueira-Filho GR. (2004) Impact of mouthrinses on morning bad breath in healthy subjects. Journal of Clinical Periodontology 31(2):85-90.

Peruzzo DC, Jandiroba PF, Nogueira Filho G R. (2007) Use of $0.1 \%$ chlorine dioxide to inhibit the formation of morning volatile sulphur compounds (VSC). Brazilian Oral Research 21(1):70-4.

Pitts G, Pianotti R, Masurat T, Schumann P. (1981) Effectiveness of an antiseptic mouthwash on determinants of oral malodour (IADR \& AADR Abstract Chicago 1981). Journal of Dental Research 60 (Special Issue A, March):379 (Abs No 276).

Quirynen M, Avontroodt P, Soers C, Zhao H, Pauwels M, Coucke W et al. (2002) The efficacy of amine fluoride/stannous fluoride in the suppression of morning breath odour. Journal of Clinical Periodontology 29(10):944-54. 
van Steenberghe D, Avontroodt P, Peeters W, Pauwels M, Coucke W, Lijnen A et al.(2001) Effect of different mouthrinses on morning breath. Journal of Periodontology 72(9):1183-91.

Witt JJ. (1998) Long-lasting breath protection by a commercial mouthrinse (IADR Abstract 1998). Journal of Dental Research 77(June Special Abstract Issue B):897 (Abs No 2125).

\section{REFERENCES INCLUDED IN 2014}

Saad S, Greenman J, Shaw H. Comparative effects of various commercially available mouthrinse formulations on oral malodour. Oral Diseases. 2011;17(2):180-6. 


\section{APPENDIX - 5}

\section{STUDIES AWAITING CLASSIFICATION}

Chotai M, Saberi M, Fakih A, Bove A, Lindgren M. (2003) Effectiveness of tongue scraping in reducing oral levels of volatile sulfur compounds and thereby decreasing the levels of halitosis. Available on-line at:

http://www.ki.se/odont/cariologi_endodonti/T1/proc2003/2c1.pdf.

Borden LC, Chaves ES, Bowman JP, Fath BM, Hollar GL.(2001) Effect of three mouthrinses on oral malodour. Journal of Dental Research 80 (Special Issue AADR Abstracts):224 (Abs No 1510).

Kozak KM, Procter LR, Hunter-Rinderle MA. (1994) Effect of scope and clear choice mouthwash on breath malodour (IADR Abstract Seattle 1994). Journal of Dental Research 73(Special Issue IADR Abstracts):160 (Abs No 470).

Nachnani S, Anson D. (1998) Efficacy of Orasan ${ }^{\mathrm{TM}}$ mouthwash on periodontitis and malodour (IADR Abstract 1998). Journal of Dental Research 77(June Special Abstract Issue B):796 (Abs No 1316).

Ono J, Lingström P, Birkhed D. (2002) The effect of chlorine dioxide (IO2) on oral malodour (IADR Abstract San Diego 2002). Journal of Dental Research 81(SpecialW Issue A): A-200 (Abs No 1484). 


\section{APPENDIX - 6}

\section{CHECKLIST AMSTAR: A MEASUREMENT TOOL TO ASSESS THE METHODOLOGICAL QUALITY OF SYSTEMATIC REVIEWS.}

1. Was an 'a priori' design provided?

The research question and inclusion criteria should be established before the conduct of the review.

2. Was there duplicate study selection and data extraction?

There should be at least two independent data extractors and a consensus procedure for disagreements should be in place.

\section{Was a comprehensive literature search performed?}

At least two electronic sources should be searched. The report must include years and databases used (e.g. Central, EMBASE, and MEDLINE). Key words and/or MeSH terms must be stated and where feasible the search strategy should be provided. All searches should be supplemented by consulting current contents, reviews, textbooks, specialized registers, or experts in the particular field of study, and by reviewing the references in the studies found.

4. Was the status of publication (i.e. grey literature) used as an inclusion criterion? The authors should state that they searched for reports regardless of their publication type. The authors should state whether or not they excluded any reports (from the systematic review), based on their publication status, language etc.

5. Was a list of studies (included and excluded) provided?

A list of included and excluded studies should be provided.

\section{Were the characteristics of the included studies provided?}

In an aggregated form such as a table, data from the original studies should be provided on the participants, interventions and outcomes. The ranges of characteristics in all the studies analyzed e.g. age, race, sex, relevant socioeconomic data, disease status, duration, severity, or other diseases should be reported.

7. Was the scientific quality of the included studies assessed and documented?

'A priori' methods of assessment should be provided (e.g., for effectiveness studies if the author(s) chose to include only randomized, double-blind, placebo controlled studies, or allocation concealment as inclusion criteria); for other types of studies alternative items will be relevant.

8. Was the scientific quality of the included studies used appropriately in formulating conclusions?

The results of the methodological rigor and scientific quality should be considered in the analysis and the conclusions of the review, and explicitly stated in formulating recommendations.

9. Were the methods used to combine the findings of studies appropriate?

For the pooled results, a test should be done to ensure the studies were combinable, to assess their homogeneity (i.e. Chi-squared test for homogeneity, $\mathrm{I}^{2}$ ). If heterogeneity exists a random effects model should be used and/or the clinical appropriateness of combining should be taken into consideration (i.e. is it sensible to combine?).

10. Was the likelihood of publication bias assessed?

An assessment of publication bias should include a combination of graphical aids (e.g., funnel plot, other available tests) and/or statistical tests (e.g., Egger regression test).

\section{Was the conflict of interest stated?}

Potential sources of support should be clearly acknowledged in both the systematic review and the included studies.
Yes

No

Can't answer

Not applicable

Yes

No

Can't answer

Not applicable

Yes

$\square$ No

Can't answer

Not applicable

Yes

No

Can't answer

Not applicable

Yes

No

Can't answer

Not applicable

Yes

No

Can't answer

Not applicable

Yes

No

Can't answer

Not applicable

Yes

No

Can't answer

Not applicable

Yes

No

Can't answer

Not applicable

Yes

$\square$ No

Can't answer

Not applicable

$\checkmark$ Yes

No

Can't answer

Not applicable

Reproduced from Shea et al.2007. Available for download at: [http://www.biomedcentral.com/content/supplementary/1471- 2288-7-10-S1.doc] 


\section{APPENDIX - 7}

\section{Available at: http://scholar.google.com.br/citations?user=VUjWruoAAAAJ\&hl=pt-BR}

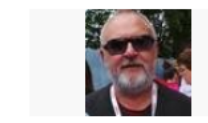

Zbys Fedorowicz

Supreme Council of Health, Bahrain

E-mail confirmado em batelco.com.bh

$$
\text { Titulo } \quad 1-20
$$

Interventions for rosacea

EJ van Zuuren, S Kramer, B Carter, MA Graber, Z Fedorowicz
Cochrane database syst Rev 3

Tongue scraping for treating halitosis

TL Outhouse, R Al-Alawi, Z Fedorowicz, JV Keenan

Cochrane Database Syst Rev 2

Mouthrinses for the treatment of halitosis

Z Fedorowicz. H Aliufairi, M Nasser. TL Outhouse, V Pedrazz

Z Fedorowicz, H Aljufairi, M Nasser,
Cochrane Database Syst Rev 8 (4)

In-terventions for cleaning dentures in adults

RF De Souza, H de Freitas Oliveira Paranhos, CH Lovato da Silva,

status and date: New, published in

Commentaries on 'Antiemetics for reducing vomiting related to acute gastroenteritis in children and adolescents'

EJ Elliott, E Peadon, J Bayreuther, I Maconochie

Evidence-Based Child Health: A Cochrane Review Journal 1 (4), 1233-1237

Resection versus no intervention or other surgical interventions for

colorectal cancer liver metastases

Z Fedorowicz, M Lodge, A Al-asfoor, B Carter

Cochrane database of systematic reviews

Antibiotic use for irreversible pulpitis

Z Fedorowicz, JV Keenan, AG Farman, T Newton

Cochrane Database Syst Rev 2

Effective and evidence-based management strategies for rosacea

summary of a Cochrane systematic review

EJ Van Zuuren, SF Kramer, BR Carter, MA Graber, Z Fedorowicz

EJ Van Zuuren, SF Kramer, BR Carter, MA Graber,
British Journal of Dermatology 165 (4), 760-781
$61 * 2005$

ॠ Seguir- Google Acadêmico

Citado por Ano

2011

\begin{tabular}{lrr}
\hline Citações & 1900 & 1473 \\
Indice $\mathrm{h}$ & 24 & 21
\end{tabular}

índice 110

24

$56-55$

$83 \quad 2006$

$74 \quad 2008$

$64 \quad 2009$

$64 \quad 2006$

$61 \quad 2008$

200820092010201120122013201420152016

Coautores Visualizar todos

Mona Nasser

Raphael Freitas de Souza

Vinicius Pedrazzi

Helena de Freitas Oliveira Paranhos

mina mahdian

Jan W. Schoones

Carlos F. Santos

E van Zuuren

Elizabeth Waters

PD Dr. Christian Apfelbacher PhD

Anirudha Agnihotry

Mahtab Nouri

Mohammad H. Khoshnevisan

Reshma Carlo

Anthonv Montaomery 